\title{
Perioperative nutrition in GI cancer patients : assessment of surgical risk, postoperative morbidity and long term survival
}

Citation for published version (APA):

Meijerink, W. J. H. J. (1992). Perioperative nutrition in Gl cancer patients : assessment of surgical risk, postoperative morbidity and long term survival. [Doctoral Thesis, Maastricht University]. Rijksuniversiteit Limburg. https://doi.org/10.26481/dis.19921016wm

Document status and date:

Published: 01/01/1992

DOI:

10.26481/dis.19921016wm

Document Version:

Publisher's PDF, also known as Version of record

\section{Please check the document version of this publication:}

- A submitted manuscript is the version of the article upon submission and before peer-review. There can be important differences between the submitted version and the official published version of record.

People interested in the research are advised to contact the author for the final version of the publication, or visit the DOI to the publisher's website.

- The final author version and the galley proof are versions of the publication after peer review.

- The final published version features the final layout of the paper including the volume, issue and page numbers.

Link to publication

\footnotetext{
General rights rights.

- You may freely distribute the URL identifying the publication in the public portal. please follow below link for the End User Agreement:

www.umlib.nl/taverne-license

Take down policy

If you believe that this document breaches copyright please contact us at:

repository@maastrichtuniversity.nl

providing details and we will investigate your claim.
}

Copyright and moral rights for the publications made accessible in the public portal are retained by the authors and/or other copyright owners and it is a condition of accessing publications that users recognise and abide by the legal requirements associated with these

- Users may download and print one copy of any publication from the public portal for the purpose of private study or research.

- You may not further distribute the material or use it for any profit-making activity or commercial gain

If the publication is distributed under the terms of Article 25fa of the Dutch Copyright Act, indicated by the "Taverne" license above, 


\section{PERIOPERATIVE NUTRITION IN GI CANCER PATIENTS}

ASSESSMENT OF SURGICAL RISK, POSTOPERATIVE MORBIDITY AND LONG TERM SURVIVAL. 



\section{PERIOPERATIVE NUTRITION \\ IN GI CANCER PATIENTS}

\section{ASSESSMENT OF SURGICAL RISK, POSTOPERATIVE MORBIDITY AND LONG TERM SURVIVAL.}

\section{PROEFSCHRIFT}

ter verkrijging van de graad van doctor aan de Rijksuniversiteit Limburg te Maastricht, op gezag van de Rector Magnificus, Prof.Mr. M.J. Cohen, volgens het besluit van het College van Dekanen, in het openbaar te verdedigen op vrijdag, 16 oktober 1992 om 16.00 uur

$$
\text { door }
$$

Wilhelmus Jan Hendrik Jeroen Meijerink

geboren te Hoeven op 27 oktober 1961 
Promotor:

Prof.dr P.B. Soeters

Co-promotor:

Dr M.F. von Meyenfeldt

Beoordelingscommissie:

Prof.dr J. De Haan (voorzitter)

Prof.dr P.J.E.H.M. Kitslaar

Prof.dr K. Lundholm, Sahlgrenska Sjukhuset Zweden

Prof.dr H. Obertop, hoogleraar Heelkunde, RUU

Prof.dr C.J.H. van de Velde, Rijksuniversiteit Leiden

\section{CIP-GEGEVENS KONINKLIJKE BIBLIOTHEEK, DEN HAAG}

Meijerink, Wilhelmus Jan Hendrik Jeroen

Perioperative nutrition in Gl cancer patients : Assessment of surgical risk, postoperative morbidity and long term survival / Wilhelmus Jan Hendrik Jeroen Meijerink. - [S.l. : s.n.] (Katwijk: Albedon Klop). - Ill.

Proefschrift Maastricht. - Met lit. opg. - Met samenvatting in het Nederlands.

ISBN 90-9005393-X

Trefw.: perioperatieve voeding/ postoperatieve complicaties.

Vormgeving en layout : Jeroen Meijerink

Ontwerp omslag : Jeroen Meijerink en Nicole Groenendal

Druk : Albedon-Klop Katwijk

The trial was financially supported by Baxter (Clintec) and Wander Research.

The publication of this thesis was financially supported by Kabi Pharmacia, Clintec and Nutricia. 


\section{CONTENTS}

Chapter 1: GENERAL INTRODUCTION

page

$1.1 \quad$ Nutritional assessment and surgical risk ..............................11

$1.2 \quad$ Perioperative nutritional support ……................................ 12

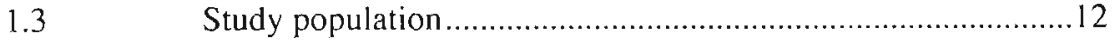

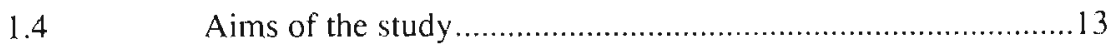

Chapter 2: METHODOLOGICAL CONSIDERATIONS

2.1 General aspects: trial design .............................................. 15

$2.2 \quad$ Number of patients required .................................................. 15

$2.3 \quad$ Duration of the trial .............................................................. 15

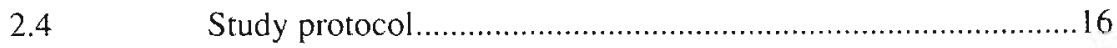

$2.5 \quad$ Analysis of results ............................................................. 19

Chapter 3: AN ASSESSMENT OF NUTRITIONAL DEPLETION AND SURGICAL RISK

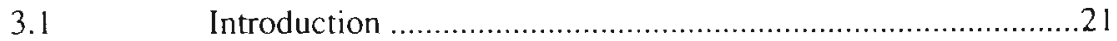

3.2 Starvation experiments: impaired intake …………................22

3.3 Disease status: increased loss ..............................................23

3.4 The combination of impaired intake and increased loss............24

3.5 Abnormal parameters: relation with response to disease ..........25

3.6 Combination of parameters ...............................................28

Chapter 4: PERIOPERATIVE NUTRITIONAL SUPPORT: A TRIAL REVIEW

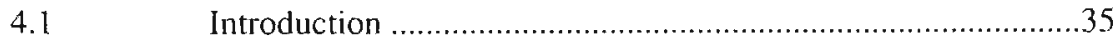

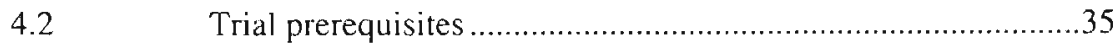

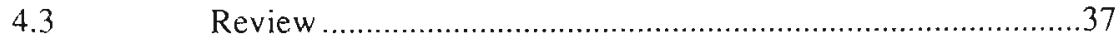

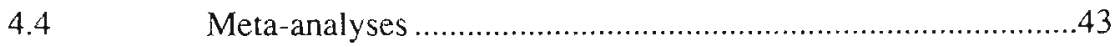


Chapter 5: RISKFACTORS FOR POSTOPERATIVE COMPLICATIONS IN GASTRIC AND COLORECTAL CANCER PATIENTS

\begin{tabular}{|c|c|}
\hline 5.1 & 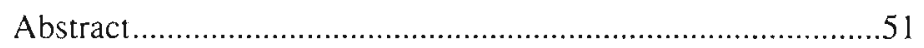 \\
\hline 5.2 & Introduction .................. \\
\hline 5.3 & Patients and methods. \\
\hline 5.4 & Results \\
\hline 5.5 & Discussion.. \\
\hline 5.6 & Conclusion .... \\
\hline
\end{tabular}

Chapter 6: THE INFLUENCE OF PERIOPERATIVE NUTRITIONAL INTER VENTION ON POSTOPERATIVE COMPLICATIONS

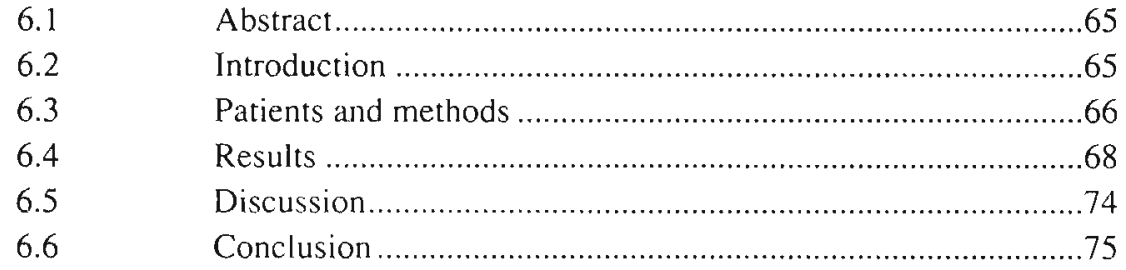

Chapter 7: THE RELATION OF PREOPERATIVE SURGICAL RISK PARAMETERS WITH LONG TERM SURVIVAL OF PATIENTS WITH GASTRIC AND COLORECTAL CANCER

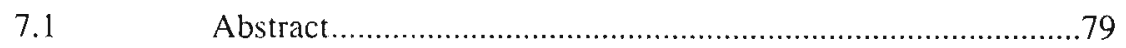

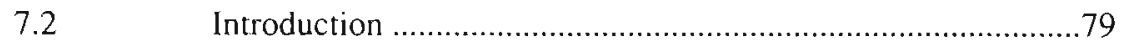

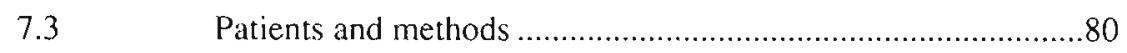

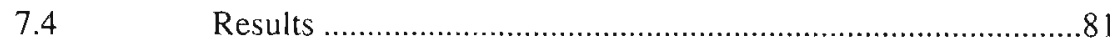

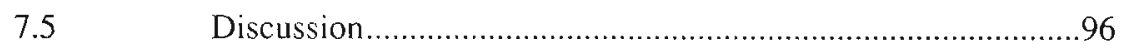

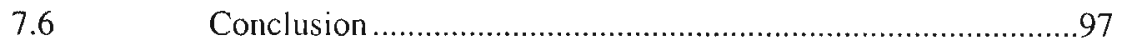

Chapter 8: INFLUENCE OF PERIOPERATIVE NUTRITIONAL INTERVENTION ON LONG TERM SURVIVAL OF PATIENTS WITH ADVANCED COLORECTAL CANCER

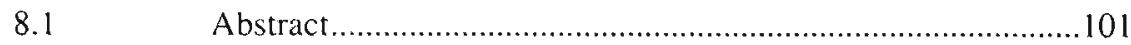

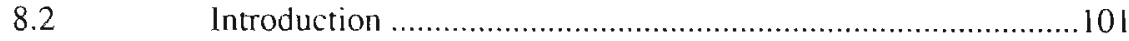

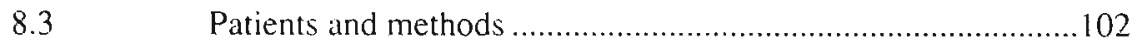




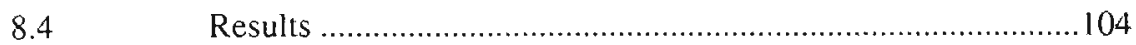

8.5 Discussion..................................................................... 11

$8.6 \quad$ Conclusion .......................................................................

Chapter 9: FINAL DISCUSSION

9.1 Depletion parameters .......................................................... 115

$9.2 \quad$ Prerequisites of trials .............................................................

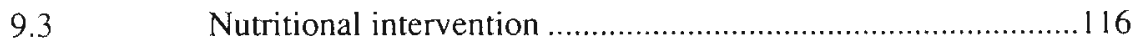

9.4 Survival.........................................................................

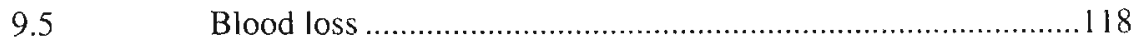

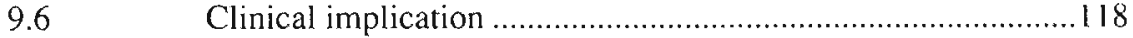

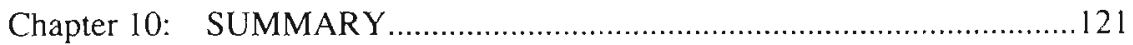

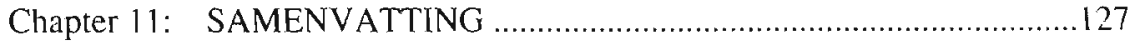

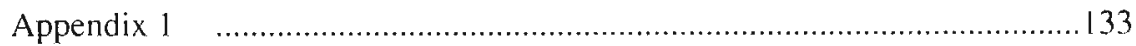

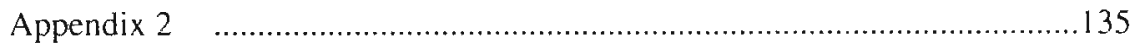

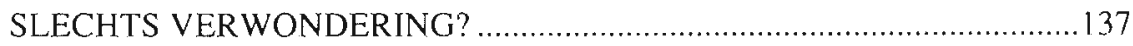

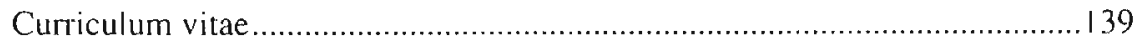


De wijsheid, die iemand voor een ander toegankelijk probeert te maken, klinkt altijd als iets dwaas. Wijsheid en wetenschap zijn twee verschillende begrippen. Laten we daarom de wijsheid vergeten en beginnen met wetenschap. 


\section{Chapter ]}

\section{General introduction}

\subsection{Nutritional assessment and surgical risk}

Malnutrition or depletion is associated with an increased incidence of mortality and morbidity of surgical therapy ${ }^{1.8}$. The compromised ability of the depleted patient to cope with the metabolic stress of surgery requires a careful and thorough evaluation of nutritional status in the preoperative period. Assessment of the nutritional status of a patient, is complicated. Objective measurements of preoperative nutritional status commonly used include levels of plasma proteins (total protein, albumin, pre-albumin, gamma globulins, plasma transferrin), delayed cutaneous hypersensitivity skin tests, anthropometric measurements (such as arm muscle circumference, skinfold thickness, weight parameters e.g. actual weight, weight loss, and ideal weight), and body composition measurements (impedance. measurement of total body water).

Most of these parameters are altered by both disease and insufficient food intake. Only very few studies have tried to separate the influence of disease and insufficient food intake on these parameters. In addition, the definition of what is considered an abnormal value of a given nutritional parameter is often based on the erroneous concept that alterations in these parameters are the sole result of insufficient food intake. Whether the separation of influence of disease and insufficient food intake has any practical implication is difficult to appreciate. This has led to a widely varying incidence of malnutrition in all sort of patients reported in the literature. However, most studies indicate a high incidence of malnutrition of patients on admission in a general hospital ${ }^{y-32}$.

Nutritional status parameters alone do not effectively identify patients which are at risk for developing postoperative complications. Many studies showed in monofactorial analyses significant associations between individual parameters of nutritional status and postoperative outcome. Several (nutritional) indices obtained by means of multivariate analyses were proposed to predict morbidity and mortality better (Chapter 4). Unfortunately, such data are not of sufticient precision to be used for the individual patient, because they are affected by several patient related factors such as hydration, stress and prior starvation. 


\subsection{Perioperative nutritional support.}

The acknowledgement that an impaired nutritional status has an adverse effect on outcome of disease and therapy has contributed to the development of artificial nutrition. Much effort has been put in the assessment of the efficacy of nutritional support. The benefit of nutritional support, either by the parenteral or by the enteral route, in the perioperative management of the depleted cancer patient, is still under debate. The causes for this controversy will be discussed in chapter $3 \& 4$.

\subsection{Study population}

Cancer patients form an appropriate group to study the effects of depletion on postoperative outcome as well on the potential benefit of preoperative nutritional intervention. Anorexia, obstruction, increased energy expenditure, taste alterations, etc. leading to depletion, are common features in cancer disease. Therefore, this group of patients should, on theoretical grounds, benefit from preoperative nutritional intervention. However, tumor-host relationships are different between types of cancer and interfere with trial results if all kinds of cancer are included. Nonetheless, in literature most trials used miscellaneous types of cancers.

We, therefore, chose to select a homogeneous cancer patient group. Gastrointestinal cancer patients form a proper study population because tumour behaviour and characteristics are comparable. gastro-intestinal cancer has a high incidence in western countries, and above mentioned metabolic aberations will occur in an early stage in this type of cancer. All these reasons lead to a rapid intake of depleted cancer patients in the study.

The incidence of gastric cancer in western countries is between 5 and 10 new cases per 100.000 per year ${ }^{13.14}$, with a predominant incidence in males ${ }^{15,16}$. Adenocarcinoma is the most frequent malignant tumor of the stomach; it comprises $97 \%$ or more of these lesions ${ }^{16}$. Survival in most gastric cancer series is limited. Eighty-five percent of patients at time of diagnosis are surgical candidates ${ }^{16.17}$. Half of these $85 \%$ will undergo 'curative' resection with a 5-year survival rate of approximately $25 \%$. The other half will undergo palliative surgery with no long term survival ${ }^{17}$. Overall survival at 5 years is between 5 10 percent $^{10.1}$.

In Western countries cancer of the colon and rectum ranks second after lung cancer in incidence of new cases and death rates ${ }^{13.16}$. The incidence varies in 
Western countries between 25 and 60 new cases per 100.000 population per year ${ }^{13.14}$. Males and females are equally affected. The incidence increases with age, beginning to rise at age 40 and reaching a peak at $75-80$ years ${ }^{6.15}$. Primary therapy consists of surgery ${ }^{13.16}$. About $10 \%$ is inoperable at time of diagnosis ${ }^{16}$. One-third will undergo a palliative resection with less then 5\% 5-year survival. After 'curative' resection 5-year survival is about $40 \%$. Overall 5 -year survival is between $25-30 \% \%^{13,14,19}$.

\subsection{Aims of the study}

The aim of this study was to investigate in a randomised trial the effects of perioperative nutritional support, given by either the parenteral or enteral route, on the incidence of postoperative morbidity and mortality in depleted patients undergoing surgical treatment of a gastric, colon or rectal malignancy.

Secondary goals in this clinical trial were:

1. to identify factors which are significantly associated with postoperative morbidity and mortality of gastric and colorectal cancer surgery.

2. to identify parameters wich are associated with long term survival of gastric and colorectal cancer treatment.

3. to investigate whether perioperative nutritional support results in improvement of long term survival of gastric and colorectal cancer patients.

References

1. Mullen JL. Conseyuchess of malnutrition in the surgicial parient

Surg.Clin.North.Am. 1981:61:46,5-487

2. Mullen JI. Genner MH. Buzby GP, el al. Implications of malnutrition in surgical parient. Arch. Surg 1979:1 14:121-125

3. Burby GP. Mullen JL. Methews DC. et al. Prognostic nutritional index in gastrointestinal surgery. Am.J.Sur: 1980;139:160-167

4. Studley HO. Percentage of weight loss, a baric indicator of surgical risk in patients with chronic peptic ulcer J.A.M.A. $1936: 106: 458-460$ 


\section{Chapter I}

5. Tweedie FJ, Long RC. Abdominal wiwund disruption. S.G.O. 1954:99:4!-47

6. Elfron G. Abdominal wound disruption. Lancel 1965:1:1287-1200

7. Rhoads JE, Alexander CE. Nutritional problems of surgical patients Ann.NY.Acad.Sci. 1955:63:268-275

8. Cannon PR, Wissler RW. Woolridge RL, Benditt EP. The relationship of protein deficiency to surgical infection. Ann.Surg. 1944:120:514-525

9. Bristrian BR. Btackbum GL. Hallowell E, Heddle R. Protein status of gencral surgical patients. J.A.M.A. 1974:230:858-860

10. Bristrian BR, Blackbum GL. Vitale J, et al. Prevalence of malnutrition in general medical patients. J.A.M.A. 1976:23:5:1567-1570

11. Hill GL., Blackett RL. Pickford I, et al. Malnucrition in surgical patients: an unrecognised problem. Lancet 1977:1:689-69?

12. Mueller JM. Keller HW. Brenner U. Walter M. Holtzmueller W. Indications and effects of preoperative parenteral nutrition

World J.Surg. 1986:10:53-63

13. Fink AS. Longmire WP. Carcinoma of the stomach. in: Textbook of Surgery. Chapter 31, Sabiston ed. Saunders \& Co, 1986

14. DeVita VT. Hellman S, Rosenberg SA. Cancer. Principles \& Practice of Oncology. $3^{\text {wed }}$ 1989. Chapter 29 \& Chapter 25

JB Lippincou Co. Philidelphia

15. Detsky AS. Baker JP. O'Rourke K, et al. Predicting nutrition-associated complicalions for patients undergoing gastrointestinal surgery.

J.P.E.N. 1987:11:440-446

16. Monon JM. Poulter CA. Pandya KJ. Alimentary tract cancer.

in: Clinical Oncology. Chapter 14. Rubin ed. American Cancer Society, 1983

17. Dupont JB, Lee JR. Button GR. Cohn I. Adenocarcinoma of the stomich. Cancer 1978:41:941-944

18. Buzby GP, Mullen JL. Matthews DC. Hobbs CL. Rosato EF. Prognostic nutritional index in gastrointestinal surgery.

Am.J.Surg. 1980;10:53-63

19. Falteman KW, Hill CB. Markey JC. Fox JW. Cohn l. Cancer of the colon. rectum, and anus Cancer 1974;34:951-955 
Chapter 2

\section{Methodological considerations}

\subsection{General aspects: trial design}

The trial was designed as a sequential trial to compare three groups stratified for the most relevant patient factors'. A sequential trial design was chosen because of ethical reasons: it would allow termination of the trial after performance of an interim analysis if one of the treatments would have a clear advantage or if it was unlikely that prolongation of the trial would result in a significant difference between trial arms.

\subsection{Number of patients required}

To estimate the number of patients necessary for an adequate answer on the trial objection and to estimate the expected duration of the trial, a postoperative major morbidity rate of $30 \%$ in depleted cancer patients was assumed. A reduction of $20 \%$ of major morbidity was regarded to be of clinical significance. Alpha (the chance to reject incorrectly the statistical null hypothesis of no difference) was set to $5 \%$ and beta (the chance to detect a reduction of $20 \%$ of major morbidity) was set to $95 \%$. On this basis a total of \pm 80 patients per study arm was required to obtain an answer in a 2 -tailed $X^{2}$-test.

The percentage gastrointestinal cancer patients with signs of depletion was expected to be $60 \%$ of all admitted patients with a gastrointestinal malignancy. It was expected that upto $20 \%$ of the patients were not eligible for operation because of the stage and condition of the patient (inoperability), or because of the age of the patient (patients over 80 years were excluded from randomisation). This implied that without a significant improvement in morbidity in one of the treatment arms in an interim analysis, a total number of about 500 patients was required $(80 \times 3 \times 100 / 60 \times 100 / 80=500)$.

\subsection{Duration of the trial}

With an admittance rate of \pm 100 patients per year (96 in 1982) to the University Hospital Maastricht, the expected duration of the trial was 4 - 5 years. If results of the interim analysis would show a statistical benefit for the treatment arm, the 
trial was to be discontinued. Also, if the interim analyses would indicate no difference between control and treatment arms, this too would be a reason to discontinue the trial.

\subsection{Study protocol}

\subsubsection{Patients}

The effect of perioperative nutritional support was prospectively studied in consecutive patients admitted to undergo major surgical therapy for newly detected and histologically proven gastric, colon or rectal cancer. The procedure was defined by non-emergency laparotomy for curative or palliative surgical therapy for gastric or colorectal cancer.

Specific exclusion criteria were:

-a contraindication for delaying surgery for 10 days

-a contraindication for parenteral or enteral nutritional support -over 80 years of age.

All excluded patients were monitored for their postoperative clinical course and they were included in the risk factor analysis (Chapter 5). Informed consent was obtained from all participating patients.

\subsubsection{Nutritional assessment}

Because it was considered ethically unjustified to subject patients that had a normal percentage ideal body weight (PIW), plasma albumin (Alb) and total lymphocyte count (TLC) to nutritional intervention, these patients were excluded from randomisation. In 1985 we computed an index ${ }^{3}$ consisting of parameters which distinguished patients that on clinical grounds were judged to be nutritionally depleted, from a healthy control group by the next formula:

$(0.14 \times$ Alb $(\mathrm{gr} / \mathrm{l}))+(0.03 \times \mathrm{PIW}(\%))+\left(0.73 \times \mathrm{TLC}\left(10^{2} / \mathrm{mm}^{3}\right)\right)-8.90$

In the current study all patients who had a value below the mean of the reference group (1.31) in the original study of de Jong ${ }^{2}$ were randomised. This is an arbitrary choice, resulting in inclusion in the trial of patients in the grey area between absence and presence of depletion. Within this area it is difficult to draw strict limits.

Non-depleted patients were excluded from randomisation. They served as nondepleted control group. These patients were operated without delay within 2 - 3 days after admission to the hospital. 


\subsubsection{Stratification}

Patients with an index below 1.31 were stratified for age, tumor localisation, and weight loss.

-tumor localisation

-gastric cancer -colon or rectal cancer

-weight loss

$-<15 \%$

$-\geq 15 \%$

-age

$-<65$ years

$-\geq 65$ years

\subsubsection{Randomisation}

The patients with a value below the cut-off point were after stratification for tumor localisation, age and weight loss, randomised to receive perioperative total parenteral nutrition (TPN), preoperative enteral nutrition (TEN), or to serve as depleted controls. Patients in the control group were operated without delay, within 2 - 3 days. Patients who refused after randomisation to participate in one of the nutritional supported trial groups, were analysed according to the intention-to-treat principle. They also were operated without delay.

\subsubsection{Surgical procedures}

Surgical procedures preformed were -gastro-enterostomy

-gastric tumor resection with anastomosis

-entro-enterostomy without tumor resection

-entro-enterostomy with tumor resection

-colon resection with end colostomy

-low anterior resection

\subsubsection{Data collection}

Blood was sampled preoperatively from all patients according to protocol to determine hematological parameters, electrolyte status, protein parameters. Preoperative anthropometric evaluation included determination of weight, height, weight loss during the preceeding year, and percent weight loss (Appendix 1). Weight loss was obtained by standard dietary evaluation by a registered dietitian. Percent ideal weight was calculated using the Metropolitan Life tables?.

Peroperative blood loss was estimated and recorded by the anaesthesiologist, duration of the surgical procedure was recorded from the anaesthesiology report. Tumor stage was scored according to the TNM-classification (Appendix 2). 
Postoperative complications were scored until hospital discharge. They were categorised as absent, minor or major complications. Mortality was total, in hospital mortality from any cause.

Complications related to the insertion of a central venous catheter, technical or septic, metabolic complications related to the parenteral nutritional support, or metabolic and mechanical complications related to the enteral nutritional support were scored separately.

\subsubsection{Nutritional support}

Preoperative nutritional support, both parenteral and enteral, was planned to contain 150\% basal energy expenditure (BEE) calculated with the HarrisBenedict formulat as non protein calories and to last at least 10 days.

\subsubsection{Parenteral nutrition}

T.P.N. solutions were prepared in the hospital pharmacy according to current standards. Basis solutions contained 7 gr nitrogen per liter (Synthamin $14^{\mathrm{R}}$ ), $25 \%$ glucose per liter. Intravenous lipid emulsions were administered at least 3 times weekly $\left(500 \mathrm{ml}\right.$ Intralipid ${ }^{R} 20 \%$ ). Vitamins (MVI ${ }^{R}$ ) and trace metals (zinc, copper, manganese, selenium, chromium, and iodine) were supplemented daily. Electrolytes (potassium, sodium, magnesium, calcium, chloride, phosphate) were supplemented according to the individual patient's needs.

Postoperative parenteral nutrition was continued in the T.P.N. group until patients were able to take $120 \%$ BEE orally.

\subsubsection{Enteral nutrition}

Enteral nutrition, (Precitene ${ }^{k} \mathrm{~N}$ or Isotein $^{k}$ (N:kcal ratio 1:92, protein $107 \mathrm{gr} / \mathrm{l}$, $1575 \mathrm{kcal} / \mathrm{l})$ ), was administered by naso-gastric tube or orally. Postoperatively the patients resumed oral nutrition as tolerated.

\subsubsection{Control patients}

Patients in the depleted control group and in the non-depleted reference group were planned to undergo surgery without delay. Normal preoperative care was given according to the planned procedure e.g. bowel lavage. In the postoperative phase patients in these groups, as in the enteral group, were allowed increasing amounts of liquids and solids as tolerated. Only in the event of a major postoperative complication parenteral nutrition was started on indication. 


\subsection{Analysis of results}

\subsection{Complication analysis}

All patients in the trial groups were analysed according to the intention-to-treat principle. Data were summarised as means and standard deviations in each outcome group. Groups were compared on continuous parameters using ANOVA and Scheffé's post hoc t-test'. After categorisation using clinically accepted cut-off points, Mantel-Haenszel chi-square tests ${ }^{6}$ were applied to test the association of parameters with outcome (scored as 1, 2, 3 for no. minor, major complications).

The association of several parameters simultaneously with outcome was assessed with a continuation-ratio multiple logistic regression model ${ }^{7.8}$. In these analyses the occurrence of a complication and the occurrence of a major complication, given any complication, were taken as dependent variables. We assumed the same parameters to be explanatory for both, unless the coefficients were significantly different.

P-values smaller than 0.05 were considered significant.

\subsubsection{Survival analysis}

Survival was measured from date of the surgical procedure. Survival analysis included the in hospital postoperative mortality. The medical records of all patients were reviewed to assess survival and cause of death till may 1991. The general practitioner was called for information on the actual status of the patient when the patient was lost to surgical outpatient follow-up or when the last attended control at the surgical outpatient clinic was longer than 2 months prior to last follow-up date.

Survival was analysed using the Kaplan-Meier method", for all patients as well as for subgroups. The survival curves of groups of patients were compared using the log-rank test ${ }^{10}$. The efficacy of perioperative nutrition and prognostic potential of nutritional parameters, adjusted for effects of the other riskfactors was tested using a Cox (proportional hazards") regression model. This regression model included all preoperative parameters which appeared to be important in the log-rank analyses, and the nutritional support parameters.

P-values smaller than 0.05 were considered significant. 


\section{Chapter 2}

\section{References}

1. Pocuck SJ. Clinical trials. A practicul approach. (Chapter 5). 1983 John Wilcy \& Sons Lid

2. De Jong PC.M. Wesdorp RIC. Volovics A. Rouflart M. Greep JM. Soeters PB. The value of objective measurements to select patients who are malnourished.

(linical Nutrition 1955:4:61-66

3. Assuciation of life insurance medical directors: Medico-actuarial mortality investigations. Ass.Liti Ins.Med.Dir, and Acluarial Soc.Am. 19/2; vol.1

4. Harris JA. Benedict FG, A biumctric study of basal metabolism.

Washinglon. Camcyic institution of Washington 1919

5. Schefré H. The analysis of variance. New York. John Wiley \& Sons, 1959.

6. Mantcl N, Haenszel W. Statistical aspects of the analysis of data from retrospective studies of disease J.'iat.Cancer Inst. 1959:22:719-748

7. Agresti A. Analysis of ordinal calegnrical data New York. Wiley 1984:pl12-117

8. Cox C. Multinominal regression models based on continuation ratios.

Statistics in Medicine 1988;7:435-441

9. Kuplan lit. Meier P. Numparanetric estimation from incomplete observations.

J.Am.Sititist.Ans. 1958:53:457-481.

10. Mantel N. Evaluation of survival data and two new rank order statistics arising in its consideration. C'mer Chemoherapy Reports 1966:50:163-170

11. Cox DR. Regression models and life tables (with discussion) J.R.Statist.Sor.B. 1972:34:187.220. 
Chapter 3

\section{An assessment of nutritional depletion and surgical risk}

\subsection{Introduction}

The effectivity and validity of nutritional assessment methods are still uncertain. There are several reasons for this uncertainty. In the past it has been proposed that it is possible to determine solely by means of nutritional assessment, which patients are at risk for postoperative complications. Furthermore, nutritional assessment methods have often focused on (a decreased) nutritional intake. Finally, parameters for nutritional state and indicators for surgical risk are frequently used as equivalents, because 'malnourished' patients often have a less favourable outcome of therapy.

It is the purpose of this chapter to analyse which factors can cause depletion of a patient and how these factors are related with other factors traditionally thought to influence the outcome of therapy.

When patients are metabolically stable. body composition is kept constant over longer periods of time through maintenance of a balance between intake and losses of energy, protein, and other essential nutrients. Deficiencies are the result of a derangement of the balance, either on the intake side or on the expenditure side, and lead to changes in body composition and disturbed organ functioning.

Nutritional assessment signifies detection of abnormal body composition and organ function resulting from insufficient nutritional intake; including energy and protein intake, and also intake of other essential nutritients.

However, the actual intake of energy, protein and other nutrients by depleted patients is not always decreased. Some studies in cancer patients revealed a normal food intake compared to a control group ${ }^{1.2}$. Therefore, nutritional assessment in these depleted patients becomes metabolic assessment. Nutritional assessment under these circumstances is used to detect abnormal body composition and disturbed organ function resulting from increased loss: increased energy expenditure, increased protein degradation, increased loss of total body nitrogen, and increased loss of essential nutrients. In most cases a mixture of both conditions is present.

As a result of abnormal body composition and the ensuing disturbed organ 
function the response to the presence of disease or trauma may become impaired. Abnormal body composition and organ function therefore impose additional risks to the patient, but are not synonymous to the development of complications of disease, or the outcome of the treatment of disease.

This chapter intents to sort out the responses of several parameters of body composition and organ function to:

- impaired intake of energy and protein

- increased losses of energy and protein

- a mixture of both derangements

Furthermore. the relationship of abnormal parameters with the response to disease and trauma will be described.

The ultimate goal is to estimate which improvements nutritional support can have on the response of the patient to disease and trauma.

\subsection{Starvation experiments: impaired intake.}

Under normal circumstances food intake is adapted to changing needs, regulated by sensation of hunger. which depends on factors such as the amount of energy expenditure in work, climatological circumstances, and the nutritional value (energy content) of nutrients.. After uptake of nutrients in the absorptive phase directly after a meal. in the post-absorptive phase glucose levels are maintained within a rather narrow range. In this phase the brain is still largely dependent on glucose, but other tissues, particularly skeletal muscle, become increasingly dependent on free fatty acids. mobilised from adipose tissue. Plasma free fatty acids levels are rising ${ }^{+i}$ and liver glycogen is falling and nearly depleted after 24 - 48 hours". Gluconeogenesis becomes increasingly significant, so that after 24 hours of abstinence of caloric intake gluconeogenesis is the prime contributor of hepatic glucose production". Early fasting is accompanied by lower insulin levels and elevated glucagon levels, provoking hepatic glycogenolysis and hepatic gluconeogenesis, supported by release of nitrogenous substrates, mainly glutamine and alanine. from skeletal muscle"". These lower plasma insulin concentrations are also of influence on fat metabolism. Insulin is a potent antilipolytic hormone. A fall in insulin levels make long chain fatty acids the most important source of energy during prolonged starvation, thus preserving muscle mass.

It has been demonstrated that a healthy person can withstand prolonged starvation without any damage to the individual. Benedict" showed in a healthy volunteer during a 30 day fast a progressive decrease in oxygen consumption, indicating a corresponding decrease in energy expenditure. Even total food 
abstinence over a period lasting more than two months by Irish political detainees was survived by 33 out of 43 prisoners". Russel'2 demonstrated in anorexia nervosa patients that prolonged decreased intake, extending over a mean of 4.3 years, resulted in slightly decreased serum albumin values, with normal lymphocyte counts and a creatinin-height index within normal ranges. Total body weight, lean body weight and percent body fat were decreased.

Thus, a decreased intake of energy, protein and other nutrients without concomitant disease shows a gradual decrease of body weight and energy expenditure with substantial loss of body fat mass and relative preservation of lean body cell mass.

\subsection{Disease status: increased loss.}

Damage of tissues. irrespective of the cause (infection, malignancy, surgery, trauma, and especially sepsis), is accompanied by changes in glucose and lipid metabolism, an increased net protein degradation, resulting in increased losses, hypermetabolism, and a negative nitrogen balance ${ }^{13}$. These injuries alert central nervous systems, via afferent neural impulses ${ }^{14}$. This arousal of the central nervous system results in activation of autonomous nervous and neuroendocrine systems ${ }^{14}$, with elevation of the so-called stress hormones (cortisol, glucagon and catecholamines'").

In muscle, a decline in net amino acid (AA) uptake and an increase in muscle degradation occurs. In the splanchnic region, glutamine (GLN) and alanine (ALA) uptake are increased ${ }^{10}$. The net liver AA uptake increases, probably caused by an increased hepatic protein synthesis, ureagenesis and gluconeogenesis. This gluconeogenesis and the concomitant peripheral glucose resistance contributes to hyperglycemia ${ }^{1:}$, commonly observed during trauma and sepsis.

The glucocorticoid hormones seem to be the key regulators of the accelerated intestinal protein metabolism that occurs following surgical stress ${ }^{1 ?}$. During stress states, an elevation of arterial corticosteroid concentration causes an increased net gut GLN uptake, and a net glucose, ALA, and ammonia release from the gut ${ }^{1 *}$ and possibly spleen. The intestinal release of ALA supports hepatic gluconeogenesis, while ammonia is converted to a large extent to urea, excreted by the kidney and thus contributing to the negative nitrogen balance associated with stress ${ }^{17}$.

The hypermetabolic state, which often accompanies major trauma, is not only coupled with an elevation of the stress hormones, but also with a (temporary) elevation of cytokines (e.g. TNF. IL-6) ${ }^{14}$. It is very likely that these cytokines 
moderate the changes in metabolism, observed in trauma and/or sepsis. It is as yet uncertain whether their release is proportional to the amount of circulating stress hormones, and how the elevated cytokine levels are influenced by the catabolic condition.

Patients with septicemia, episodes of fever, and trauma show increased loss of energy and protein, decreasing weight parameters ${ }^{20.21}$ and decreasing plasma albumin $^{20.22 .25}$ levels. The cancer-bearing-state is often accompanied by increased losses, which in some types of cancer can be caused by a hypermetabolic state resulting from an increased basal energy expenditure ${ }^{24}$. Thus, disease is in general associated with alterations in intermediary metabolism, hormonal changes, and probably changes in cytokine levels. They play a (major) role in depletion, although their relationship is not yet fully understood.

Disease state and especially the septic state is accompanied by rapidly falling plasma total protein and albumin concentrations, decreasing lymphocyte counts, and rapid changes in electrolytes and trace elements. This may demonstrated best in (healthy) young trauma patients at the Intensive Care Unit with signs of sepsis where these changes occur within few days.

\subsection{The combination of impaired intake and increased loss.}

In most cases a mixture of starvation and increased loss exists. The recognition of depletion having a nutritional origin and a metabolic origin may also explain why nutritional intervention is not always succesful in reversing ongoing 'malnutrition'. The possible origin of impaired 'nutritional' status and, therefore, the impaired capability to respond to intrusions, may have either a nutritional origin (a result of food intake of insufficient quantity or suboptimal quality), or may have a metabolic origin (a result of metabolic alterations) (figure 3.1). Both result in depletion. As the term 'malnutrition' acknowledges

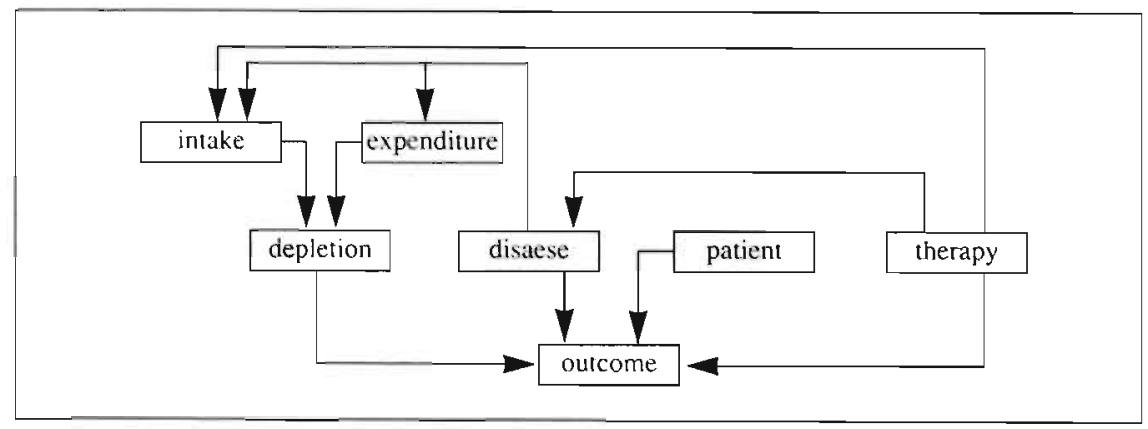

Figure 3.1 
only the nutritional origin, the term depletion reflects more accurately than the term 'malnutrition' the clinical condition we seek to descibe. The metabolic side of depletion is probably not easily reversed with 'ordinary' nutritional intervention. This may explain why for example the depleted patient with Crohn's disease having ongoing septicemia or chronic infection. cannot recover from his depletion by means of nutritional intervention, as long as the underlying disease (the active inflammation with the metabolic and hormonal changes) is not cured. The patient, depleted to a similar degree, with stenosis of the bowel as result of Crohn's disease without active inflammation, will recover rapidly after nutritional intervention has started ${ }^{25}$.

By assuming both nutritional and metabolic factors as cause of depletion the fact is acknowledged that the response to an intrusion is not exclusively dependent on the nutritional status of the subject, but rather on the the integrity of body composition and organ function. Thus, by including the causes of depletion in the assessment of depletion, not only those groups that need additional nutritional therapy may be identified, but it may also become possible to predict the effect of nutritional therapy.

\subsection{Abnormal parameters: relation with response to disease.}

The goal of the assessment of the presence of depletion is to identify patients that are unable to stage a normal response to a disrupting factor (trauma, operation, infection). These patients carry an additional risk for development of complications of their disease or of the treatment of their disease. Depletion is one of the risk factors for outcome of therapy, be it surgical therapy, chemotherapy, or radiation therapy. The outcome of therapy is a result of several factors e.g. patient related factors (age, coexisting diseases), treatment of disease, or disease itself, together with depletion (figure 3.1).

This view differs from usual definitions of 'nutritional status' or malnutrition in this respect that these definitions assume 'nutritional status' to be impaired if associated with morbidity and mortality. This approach assumes impaired 'nutritional status' to be the only determinant of the development of morbidity and mortality, and denies the role of other factors in this proces. This has led to overestimation of the importance of 'nutritional status' as determinant of the outcome of disease or treatment of disease. If one accepts that the development of morbidity and mortality of chemo-, radiation or surgical therapy is dependent on the magnitude of the trauma itself, and the capability of the host to respond to the trauma, the poor results of nutritional support trials designed to decrease morbidity and mortality can be explained. The capability to stage a response is 
only in part dependent on 'nutritional status', and nutritional support can, therefore, only partly influence or modify this response.

Many individual parameters have been suggested to describe depletion and the degree of malnutrition. In monofactorial analyses these parameters showed a fair to good correlation with the incidence of postoperative complications. But no single indicator has been proven superior to any other. Several studies demonstrated that single abnormalities in nutritional parameters tend to lose their discriminatory capacity, because very few patients display normal values for all parameters used ${ }^{0.2629}$. In the individual patient these parameters were not very useful in predicting the occurrence of complications. Combination of parameters does not always increase sensitivity, reliability and applicability for the individual patient because of the high degree of correlation among variables. Therefore, several investigators developed indices, combining multiple parameters of anthropometric, biochemical, and immunological measurements. These indices were based on multiple variate regression analyses. One of the problems of these methods is that they consider only parameters, that were traditionally thought to be associated with malnutrition. As a consequence this has led to overemphasis of the nutrition related risk factors. In addition, it gradually became clear that some of the parameters used to identify impaired "nutritional status", rather demonstrate the presence of metabolic stress". Futhermore, considerable confusion has been created because many authors defined 'nutritional status' parameters as abnormal only on the basis of their association with the development of complications.

Finally, the relative importance of 'nutritional status' was - indirectly - shown to be small, because trials investigating the effect of nutritional intervention on outcome of for example surgical therapy, almost invariably failed to demonstrate a benefit (chapter 4 ).

The emphasis on the role of 'nutritional status' parameters as risk indicators has distracted the attention from the role that disease and treatment, i.e. surgery, related factors have in the development of postoperative outcome. To our knowledge there are no studies that combine depletion parameters with non nutritional status related risk factors, which are traditionally found to be responsible for the postoperative outcome of surgical therapy, aimed at determination of the additional risk that originates from depletion.

Originally most interest was directed towards parameters that were considered to be objective measurements of an impaired 'nutritional status' or 'malnutrition'. Generally accepted parameters for nutritional assessment are total protein, transferrin, albumin and pre-albumin, alone $e^{22 \%}$ or in nutritional 
indices ${ }^{20.26-29.31-33}$, parameters identifying musclemass and fatstores, creatininheight index, muscle function tests, immunological status, and weight and weight $\operatorname{loss}^{20,21,30,4-37}$. Many of these parameters show a significant correlation with postoperative morbidity and mortality ${ }^{20,26-28,31,34,35,35-47}$, and are therefore often used to calculate the risk for development of postoperative complications ${ }^{2022 .}$ 25.28.31,34.35.39.

Age $^{38.51}$, extent of surgical procedures or any other disease treatment, peroperative blood loss and transfusion ${ }^{205253}$, and individual coexisting diseases have been studied much less frequently for their relation with outcome.

Weight loss and weight relative to ideal weight are parameters that have been used succesfully by many authors to identify patients at risk for the development of (postoperative) complications ${ }^{545}$. In 1936 Studley $^{\text {so }}$ already reported weight loss as prognostic factor for postoperative outcome. Weight loss is a simply obtained indicator, with a high reliability when obtained by standard dietary methods by registered dieticians, and is of value when it is combined with clinically obvious impairment of organ function ${ }^{21}$.

Transferrin and albumin have half lives of 10 and 20 days, respectively. Plasma levels of these proteins therefore change slowly in response to alterations in nutritional intake ${ }^{57,58}$. They decrease very quickly, however, in response to trauma ${ }^{59}$ (including elective surgery), myocardial infarction ${ }^{60}$, sepsis ${ }^{\mathrm{th}}$, and severe illness ${ }^{58}$. These changes are caused by inter-compartmental fluid shifts, alterations in vascular permeability ${ }^{62}$, and changes in rates of synthesis and degradation ${ }^{\circ}$. Therefore, albumin has been claimed a parameter of disease instead of being a nutritional parameter ${ }^{22}$. Despite this, serum albumin concentration is the most widely used single indicator of surgical risk.

There have been several attempts to increase the predictive value of nutritional parameters. Combinations of various parameters were presented as nutritional indices or risk indices, mostly being the result of multivariate stepwise regression analyses. Again, the assumption was made that malnutrition is synonymous to increased risk. However, the effort to improve the methods to define malnutrition by combining parameters, did not result in improvement of the predictive value for postoperative complications because these two terms are not equivalent. Increasing the predictive value of indices for postoperative complications is only then possible, if other factors, also related with postoperative complications, are considered too. Such factors are age, coexisting diseases, extent and duration of surgical procedure and peroperative blood loss, anesthesia technique, and skill of the surgeon. 


\subsection{Combination of parameters}

A summary of combinations of "nutritional' parameters as they have been proposed in the literature is presented below.

In 1979 the Prognostic Nutritional Index (PNI) ) $^{32.63 .65}$ was presented by Mullen et al.:

PNI (\%): $\left.158-\left(16.6 \times \mathrm{Alb}^{\circ}\right)-(0.78 \times \mathrm{TSF})-0.20 \times \mathrm{TFN}\right)-(5.8 \times \mathrm{DH})$

Seltzer ${ }^{60}$ proposed the Instant Nutritional Assessment (INA), based on 2 parameters:

INA: Malnourished when either $\quad$ Alb $<3.5 \mathrm{~g} / 100 \mathrm{ml}$

or $\quad$ TLC $<150010^{\circ} / \mathrm{mm} 3$

Harvey et al. ${ }^{67}$ presented the Hospital Prognostic Index (HPI):

HPI: $(0.91 \times \mathrm{Alb})-(1.00 \times \mathrm{DH})-(1.44 \times$ sepsis $)+(0.98 \times$ diagn $)-1.09$

Baker et al. ${ }^{68.69}$ made the clinical judgement essential part of the index, called Subjective Global Assessment (SGA):

SGA: normal nutritional status/mild-/severe malnutrition to be determined on information obtained from a careful history on intake, weight loss, underlying discuse, and functional status and physical examination of anthropometric parameters.

Gassull et al. ${ }^{70}$ combined the outcome of 3 parameters: TSF, MAMC, Alb.

De Jong et al. ${ }^{71}$ compared a group of healthy people with a group of patients considered malnourished on clinical grounds, as established by experienced clinicians. This Nutritional Index (NI) indicated the clinical impression of malnutrition:

NI: $20.68-(0.24 \times \mathrm{Alb})-(19.21 \times$ Pre-Alb $)-(1.86 \times$ TLC $)-(0.04$ PIW $)$

Alb $=$ plasma albumin $(\mathrm{g} / \mathrm{l})$. TSl : triceps skin fold $(\mathrm{cm})$, TFN $=$ transterrine $(\mathrm{mmol} / \mathrm{l}) . \mathrm{DH}=$ delayed hypersensitivity (response $1-3)$. TLC $=$ total lymphocyte count $\left(10 \% / \mathrm{mm}^{\prime}\right)$, MAMC $=$ mid-arm muscle circumference $(\mathrm{cm})$. Pre-Alb $=$ plasma pre-albumin $(\mathrm{g} / \mathrm{/}) . \mathrm{PIW}=$ percent ideal weight $(\%)$. FeBC $=$ iron binding cupacity $\mu \mathrm{g} / \mathrm{dl}$. 
Meguid et al. ${ }^{22}$ used a nutritional assessment method with attention to the hydration state of the patient:

Malnourished when posthydration albumin $<3.5 \mathrm{gr} / 100 \mathrm{ml}$

and recent weight loss $>10 \%$

and 2 factors below the 10 th percentile from

weight/height, MAMC and TSF

Braga et al. ${ }^{73}$ performed assessment of malnutrition with the following parameters:

malnourished: $\quad$ when $\mathrm{Alb}<3.0 \mathrm{~g} / 100 \mathrm{ml}$

or Total FeBC $<220 \mu \mathrm{g} / \mathrm{dl}$

or weight loss $>10 \%$

This survey does not give a complete overview of all nutritional indices in use. In most formulas morbidity and mortality (PNI, SGA) or clinical and physical impression (SGA, HPI, NI) are used as outcome which can be predicted by the formula. A major problem with most indices is that the same data set is used to calculate the index and to test validity of the index. The lack of a gold standard, and the index developed in a specific patient group, explains the poor outcome of these indices when applied to other patient groups ${ }^{7675}$. Because of this selection of patients. not only depletion is measured, but also the underlying cause, disease. It is impossible to exclude the influence of disease. Thus, indices are not only establishing the influence of depletion, but also the influence of disease on surgical outcome.

Almost all studies revealed positive relations between depletion and postoperative complications. In this literature it is suggested that this relation is absolute and independent. That has not been substantiated in any study until now. Only in multivariate analyses it is possible to analyse depletion or 'nutritional' parameters in addition to other, probably equally or even more important factors with respect to outcome of therapy.

Retirinces

1. Hansell DT, Davies JWL, Bums HJG. The relationship between resting cuergy expenditure and weight loss in henign and malignant disease.

Am. Surg. 1986:203:240-245

2. Burke M. Bryon EI, Kark AE. Dietary intakes, resting metabolic rates. and body composition in benign and malignant gastrointestinal disease.

Br.Med.J. 1980:1:211-215 
3. Schmidt RF. Thirst and hunger: general sensations. In: Schmidt RF, Theus G (eds.), Human Physiology. Springer, Berlin 1983, pp 307-314.

4. Owen OE. Reichard GG. Fuels consumed by man: the interplay between carbohydrates and fatly acids. Progr.Biochem.Pharmacol. 1971;6:199

5. Cahill GF. Herrera MG. Morgan AP. et al. Hormone-fuel interrelationships during fasting. J.Clin.Invest. 1966;45:1751-1769

6. Garber AJ. Menzel PH, Boden G, et al. Hepatic ketogenesis and gluconeogeness in humans. J.Clin.Ivest. 1974:54:981-989

7. Oven OE. Fclig P. Morgan AP, et al. Liver and kidney metabolism during prolonged starvation. J.Clin.Invest. 1969:48:574-583

8. Hultman E. Regulation of carbohydrate metabolism in the liver during rest and exercise with special reference to diel. In: Landry P, Orbanwar R (eds.), 3rd Int. Symposium on Biochemistry of Exercise. Symposia Spec.Inc. Miami. Florida, 1978. pp99-126

9. Cahill F. Starvation: some biological aspects. In: Kinney JM, Jeejeebhoy KN, Hill GL, Owen OE (eds.). Nutrition and metabolism in patient care. Saunders. Philade!phia, 1988, pp 193-204.

10. Marliss EB. Aoki TT. Pozetsky AS. et al. Muscle and splanchnic glutamine and glutamate metabolism in postabsulptive and starved man.

J.Clin.Invest. 1971:50:814-817

11. Benedict FG. A study of prolonged fasting. Washington. DC. Camegie Institute of Washingron. Publication 203, 1915

12. Russel DM, Prendergast PJ, Darby PL. Gartinkel PE, Whitwell J, Jeejeebhoy KN. A comparison between muscle function and body composition in anorexia nervosa: the effect of refeeding Am.J.Clin. Nutr. 1983:38:229-237

13. Fowlie S., Eastwood M.A. Oral nutrition and gistroenterology. Curr. Op.Gastroent. 1987:3:297

14. Walters JM. Wilmore DW. The metabolic response to trauma and sepsis. In: DeGroot LJ (ed.), Endocrinology. Saunders. Philadelphia, 1989, pp2367-2393

15. Bessey PQ, Watters JM. Aoki TT, Wilmore DW. Combined homonat infusion stimulates the metabolic rexponse to injuiy.

Ann.Surg. 1984:200:264-281

16. Souba WW. Wilmore DW. Postoperative atteration of arteriovenous exchange of amino acids across the gasitrintestinal trat.

Surgery $1983: 04: 342$

17. Souba WW, Klimberg S. Plumley DA. SalloumRM. Flynn TC. Bland KI, Copeland III EM. The role of glutumine in maintaining a heallhy gut and supporting trhe metabolic response to injury and infection. J.Surg. Res. 1900:48:38:3

18. Wilnow; D.W., Smith R.J.. O'Dwyer S.T., Jacobs D.O.. Ziegler T.R., Wang X-D. The gut: A central (1)!itu atter surgecial stress.

Surgery 1988: $10+517$

19. Simms JM. Smih JAR, Woods FIF. A modified prognostic index based upon nuritional measurements. Clinical Nutrition 1982:1:71-79 
20. Warnold I, Lundholm K. Clinical significance of preoperative nutritional status in 215 noncancer patients.

Ann.Surg. 1984:199:299-305

21. Windsor JA. Hill GL. Weight loss with physiologic impaiment. A hasic indicator of surgical risk Ann.Surg. 1988:207:290-296

22. Eitiorial. Indicators of surgical risk.

Lancel 1986:1:1422-1423

23. Bistrian BR. Blackbum Gi.. Hallowel E, Heddie R. Protein status of general suricical patients J.A.M.A. 1974:230:858 860

24. Fredrix EWHM. Wouters EFM. Souters PB. el al. Resting energy expenditure in non-small cell lung cancer patients

Clin. Vutrit. 1990:9:319-324

25. Gouma DJ, von Meyenfeldi MF. Rouflart M. Soeters PB. Preoperative tolal parenteral nutrition (TPN) in severe Crohn's disease:

Surgery $1988 ; 103: 648-652$

26. Detsky AS, Baker JP. Menelson RA, Wolman SL, Wesson DE. Jeejecbhoy KN. Evaluating the accuracy of nutritional assessment techniques applied to hospitalized patients: Methodology and comparisons. J.P.E.N. 1984:8:153-159

27. Mullen JL. Gertner MH. Buzby GP. Goodhan GL. Rosato EF. Implications of malnutrition in the surgical patient.

Arch.Surg. 1979:114:121-125

28. Mullen JL. Buzby GP. Waldman MT. Gertner MH. Hobbs CL, Rosato EF. Prediction of operative morbidity and mortality by preoperative nutritional assessment.

Surg.Forum 1979:30:80.82

29. Dionigi R. Cremitschi RE. Jemos V. Dominioni L, Monico R. Nutritional assessment and severity of illnews classilication systems: A critical review on their clinical relevance.

World J.Surg. 1986:10:2-11

30. Hickman DM. Miller RA. Rombeau JL. Twomey PL. Frey CF. Serum albumin and body weight as predicuss of postoperative course in colotutal cancer.

J.P.E.N. 1980:-.314-316

31. Klidjian AM, Foster KJ. Kammerling RM. Kartan SJ. Rulation of anthropometric and dynamonctric variables to serious postoperative complications.

Brit.Med.J. 1980:281:899-901

32. Mullen JL, Buzby GP. Waldham MT. Gertner MH, Hobbs CL. Rosato EF. Prodiction of operative mobidity and mortality by preoperative nutritional assessment

Surg.Forum 1979:30:80-82

33. Harvey KB. Moldawer LL, Bristrian BR, Blackbum GL. Biological mcasures for the formulation of a hospital prognostic index.

Am.J.Clin.Nuts. 1981:34:201,3-2022

34. Hickman DM. Miller RA.Rombeau JL. Twomey PL. Frey CF. Serum albumin and body weight as predicrors of postoperative course in colorectal cancer

J.P.E.N, 1980:4:314-316 
35. De La Hunt. McDonald PJ, Kartan SJ. Anthropometric nutritional assessment is of value in colorectal patients.

Dis.Col.\&Rect. 1984:27:296-298

36. Elwyn DH. Nutritional requirements of adult surgical patients.

Crit.Care Med. 1980:8:9-19

37. Ennis CE. Andrassy RJ. Nutritional management of the surgical patient. A.O.R.N.J. 1980:31:1217-1224

38. Collins JP, McCarthy ID, Hill Gi. Assessment of prorein nutrition in surgical patients. The value of anthropometrics.

Am.J.Clin.Nutr. 1979:32:1527-1530

39. Forse RA. Chrisiou N. Meakins JL, MacLean LD, Shizgal HM. Reliability of skin testing as a measurement of nutritional state.

Arch.Surg. 1976:111:1357-1361

40. Nordenström J, Carpentier YA. Askenazi J, Robin AP, Elwyn DH. Hensle DH, Kinney JM. Metabolic utilization of intravenous fat emulsion during total parenteral nutrition.

Ann.Surg. 1982: 196:22 L-231

41. Bellantone R. Doglietto GB,Bossola M, Pacelli F, Negro F. Sofo L. Crucitti F. Preoperative parentera! nutrition of malnourished surgical patients.

Acta Chir.Scand. 1988:22:249-251

42. DeMatteis R. Herman RE. Supplementary parenteral nutrition in patients with malignant disease. Cleveland Clinic Quanerly 1973:40:139.145

43. Mullen JL. Complications of total parenteral nutrition in the cancer patient.

Cancer Treal.Rep. 1981:05:107-113

44. Daly JM. Use of parenteral nutrition in the patient with cancer Surgery 1985:97:756-758

45. Mueller JM. Keller HW. Brenner U, Walter M. Holzmueller W. Indications and effects of preoperalive parcnteral nutrition.

World J.Surg. 1986:10:53-63

46. Sutton G. Karran SJ. The diagnosis of malnutrition: nutritional parancters. Curr.Op.Gastrent. 1985;1:281-287

47. Mueller JM, Brenner U, Diest C. Pichelmaier H. Preoperative parenteral feeding in patients with gastrointestinal carcinoma.

The Lancet 1982:1:68-7!

48. St:urker PM. Askenazi J. L asala PA. Elwyn DH. Gump FE, Kinney JM. The effecr of parenteral nutritional repletion on muncle water and electrolytes. Implications for body composition.

Ann.Surg. 1983:198:213-217

49. Staker PM, Lasala PA, Askenazi J, Gump FE. Forse RA. Kinney JM. The response to TPN. A form of nutritional assessment.

Ann.Surg. 1983:198:720-724

50. Harbrecht PJ, Garrison RN. Fry DE. Role of infection in incrensed mortality associated with age in lapsotomy.

Am.J.Surg. 1983:49:173-178 
51. Linn BS. Robinson DS. Klimas NG. Effects of age and nutritional status on surgical outcome in head and neck cancer.

Ann.Surg. 1988:207:267-27;

52. Szczepanski KP. Skaarup P. Stear-Johansen T. Pleuropulmonary complications following major surgery (Thoracic surgery excluded).

Acta Chir.Scand. 1973; 139:425-430

53. The Norwegian Gastro-Intestinal Group (NORGAS). Infectious problems after elective surgery of the alimentary tract: the influence of perioperative factors.

Curr.Med.Res.Op. 1988:11:179-195

54. Rhoads JE. Alexander CE. Nutritional problems of surgical patients.

Ann.N.Y.Acad.Sci. 1955;63:268-275

55. Grant JP, Custer PB. Thurlow J. Current techniques of nutritional assessment.

Surg.Clin.North Am. 1981:61:437-463

56. - Studley HO. Percentuge of weight loss. A basic indicaror on surgical risk in patients with chronic peptic ulcer.

J.A.M.A. 1936:106:458-460

57. Carpentier YA. Barthel J. Bruyns J. Plasma concentration in nutritional assessment.

Proc.Nutr.Soc. 1982:41:405-417

58. Fleck A. Colley CM. Myers MA. Liver export proteins and trauma

Br.Med.Bull. 1985:41:265-273

59. Aronsen KF. Ekelund G, Kindmark CO, Laurell CB. Sequential changes of plasma proteins after surgical traumit.

Scand.J.Clin.Lab.Invest. 1972;29:127-136

60. Johansson BG. Kindmark CO. Trell EY, Wollheim FA. Sequential changes of plasma proteins afier myociurdial infurcion.

Scand.J.Clin Lab.Invest. 1972:29:117-126

61. Beisel WR. Sepsis and metabolism. In: Litule RA. Frayn KN. eds. The scienunte basis for the care of the critically ill. Manchester: Manchester University Press 1986:pp 103-122

62. Fleck A, Raines G, Hawker F. et al. Increased vascular permeability: A major cause of hypoalbumineamia in disease and injury.

1.ancet 1985:1:781-784

63. Buzby GP. Mullen GL, Mathews DC. Hobbs CL, Rosato EF. Prognostic nutritional index in gatstrointestinal surgery

Am.J.Surg. 1980;139:160-167

64. Smale BF. Mullen EF. Buzby GP. Rosato EF. The efficacy of nutritional assessment and suppon in cancer surgery.

Cincer 1981:47:2375-2381

65. Dempsey DT. Buzby GP. Mullen JL. Nutritional assessment in the seriously ill patient. J.Am.Coll.Nutr. 1983:2:15-23

66. Selizer MH. Instant Nutritional Index.

J.P.E.N. 1979;3:157-159 


\section{Chapter 3}

67. Harvey KB, Moldawer LL, Bistrian BR, Blackbum GL. Biological measures for the formulation of a hospital prognostic index.

Am.J.Clin.Nutr. 1981:34:2013-2022

68. Baker JP, Detsky AS, Wesson DE et al. Nutritional assessment. N.Engl.J.Med. 1982:306:969-972

69. Baker JP. Detsky AS, Whitewell J, Langer B, Jeejeebhoy N. A comparison of the prediclive value of nutritional assessment techniques.

Hum. Nutr.Clin. Nutr. 1982;36(c):233-241

70. Gassull MA, Cabre E, Vilar L. Alastrue A. Montserrat A. Protein-energy malnutrition: an integral approach and a simple new classification.

Hum. Nutr.Clin. Nutr. 1984;38(c):419-431

71. de Jong PCM, Wesdorp RIC, Volovics A. Roulflan M, Greep JM. Soeters PB. The value of objeclive measurements to select patients who are malnourished.

Clin.Nutr. 1985;4:61-66

72. Meguid MM. Mughal MM, Meguid V, Terz JJ. Risk benefit analusis of malnutrition and perioperative nutritional support: a review.

Nutr.Int. 1987:3:25-34

73. Braga M, Baccari P, Scaccabarozzi S, et al. Ptognosic role of preoperative nutritional nutritional and immunological assessment in the surgical patient.

J.P.E.N. 1988:12:138-142

74. Detsky AS, Jeftrey PB, Mendelson RA, Wolman SL, Wision DE. Jecjecbhoy KN. Fi aluating the accuracy of nutritional assessment techniques applied to hospitalized partents: metiudology and comparisons.

J.P.E.N. 1984:8:153-159

75. Roy LR, Edwards PA, Barr LH. The value of nutritional asisessment in surgical paticnt. J.P.E.N. 1985:9:170-172 


\section{Perioperative nutritional support: a trial}

\section{review}

\subsection{Introduction}

Many trials investigating the effect of nutritional support on the incidence of postoperative complications have been performed in patients undergoing surgical therapy for malignant disease. The reason to focus on cancer patients is the relatively high incidence of depletion in these patients. Depletion is an important risk factor, especially in patients undergoing major gastrointestinal surgery (chapter 3 ).

The depleted state of gastrointestinal cancer patients has often many reasons e.g. mechanical obstruction of the GI tract, diagnostic procedures necessitating patients to be starved repeatedly, disease related factors resulting in a disruption of the balance between energy intake and expenditure, and alterations in food intake regulating mechanisms. Depletion in these patients reduces the tolerance to a surgical trauma and may lead to a (severely) catabolic state aggravating postoperative complications (chapter 3 ).

Nutritional support during the perioperative period may restore body reserves and functions, and thereby decrease morbidity in patients who undergo surgical procedures. Preoperative nutritional support has been claimed to induce improved woundhealing ${ }^{1.2}$, decreased incidence of wound infections ${ }^{3}$, respiratory insufficiency ${ }^{4}$, septic complications ${ }^{4.5}$, less weight loss ${ }^{10.5}$, improved nitrogen balances $s^{6,16+20}$, improved serum protein parameters ${ }^{6,8,10,11.15,21.22}$ and increased lymphocyte counts ${ }^{\mathrm{x} .18 .22}$.

However, the effect of preoperative parenteral nutrition on postoperative outcome has been tested in only a few properly designed comparative trials.

\subsection{Trial prerequisites}

The organisation and set-up for clinical trials investigating the effect of perioperative nutritional support should fulfill certain criteria.

To avoid patient selection, the study should have a prospective randomised design. Comparison with historical or matched control groups harbours the danger of a selection bias and endangers a correct interpretation of results. To 
avoid a selection bias the study should include all eligible patients fitting the descriptive criteria of the study population, and the study should clearly define exclusion criteria. Both inclusion and exclusion criteria must be mentioned in the patients and methods section, when a trial is reported. After randomisation, the non-treatment control group should be operated at once. Presenting control patients with a normal hospital diet, during the same period prior to surgery as the patients receiving preoperative artificial nutrition without careful registration of actual intake may overestimate the intake of these patients: they often suffer from a decreased appetite while, in addition, diagnostic procedures often prohibit the use of food during significant parts of the day.

Inclusion of a non-depleted control group results in the possibility to evaluate the complication rate that is the result of the treatment procedures used, without the additional effects of an impaired nutritional status.

Nutritional status parameters should identify a patient group that is relevant. With 'relevant' we imply that the patient group that is selected carries a, preferably proven, additional risk for the development of postoperative complications. In addition, only depleted patients are to be subjected to randomisation, because it is not ethically justifiable to subject patients who have a normal body weight, no weight loss, normal plasma protein levels, normal values of parameters of immunological functioning to nutritional therapy. These nondepleted patients should therefore be excluded from randomisation.

The trial should be stratified for factors which have a significant association with the outcome of the treatment. Stratifications should include tumor localisation if more malignancies are to be included; age, because of association of age with increasing numbers of coexisting diseases; and severity of the impairment of the nutritional status. Each of these factors may contribute to outcome and should therefore be controlled for in the randomisation of patients. Advance calculations (power analysis) should result in patient groups of sufficient size to reach significance of the expected differences. Interim analyses are necessary to avoid treatment which has already been shown to be inferior to the other treatment.

A complete material and methods description should include the statistical analyses used, making comparisons between studies possible.

One relevant evaluation criterium should determine the trial goal, becoming the basis for the statistical calculations. Evaluation criteria may include minor and major morbidity, and mortality, where both minor and major complications need accurate definitions.

It is crucial to supply sufficient and adequate nutrition to the patients in the treatment $\operatorname{arm}(\mathrm{s})$. Calculation of the amount of energy may be based on a calculation of basic enery expenditure with the help of the Harris-Benedict 
formula ${ }^{23}$, or on measured energy expenditure using a ventilated hood system ${ }^{24}$. When reporting the results of a study, the composition and the amount of the nutritional support administered must be mentioned.

It is beyond discussion that the daily care of central venous catheters and administration of nutritional support are routine procedures for participating surgeons and nurses, making it a safe procedure.

\subsection{Review}

In the English literature at least 53 retrospective or prospective trials have been published, most of them between 1976 and 1982. These trials were published mainly in surgical journals. Several trials have been published more than once with minor or major adaptations of the text, but seemingly including the same patient groups.

Of these trials on pre-operative and postoperative nutritional support. 15 were published as abstracts ${ }^{7.813,18,22.25 \cdot 4}$ or as a letter ${ }^{35}$ to the editor.

Twenty of the trials included only cancer patients $s^{6.10 .12,14.15,1,14}$, while 17 trials included patient groups with both malignant and benign diseasc. or trauma

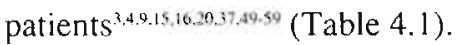

We investigated whether these 53 studies fulfilled the criteria described earlier in this chapter.

Nine studies 3 3/.31.43.46.5052.55 involving parenteral nutritional support did not have a prospective randomised design including a control group. Intervention and control patient groups were compared and matched for several clinical and biochemical parameters, and sometimes a comparison with historical control groups was made.

A 'normal', i.e. non-depleted patient group that can serve as a reterence group, is scarcely included ${ }^{10.38 .58}$.

Six trials ${ }^{12.20,45-77555759}$ comparing parenteral and enteral nutritional support did not include control groups without nutritional support. Whether preoperative nutritional support has a beneficial effect on the outcome of thuse patients cannot be assessed from these trials. 
Table 4.I: Overview of trials: perioperative nutritional support trials

\begin{tabular}{|c|c|c|c|c|c|c|c|c|c|c|c|c|c|}
\hline \multirow[t]{2}{*}{$\begin{array}{l}\text { author } \\
\text { (reference) }\end{array}$} & \multirow[t]{2}{*}{ trial set-up } & \multirow[t]{2}{*}{ n } & \multirow[t]{2}{*}{$\begin{array}{l}\text { outeome } \\
\text { eriteria }\end{array}$} & \multirow{2}{*}{$\begin{array}{l}\text { TPN/ } \\
\text { TEN } \\
\mathrm{n}\end{array}$} & \multicolumn{2}{|c|}{$\begin{array}{l}\text { nutritional } \\
\text { support days }\end{array}$} & \multirow{2}{*}{$\begin{array}{l}\text { only } \\
\text { MN } \\
\text { patients }\end{array}$} & \multirow[t]{2}{*}{ preop. regimen } & \multirow[t]{2}{*}{$\begin{array}{l}\text { control } \\
\text { group }\end{array}$} & \multirow[t]{2}{*}{$\begin{array}{l}\text { regimen control } \\
\text { patients }\end{array}$} & \multirow{2}{*}{$\begin{array}{l}\text { preop. } \\
\text { days } \\
\text { controls }\end{array}$} & \multirow[t]{2}{*}{ remarks } & \multirow[t]{2}{*}{ resulis } \\
\hline & & & & & preop. & post & & & & & & & \\
\hline $\begin{array}{l}\text { Askenazi } \\
\text { (40) }\end{array}$ & $\begin{array}{l}\text { retrospective and } \\
\text { only postoperative } \\
\text { TPN }\end{array}$ & 35 & $\begin{array}{l}\text { length of } \\
\text { hospitalisation }\end{array}$ & 22 & no & 2 & no & $\begin{array}{l}\text { 1.3-1.6 BEE } \\
0.28-.04 \mathrm{~g} \mathrm{~N}\end{array}$ & yes & $400 \mathrm{kcal} / \mathrm{day}$ & as normal & $\begin{array}{l}\text { radical cystectumy, } 2 \\
\text { deaths in control group }\end{array}$ & $\begin{array}{l}\text { significtun reduction of } \\
\text { hospizalisation }\end{array}$ \\
\hline Sinale (37) & $\begin{array}{l}\text { retrospective non- } \\
\text { randomised TPN }\end{array}$ & 159 & complications & 54 & $>6$ & ? & no & $\begin{array}{l}>3.5 \mathrm{kcal} / \mathrm{kg} / \mathrm{day} \\
>1.5 \mathrm{~g} \text { protein }\end{array}$ & yes & 4 & as normal & $\begin{array}{l}\text { patients retrospectively } \\
\text { assigned to low or ligh } \\
\text { risk group depending } \\
\text { on index }\end{array}$ & $\begin{array}{l}\text { in high rish patients } \\
\text { reduced } \\
\text { morbidlity }\end{array}$ \\
\hline Clark (52) & $\begin{array}{l}\text { retrospective non- } \\
\text { randomised TPN }\end{array}$ & 70 & $\begin{array}{l}\text { major septic - } \\
\text { complications' }\end{array}$ & 26 & $>5$ or & $>5$ & no & $?$ & yes & $\begin{array}{l}\text { ? some TPN }>5 \\
\text { days posiop }\end{array}$ & us normal & mixed population & $\begin{array}{l}\text { trend towards lower septic } \\
\text { eomplieations }\end{array}$ \\
\hline Mullen (4) & $\begin{array}{l}\text { retrospective non- } \\
\text { randomised TPN }\end{array}$ & 145 & complications & 50 & 7 & $?$ & no & $\begin{array}{l}>35 \mathrm{kcal} / \mathrm{kg} / \mathrm{day} \\
1.5 \mathrm{~g} \mathrm{prot} / \mathrm{kg} / \mathrm{day}\end{array}$ & yes & $\begin{array}{l}\text { ? most had postop } \\
\text { TPN }\end{array}$ & as normal & $\begin{array}{l}\text { variety of diseuses. } \\
\text { retrospective assignment } \\
\text { by a prognostic index }\end{array}$ & $\begin{array}{l}\text { in high risk patients } \\
\text { reduced morbidity }\end{array}$ \\
\hline Daly (43) & $\begin{array}{l}\text { retrospective non- } \\
\text { randomised TPN }\end{array}$ & 244 & complications & 72 & $>5$ & $?$ & yes & $\begin{array}{l}4.5 \mathrm{kcal} / \mathrm{kg} / \mathrm{day} \\
1-2 \mathrm{~g} \text { rot } / \mathrm{kg} / \mathrm{day}\end{array}$ & yes & $?$ & $?$ & $\begin{array}{l}\text { all patients with } \\
\text { ewophageal cancer from } \\
\text { 1960-1980; patients } \\
\text { before 1973 no TPN }\end{array}$ & $\begin{array}{l}\text { reduced complication rate } \\
\text { in patients with preop. TPN }\end{array}$ \\
\hline $\begin{array}{l}\text { Starker } \\
(50)\end{array}$ & $\begin{array}{l}\text { prospective non- } \\
\text { randomised TPN }\end{array}$ & 59 & complications' & 59 & r & 9 & yes & $\begin{array}{l}150 \% \text { BEE } \\
1.5-2.0 \mathrm{~g} \text { N/day }\end{array}$ & no & & . & $\begin{array}{l}\text { heterogeneous patient } \\
\text { group }\end{array}$ & $\begin{array}{l}\text { complication rate depen- } \\
\text { ding from response to TPN }\end{array}$ \\
\hline $\begin{array}{l}\text { Collins } \\
\text { (51) }\end{array}$ & $\begin{array}{l}\text { prospective non- } \\
\text { randomised TPN }\end{array}$ & 30 & $\begin{array}{l}\text { weight } \\
\text { nitrogen } \\
\text { skin folds. } \\
\text { complications }\end{array}$ & 20 & no & $?$ & no & $\begin{array}{l}\text { AA infusion } 0.23 \mathrm{~g} \\
\mathrm{~N} / \mathrm{kg} / \mathrm{day} \text { or } \\
0,23 \mathrm{~g} \mathrm{~N} / \mathrm{kg} / \text { day }+ \\
35 \mathrm{kcal} / \mathrm{kg} / \mathrm{day}\end{array}$ & matched & $\sqrt{2}+\frac{1}{2}$ & 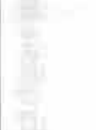 & variely of discases & $\begin{array}{l}\text { improvenen of } \\
\text { pastoperative parameters }\end{array}$ \\
\hline Yeung (55) & $\begin{array}{l}\text { TPN ys TEN } \\
\text { not randomised }\end{array}$ & 28 & $\begin{array}{l}\text { body } \\
\text { composition }\end{array}$ & $\begin{array}{l}14 / \\
14\end{array}$ & $? 2$ & $?$ & no & $\pm 42 \mathrm{kcal} / \mathrm{kg} / \mathrm{dsy}$ & $\begin{array}{l}\text { TEN } \\
\text { elemen- } \\
\text { tal diet }\end{array}$ & $\pm 36 \mathrm{kcal} / \mathrm{kg} / \mathrm{day}$ & $?=$ & $\begin{array}{l}\text { helerogeneous patients } \\
\text { groups }\end{array}$ & $\begin{array}{l}\text { no difference in boxly } \\
\text { composition }\end{array}$ \\
\hline
\end{tabular}




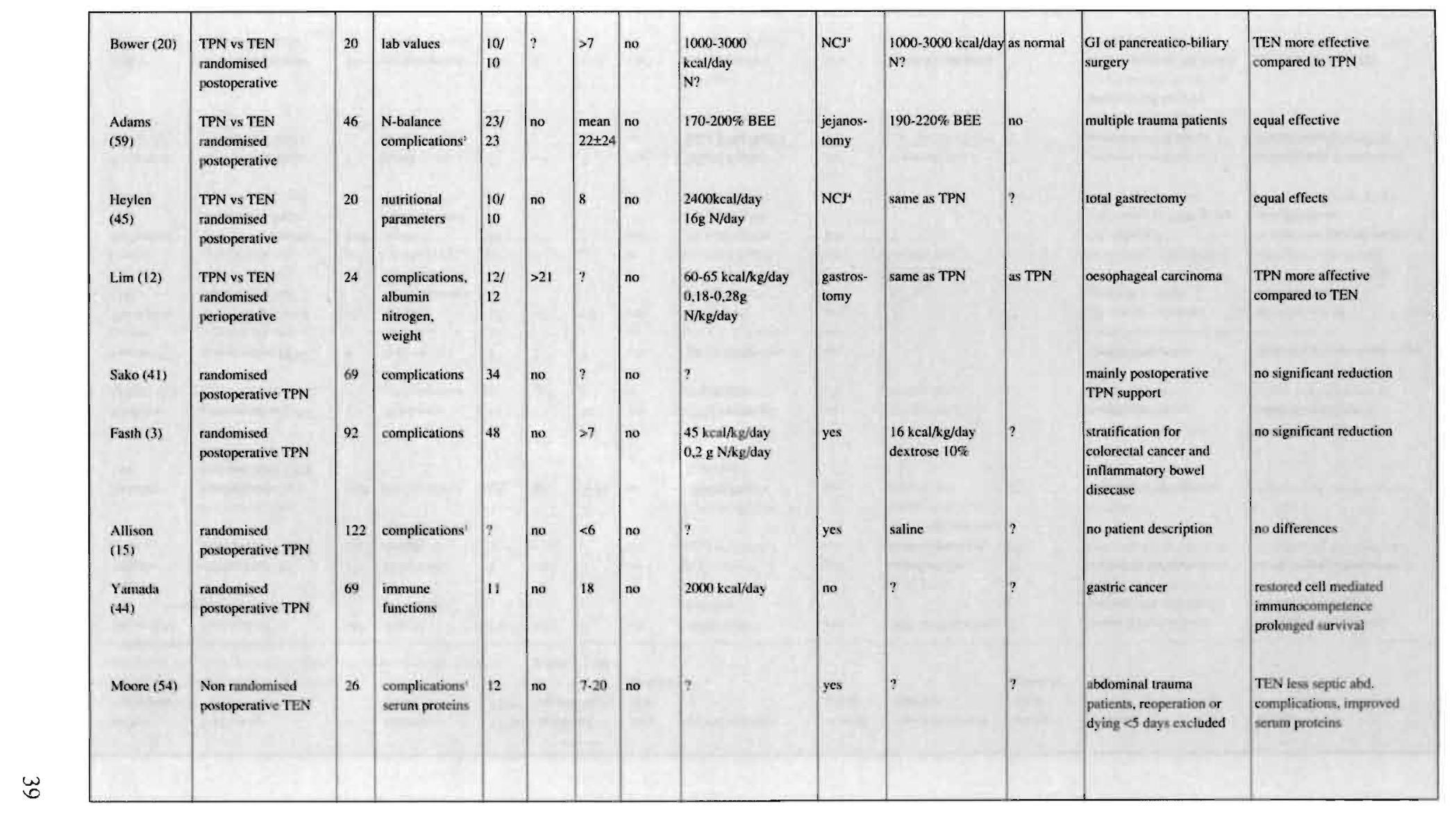




\begin{tabular}{|c|c|c|c|c|c|c|c|c|c|c|c|c|c|}
\hline \multirow[t]{2}{*}{$\begin{array}{l}\text { author } \\
\text { (reterence) }\end{array}$} & \multirow[t]{2}{*}{ trial sel-up } & \multirow[t]{2}{*}{$n$} & \multirow[t]{2}{*}{$\begin{array}{l}\text { sukome } \\
\text { criteria }\end{array}$} & \multirow{2}{*}{$\begin{array}{l}\text { TPN/ } \\
\text { TEN } \\
\text { n }\end{array}$} & \multicolumn{2}{|c|}{$\begin{array}{l}\text { nutritional } \\
\text { suppon days }\end{array}$} & \multirow{2}{*}{$\begin{array}{l}\text { only } \\
\text { MN } \\
\text { patients }\end{array}$} & \multirow[t]{2}{*}{ preop. regimen } & \multirow[t]{2}{*}{$\begin{array}{l}\text { control } \\
\text { group }\end{array}$} & \multirow[t]{2}{*}{$\begin{array}{l}\text { regimen control } \\
\text { patients }\end{array}$} & \multirow{2}{*}{$\begin{array}{l}\text { preop. } \\
\text { days } \\
\text { controls }\end{array}$} & \multirow[t]{2}{*}{ retuarks } & \multirow[t]{2}{*}{ results } \\
\hline & & & & & preop. & post & & & & & & & \\
\hline Sagar (53) & $\begin{array}{l}\text { ranclornised } \\
\text { protoperaive TEN }\end{array}$ & 30 & $\begin{array}{l}\text { weight } \\
\text { N-balance }\end{array}$ & 15 & no & $?$ & no & $\begin{array}{l}1000-1600 \\
\text { keal/iday }\end{array}$ & yes & $5001-1000$ lcal/day ? & $?$ & $\begin{array}{l}\text { major Gl operations, } \\
\text { patients not described }\end{array}$ & $\begin{array}{l}\text { less negative N-balans } \\
\text { shorter bospital stay }\end{array}$ \\
\hline $\begin{array}{l}\text { Muggia } \\
\text { (56) }\end{array}$ & $\begin{array}{l}\text { randomised } \\
\text { postoperative TEN }\end{array}$ & 15 & $\begin{array}{l}\text { N-balanice. } \\
\text { weight } \\
\text { serum proteins }\end{array}$ & 8 & no & $?$ & no & 7 & yes & $\begin{array}{l}\text { matched for } \\
\text { isonitrogenous/ } \\
\text { isocaloric amounts }\end{array}$ & $?$ & variety of GI operations & no difference observed \\
\hline $\begin{array}{l}\text { Delaney } \\
\text { (40) }\end{array}$ & $\begin{array}{l}\text { randomised } \\
\text { postoperative TEN }\end{array}$ & 115 & $?$ & 19 & no & $4-40$ & по & $\begin{array}{l}1800-2700 \\
\text { hcal/day }\end{array}$ & no & - & ? & $\begin{array}{l}\text { esoplageal and gastric } \\
\text { caicer }\end{array}$ & ? \\
\hline $\begin{array}{l}\text { Haffejec } \\
\text { (47) }\end{array}$ & postoperative TPN & 15 & N-balance & 15 & 7 & 21 & yes & $\begin{array}{l}3700 \mathrm{kcal} / \mathrm{day} \\
20 \mathrm{~g} \mathrm{~N} / \mathrm{day}\end{array}$ & no & - & . & esophageal cancer & positive N-bulans \\
\hline Goode (57) & preoperative TPN & 8 & $?$ & 8 & $?$ & $?$ & yes & 10-12 N/day & no & - & - & Crohns diseast & repletion of lean tissue mass \\
\hline $\begin{array}{l}\text { Thiompson } \\
\text { (38) }\end{array}$ & $\begin{array}{l}\text { TPN perioperative } \\
\text { randotnised trail }\end{array}$ & 41 & $\begin{array}{l}\text { weight } \\
\text { serum albumin } \\
\text { complications }\end{array}$ & 12 & $>5$ & $>8$ & yes & $\begin{array}{l}2000-40000 \\
\text { kcal/day }\end{array}$ & yes & $?$ & $?$ & $\begin{array}{l}\text { GI cancer, reference } \\
\text { group } W L>10 \mathrm{Ib}\end{array}$ & $\begin{array}{l}\text { no reduction of } \\
\text { complications }\end{array}$ \\
\hline $\begin{array}{l}\text { Bellantone } \\
\text { (49) }\end{array}$ & $\begin{array}{l}\text { TPN perioperative } \\
\text { randomised trail }\end{array}$ & 100 & $\begin{array}{l}\text { septic } \\
\text { complications }\end{array}$ & 49 & $>7$ & $?$ & yes & $\begin{array}{l}30 \mathrm{kcal} / \mathrm{kg} / \mathrm{day} \\
0.2 \mathrm{~g} \mathrm{~N} / \mathrm{kg} / \mathrm{day} \\
\text { suppl, } 10 \text { diet }\end{array}$ & yes & ? & $?$ & $\begin{array}{l}\text { Gl surgery,9 } \\
\text { exclusions in TPN group }\end{array}$ & $\begin{array}{l}\text { in high risk patients reduced } \\
\text { complications }\end{array}$ \\
\hline $\begin{array}{l}\text { Bellantone } \\
\text { (9) }\end{array}$ & $\begin{array}{l}\text { TPN perioperalive } \\
\text { randomised trail }\end{array}$ & $?$ & $\begin{array}{l}\text { septic } \\
\text { complications }\end{array}$ & $?$ & $>7$ & $?$ & yes & $\begin{array}{l}\text { 30kcal/hg/day } \\
0,2 \mathrm{~g} \mathrm{~N} / \mathrm{kg} / \mathrm{day} \\
\text { suppl, to diel }\end{array}$ & yes & ? normal dict & $?$ & $\begin{array}{l}\text { patients classified in } 3 \\
\text { groups by } 3 \text { different } \\
\text { indiees, Overlap of } \\
\text { patients? GI surgery }\end{array}$ & $\begin{array}{l}\text { in all groups reduction of } \\
\text { complications by TPN }\end{array}$ \\
\hline $\begin{array}{l}\text { Holter } \\
\text { (10) }\end{array}$ & $\begin{array}{l}\text { TPN perioperative } \\
\text { randomised trail }\end{array}$ & 84 & $\begin{array}{l}\text { complications' } \\
\text { serum albumin }\end{array}$ & 30 & 3 & $>10$ & yes & $\begin{array}{l} \pm 20 x 0 \mathrm{kcal} / \mathrm{day} \\
\pm 80 \mathrm{~g} \mathrm{prot} / \mathrm{day}\end{array}$ & yes & 2. blooxl, albumin ? & $?$ & $\begin{array}{l}\text { referencegroup } W L<10 \mid \mathrm{lb} \text {. } \\
\text { irail group } W L>101 \mathrm{~b}\end{array}$ & no reduction by TPN \\
\hline
\end{tabular}




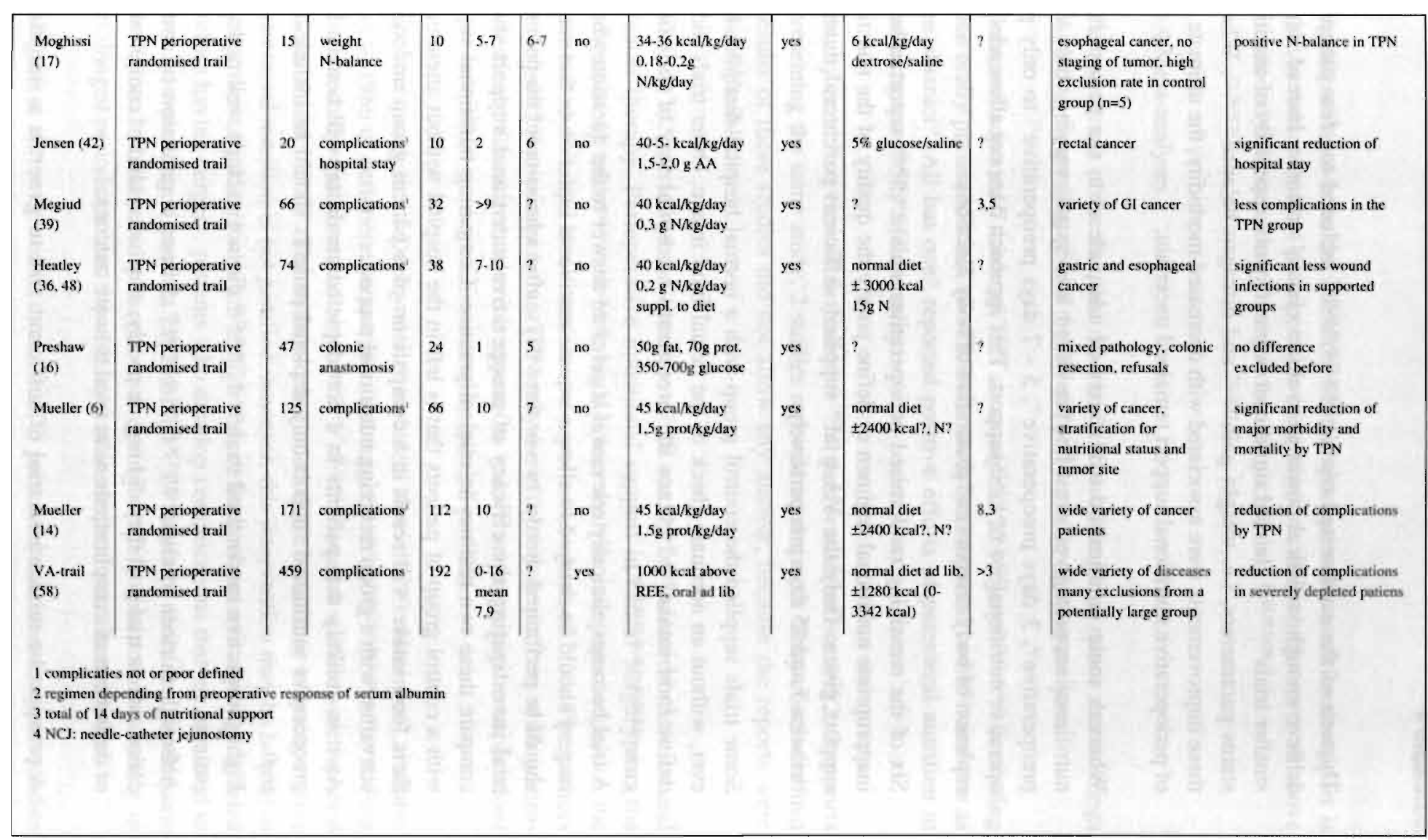


Thirteen of the randomised trials ${ }^{12,17,20,38,42,45,47,51,53-57}$ included too few patients to achieve enough statistical power to evaluate clinical outcome. Instead, several smaller trials ${ }^{50.425153,54}$ claimed significant improvements, especially of nutritional status parameters, i.e. weight gain ${ }^{125157}$ and nitrogen balance ${ }^{12,17.4753}$. Whether these improvements were associated with decreased morbidity, the ultimate goal of perioperative nutritional support remained uncertain.

Whereas some randomised trials were of adequate size, the perioperative nutritional support given must be considered inadequate, varying from 1 day preoperative $^{16}, 3$ days preoperative ${ }^{16}, 5-7$ days preoperative ${ }^{17}$ to only postoperative nutritional ${ }^{3.15,41,44,46,53,54.56}$ support. This approach does not allow adequate repletion of body reserves and restoration of body functions.

Six of the remaining randomised perioperative trials $s^{9.10 .1636,38,49}$, report either an inappropriate nutritional regimen or define poorly the quality of the nutritional support given. Only the VA-trials supplied sufficient parenteral nutrition between 7 and 15 days preoperatively.

Some trials supplied the control group with a normal hospital diet ${ }^{0.1436}$, however, without an adequate check of the actual food intake. Other trials did not

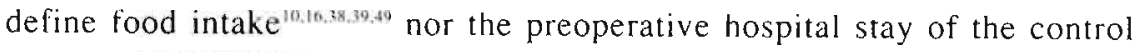
group $0.9 .10 .16,17.36,38.39,42,4058$.

A trial becomes clinically relevant if it gives an answer to the question whether surgery should be delayed to allow adequate nutritional repletion or that surgery should be performed shortly, two or three days, after admission of the patient. A trial investigating the efficacy of preoperative nutritional support should compare these two realities in clinical practice. Comparing nutritional support with a control group of patients that is left in the hospital without attention for their food intake will result in a comparison of a patient group undergoing starvation with a group receiving nutritional support.

As it is unlikely that patients in a non-depleted condition will benefit from preoperative nutritional support only depleted patients should be included in a trial.

Eight prospective randomised trials $s^{0.14,6.17,36,39.42 .49}$ did not exclude well nourished patients.

Although thirteen studies ${ }^{6,10.14,15,36,38,39.12 .4,50,52,54.54}$ defined a reduction of complication rate as trial goal they did not, or poorly, state what kind of complications or definitions of complications were used to score outcome.

A prospective randomised trial of sufficient size to generate a statistically 
significant answer to the question whether perioperative nutritional support is able to reduce (major) postoperative complications, and which meets all above mentioned criteria has only been performed once ${ }^{s s}$.

\subsection{Meta-analyses}

The awareness of the fact that most trials showed major or minor shortcomings has led to the pooling of trial results and performance of meta analyses.

Brennan $^{6(1)}$ reported 7 trials of TPN as an adjunct to surgery ${ }^{10.22,17.18,36.31}$ (including one orally presented trial), of which one study was reported twice ${ }^{10.11}$ and one as an abstract ${ }^{1 *}$. All but one ${ }^{+1}$ reported positive effects of parenteral nutrition in reducing morbidity and mortality.

Buzby et al. ${ }^{51}$ reviewed 8 trials $^{6,10-13,87.18,36}$ performed before 1982, 2 reports presenting the same study, 2 studies reported as abstracts. They concluded that results of these studies did not allow any answer, because the reports were incomparable.

Klein et al. ${ }^{02}$ reviewed the literature of 28 studies on parenteral nutrition and cancer therapy. Perioperative nutritional support in cancer surgery was the

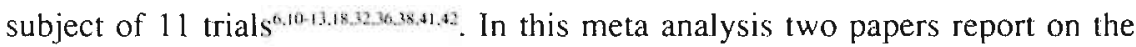
same study ${ }^{10+11}$, and three studies are reported as abstracts ${ }^{13.18 .32}$. The authors concluded that preoperative TPN may be effective in patients with gastrointestinal tract cancer, where it appears to reduce major surgical complications (pooled $\mathrm{p}=0.01$ ) and operative mortality (pooled $\mathrm{p}=0.02$ ).

The meta analysis of Detsky et al..$^{0 .}$ included 18 trials (23 references) available

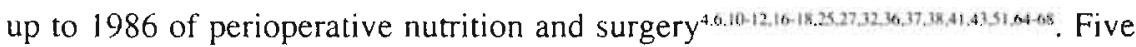
times a study was presented twice ${ }^{10+11.25+36,27+68.51+67.4+37}$, and 4 studies were reported as an abstract ${ }^{18,25,27,32}$. The authors concluded that routine use of preoperative parenteral nutrition is not justified; however, this intervention may be helpful in subgroups of patients who are at high risk, defined as patients severely depleted before having surgery, patients who develop complications that are expected to result in prolonged periods (at least 10 - 14 days) of ileus and inadequate nutritional intake, and patients undergoing surgery that results usually in prolonged periods (at least 10 - 14 days) of inadequate nutritional intake.

Meguid et al. ${ }^{69}$ reviewed in more detail 3 parenteral nutritional support studies 
including control groups ${ }^{16,4451}$, and 3 enteral nutritional support vs control group $^{53.59}$ studies. These authors concluded that both ways of nutritional intervention are equally effective in providing nutritional support. Compared with control patients they found the provision of postoperative nutritional support to be effective in improving or maintaining nutritional status. They concluded that correction of malnutrition, either before initiating therapy whenever possible or concomitant with treatment when necessary, is very likely to be beneficial.

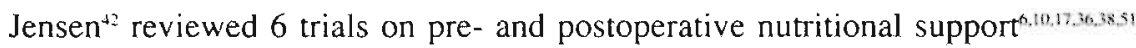
and 2 trials in which enteral nutrition is compared with parenteral nutrition ${ }^{1241}$. He concluded that nitrogen balances and plasma protein parameters improved, while weight gain was found in the parenterally supported group. No difference was found between enteral and parentral nutrition in these respects, and both may decrease postoperative morbidity and mortality, which, according to the authors, may not be limited to depleted patients.

Table 4.2 shows the references used in these reviews. Most reviews use the same studies as a reference. The references that are used three times or more are listed in table 4.3. This table also lists the most important criteria that trials should fullfill. The studies of Mueller. Heatley ${ }^{36}$, and especially the Veterans Administration-trial ${ }^{\mathrm{s}}$ are according to our criteria the most complete studies. Major criticisms on those two first mentioned trials are that non-depleted patients were not excluded from randomisation and that the control group did not undergo surgery within a few days after admission, being left on a normal hospital diet, sometimes without adequate control of this intake. In the study of Mueller control patients stayed in the hospital as long as patients in the intervention group did. while the study of Heatley is not clear on this point.

Points of concern in the VA-trial are that patients admitted for elective minor surgery as well as cancer patients undergoing extensive thoracic and abdominal surgery are included. Criteria that designate patients 'malnourished' are rather mild. Omitting patients with concurrent illness may have induced some bias. The presumed reduction of major complication rate with $50 \%$ reflects too high expectations of the effects of perioperative nutrition. Nevertheless, the VA-trial is the best performed trial on perioperative nutrition till now.

The results are furthermore difficult to interpret because of a wide variety of diseases in the trials. Some trials use depleted cancer patients, while others look at major operations regardless of the underlying disease. Some trials evaluate 
Table 4.2: References used in the trial roviows

\begin{tabular}{|c|c|c|c|c|}
\hline author & references & & & 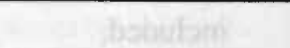 \\
\hline Detsky & 1011202122 & 2425262843 & 4546474957 & 596061626364 \\
\hline Klein & 1120212223 & $25 \quad 4$ & $\quad 47495758$ & 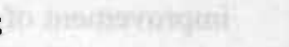 \\
\hline Buzby & 1120212223 & 25 & . & \\
\hline Brennan & 202122 & 2425 & 57 & \\
\hline Meguid & & 43 & 45 & 73 \\
\hline Jensen & 1120 & 434 & 4957 & Howe \\
\hline
\end{tabular}

Table 4.3: Analysis of trials cited at least 3 times in the reviews

\begin{tabular}{|c|c|c|c|c|c|c|c|}
\hline Author & Prospective & Compl & Suff. $n$ & Pre nutr & MN & Contr & Cancer \\
\hline Mueller & yes & no & yes & yes & ino & yes & yes \\
\hline Holter & yes & no & no & no & yes & yes & yes \\
\hline Holter & yes & & marginal & no & yes & yes & yes \\
\hline $\operatorname{Lim}$ & yes & yes & marginal & yes & no & no & yes \\
\hline Moghissi & yes & no & no & no & no & yes & yes \\
\hline Simms & abstract & & & & & & \\
\hline Heatly & yes & no & marginal & yes & no & yes & yes \\
\hline Sako & yes & yes & marginal & no & no & yes & yes \\
\hline Collins & yes & yes & no & no & no & yes & no \\
\hline Thompson & yes & no & no & no & yes & yes & yes \\
\hline \multicolumn{8}{|c|}{ Prospective : Prospective randomised } \\
\hline \multicolumn{8}{|c|}{ Compl : Complications well defined } \\
\hline \multicolumn{8}{|c|}{ Suff $n \quad:$ Sufficient patients in trial } \\
\hline \multicolumn{8}{|c|}{ Pre nutr $\quad:$ Sufficient preoperative nutrition } \\
\hline \multicolumn{8}{|c|}{ MN : Only malnourished trial patients } \\
\hline \multicolumn{8}{|c|}{ Contr $\quad$ : Inclusion of control group } \\
\hline \multicolumn{8}{|c|}{ Cancer $\quad:$ Cancer patient population } \\
\hline
\end{tabular}


only superficial wound infections or minor complications, others major morbidity. In addition, an adequate definition of a complication is only rarely included.

All studies supplying more than 7-10 days of preoperative nutrition claimed an improvement of the postoperative course for all patients or high risk subgroups of patients 4.9 .37 .39 .49 .50 , albeit that only in a few trials significant results are obtained ${ }^{6.34}$.

We conclude from this trial review that the trials performed to date, show minor or major shortcomings with regard to design, execution and reporting of the results.

1. Copeland EM III, Daly IM. Ota DM, Dudrick SI. Nutrition. cancer, and intravenous hyperalimentation. Cancer 1979:43:2108-2116

2. Moghissi K. Hornshaw J. Teasdale PR. Dawes EA. Parenteral nutrition in carcinoma of the oesophagus treated by surgery: nitrogen balance and clinical studies.

Br.J.Surg. 1977:0-4:125-128

3. Fasth S, Hulten L, Magnusison O, Nordgren S, Wamold 1. Posioperative complications in colorectal surgery in relation to picoperative clinical and nutrilional statc and postoperative nutritional trearment. Int J.Colorect.Dis. 1987:2:87-92

4. Mullen JL, Buzby GP, Matthews DC. Smale BF. Rosato EF. Reducrion of operative morbidity and mortality by combined preoperative and postoperative nutritional support.

Am.Surg. 1980:192:604-613

5. Mullen JL. Consequences of malnutrition in the surgical patient.

Surg.Clin. North Am. 1981:61:465-487

6. Mueller JM. Brenner U. Dienst C. Pichlmaier H. Preoperative parenteral feeding in patients with gastrointestinal carcinoma.

Lancet 1982:1:68-71

7. Doglietto GB. Bossola M. Pacelli F. Negro F, Bellantone R. Crucitti F. Preoperative parenteral nutrition in malnourished surgical patients: a prospective randomized study.

Clin. Nutr. 1990:9(suppl):55 (abstr)

8. Majewska K. Pertkiewicz M. Korta T. Cebulski W. Szczygicl B. Impact of perioperative parenteral nutrition on the results of surgery for gastric cancer.

Clin. Nutr. 1989:8(suppl):20(abstr)

9. Bellantone R, Dogliento GB, Bossola M. Pacelli F. Negro F. Crucitti F. Preoperative parenteral nutrition in malnourished surgical patichts.

Acta Chir.Scand 1088:22:240-251

Holter AR, I:isher Jl: The effects of perioperative hyperalimentation on complications in patients with carcinoma ind weight loss.

J.Surg. Res. 1977:23:31-34 
11. Holter AR, Rosen HM, Fisher JE. The effects of hyperalimentation on major surgery in patients with malignant disease: a prospective study.

Acta Chir Scand (suppl) 1977:466:86-87

12. Lim STK, Choa RG. Lam KH. Wong J. Ong GB. Total parenteral nutrition vs gastrostomy in the preoperative preparation of patients with carcinoma of the esophagus.

Bг.J.Surg, 1981:68:(6)-72

13. Schild B. Groth O. Larsson J. Sjodahl R. Symreng T, Wellerfors J. Failure of preoperative TPN to improve nutritional stalus in gastric carcinoma.

J.P.E.N. 1981:5:360 (abstr)

14. Mueller JM, Keller HW. Brenner U. Walter M. Holtzmueller W. Indications and effects of preoperative parenteral nutrition.

World J.Surg. 1986:10:53-63

15. Altison SP. Nutritional support: Efficacy versus cost. Nutr.Int. 1987;3:19-24

16. Preshaw RM. Attisha RP. Hollingsworth WJ, Todd JD. Randomized sequential trial of parenteral nutrition in healing of colonic anastomoses in man.

Can.J.Surg. 1979:22:437-439

17. Moghissi K, Homshaw J. Taesdale PR. Dawes EA. Parenteral nutrition in carcinoma of the oesophagus treatcd by surgery: nitrogen balance and clinical studies,

Br.J.Surg. 1977:64:125-128

18. Simns JM. Oliver E, Smith JAR. A study of total parenteral nutrition in major gastric and esophageal resection of ncoplatia.

J.P.E. $1980: 4: 42$ ? (absir)

19. Nordenstrom J. Askanazi J. Elwyn DH, el al. Nitrogen balance during total parenteral nutrition. Ann.Surg. 1983:197:27-33

20. Bower RH. Talamini MA. Sax HC. Hamilton F. Fisher JE. Postoperative enteral vs parenteral nutrition. Arch.Surg. 1986;121:1040-1045

21. Starker PM, LaSala PA. Askanazi J. Gump FE, Forse RA, Kinney JM. The response to TPN: a form of nutritional assessment.

Ann.Surg. 1983:198:720-724

22. Celaya S, Palacios V. Navarro M, et al. Efficacy of preoperative total parenteral nutrition (TPN) in neoplastic versus non neoplastic patients.

Clin. Nutr. 1989:8(suppl):19 (abstr)

23. Harris JA. Benedict FG. A bionetric study of basal metabolism.

Washington. Canegie institution of Washington 1919

24. Fredrix EWHM. PFM Schoffelen. JLJ Wouters, WHM Saris. The ventilated hood system. In: Fredrix L. Energy metabolism in cancer patients. Chapler 2, pp 13-16. Thesis Maastricht. ISEN $90-5291-019-7$

25. Williams RHP. Healiey RV, Lewis MH, Hughes LE. A randomized trial of preoperative intravenous nutrition in patients with stomach cancer.

Br.J.Surg. 1976:63:667 (abstr)

Magnusson O. Fusth S. Heilberg R, Hulten L. Isaksson B, Wamold I. Fotal parenteral nutrition versus conventional normal saline-glucose support after major bowel surgery.

J.P.E.N. 1979:3:311 (abstr) 
27. Jensen $\mathrm{S}$. Parenteral nutrition in cancer surgery.

J.P.E.N. $1982 ; 6: 335$ (abstr)

28. von Meyenfeldt MF, Meijerink WJHJ. Soeters PB, Veen H. Buit-Maessen R, Rouflar MMJ.

Perioperative nutritional support results in a reduction of major postoperative complications especially in high risk patients.

Clin. Nutr. 1990;9(suppl):55 (abstr)

29. Lombardi M. Troiani R. Isoppi E, et al. Usefullness of postoperative nutritional support (PONS) in wellnourished non complicated surgical patient: a negative report.

Clin, Nutr. 1989;8(suppl):20 (abstr)

30. Veen H. Meijerink WJHJ, Buil-Madwsen MTHJ, Soeters PB. von Meyenfeldt MF. Perioperative nutritional support does not benctit high risk patients.

Clin. Nutr. 1989:\$(suppl):21 (abstr)

31. Veen H, Mcijerink WJHJ, Buil-Maisen MTHJ. Soeters PB, von Meyenfeldt MF. Perioperative nutritional cupport: a prospective randomised trial.

Clin. Nuts. 1989:8(suppl):58 (abstr)

32. Moghissi M, Teasdale P. Dench M. Comparison between pre-operative enteral (naso-gastric tube) and parenteral feeding in patients with cancer of the esophagus undergoing surgery.

J.P.E.N. 1982;6:335 (abstr)

33. Boursteyn E. Belghiti J. Langonnet F. Fekete F. Identification of a subgroup of patients with esophageal carcinoma (EC) who might get benefice from nutritional therapy.

J.P.E.V. 1982:6:3.35 (abstr)

34. Dioneri P. Interdonato FP. Prati U. Jenos V. Dimigi R. Perioperative TPN and postoperative septic complications in patients with gastric cancer

Clin.Nutr. 1985:4(suppl):pl14 (abstr)

35. Mckuid MM. Debonis D. Meguid B, Terz JJ. Nutritional support in cancer.

Lancet 108,8:11:230.231(leter)

36. Heatley RV. Williams RHP. Lewis MH. Pre-operative intravenous feeding: a controlled trial. Postgrad.Med.J. 1979:55:541-545

37. Smale BF. Mullen JL. Buzby GP. Rosato EF. The efficacy of nutritional assessment and support in cancer surgery.

Cancer 1981:47:2375-2381

38. Thompson BR, Julian TB. Stremple JF. Perioperative total parenteral nutrition in patients with gastrointestinal cancer.

J.Surg.Res, 1981:30:497-500

39. Meguid MM. Curtas MS. Meguid V. Campos AC. Effects of pre-operative TPN on surgical risk: preliminary status report.

Br.J.Clin.Pract. 1988;63:53-58

40. Askanazi J. Starker PM. Olsson C. et al. Effect of immediate postoperative nutritional support on length of hospitalization.

Ann.Surg. 1986:203:236-239

41. Sako K. Lore JM, Kaufman S, Razack MS, Bakamijan V, Reese P. Parenteral hyperalimentation in surgical patients with head and neck cancer: a randomized study.

J.Surg. Oncol. 1981:16:391-402 
42. Jensen S. Clinical effects of enteral and parenteral nutrition preceeding cancer surgery. Med. Oncol. Tumor Pharmacother. 1985:2:225-229

43. Daly JM, Massar E, Giacco G, et al. Parenteral nutrition in esophageal cancer patients. Ann.Surg. 1982:196:203-208

44. Yamada N, Koyama H, Hioki K, Yamada T, Yamamoto M. Effect of postoperative total parenteral nutrition (TPN) as an adjunct to gastrectomy for advanced gastric carcinoma. Br.J.Surg. 1983; 70:267-274

45. Heylen AM, Lybeer MB, Penninckx FM. Kerremans RP. Frost PG. Parenteral vs needle jejunostomy nutrition after total gastrectomy.

Clin.Nutr. 1987;6:131-136

46. Delaney HM. Carnevale N. Garvey JW. Moss CM. Postoperative nutritional support using needle catheter feeding jejunostomy.

Ann.Surg. 1977:186:165-170

47. Haffejee AA, Angom IB. Oral alimentation following intubation for esophageal carcinoma. Ann.Surg. 1977:186:759-761

48. Heatley RV. Prcoperative fecding. Br.J.Clin.Prac. 1988:63: 66-68

49. Bellantone R. Doglielto GB. Bossola M, et al. Preoperative parenterat nutrition in the high risk surgical patient.

J.P.E.N. 1988:12:195-197

50. Starker PM, LaSala PA, Askanazi J. Todd G. Hensle TW. Kinney JM. The influence of preoperative total parenteral nutrition upon morbidity and mortality.

S.G.O. 1986: 162:569-574

51. Collins JP, Oxby CB. Hill GL. Intravenous aminoacids and intravenous hyperalimentation as proteinspuring therapy after major surgery: a controlled clinical trial.

The Lancet 1978:1:788-791

52. Clark Grimes CJ, Younathan MT, Lee WC. The effect of preoperative total parenteral nutrition on surgery outcones.

J.Am. Diet.Asscc. 1987:87:1202-1206

53. Sagar S. Harland, Shields R. Early postoperative feeding with elemental diel. Br.Med.J. 1979:1:293-205

54. Moore EE. Jones TN. Nutritional assessment and preliminary report on early support of the irautil patient.

J.Am.Coll.Nurr. 1983:2:45-54

55. Yeung CK. Smith RD, Hill GL. Effect of an elemental diet on body composition. A comparison with intravenous nutrition.

Gastroenterology 1979;77:652-657

56. Muggia-Sullam M. Bower RH. Murphy RF, Jolie SN. Fisher JE. Postoperative enteral versis parenteral nutritional suppor in gastrointestinal surgery. A matched prospective study.

Am.J.Surg 1985:149:106-112

57. Goode A. Hawkins T. Fegetter JWG, Johnston IDA. Use of an elemental diel for long term nutritional support in Crohn's disease.

Lance 1976:1:122-124 


\section{Chapter 4}

58. The Veterans Affairs total parenteral nutrition cooperative study group. Perioperative total parenteral nutrition in surgical patients.

N.Engl.J.Med. 1991:325:525-532

59. Adams S. Delinger EP, Werz MJ, Oreskovity MR, Simonowitz D, Johansen K. Enteral vs parenteral nutritional support following laparotomy for trauma: a randomized prospective trial.

J.Trauma 1986:26:882-891

60. Brennan MF. Total parenteral nutrition in the cancer patient.

N.Engl.J.Med. 1981:307:375

61. Buzby GP. Williford WO. Peterson OL, et al. A randomized clinical trial of rotal parenteral nutrition in malnourished surgical patients: the rationale and impact of previous clinical trials and pilot study on protocol design.

Am.J.Clin.Nutr. 1988:47:357-365

62. Klein S. Simes J, Blackbum GL. Total parenteral nutrition and cancer clinical trials. Cancer 1986:58:1378-1386

63. Detsky AS, Baker JP. O'Rourke K, Goel V. Perioperalive parenteral nutrition: a meta-analysis Ann.Int. Med. 1987; 107:195-203

64. Abel RM. Fisher JE. Buckley MJ. Barnelt GO. Austen WG. Malnutrition in cardiac surgical patients: results of a prospective, randomized evaluation of early postoperative parenteral nutrition. Arch.Surg. 1976;111:45-50

65. Garden OJ. Smith A. Harris NWS. Shenkin A. Sim AJW. Carter DC. The effects of isotonic amino acid infusions on serum proteins and muscle breakdown following surgery.

Br.J.Surg. 1983:70:79-82

66. Hensle TW. Protein sparing in cystectomy patients.

J.Urol 1978:119:335-338

67. Young GA, Hill GL. A controlled study of protein sparing therapy after excission of the rectum: effects of intravenous amino acids and hyperalimentation an body composition and plasma amino acids. Ann.Surg. 1980:192:183-191

68. Jensen S, Ginnerup P. Completc perioperative parenteral nutrition of patients with rectal adenocarcinoma: nitrogen batance and clinical course.

Ugesk.Laeger 1982:144:460-46.3

69. Meguid MM. Campos AC. Hammond WG. Nutritional support in surgical practice.

Am.J.Surg. 1990:159:345-358 (parl I)

Am.J.Surg. 1990; 159:427-443 (part ll) 
Chapter 5

\section{Risk factors for postoperative complications in gastric and colorectal cancer patients}

\subsection{Abstract}

In the past two decades much emphasis has been placed upon the relation of preoperative' nutritional status' parameters and outcome of surgical therapy. However, a combined evaluation of depletion parameters with other factors implicated in the development of postoperative complications has scarcely been performed.

In a prospective study the relation of depletion parameters in addition to parameters of preoperative health status and parameters of the extent of the surgical trauma with the incidence of postoperative complications was investigated.

One hundred seventy two patients (63 fernale, 109 male) admitted to undergo surgery for recently detected gastric $(n=45)$ or colorectal carcinoma $(n=127)$ participated in this study. Peroperative blood loss $(p<0.0001)$ and age $(p<0.05)$ were significantly associated with the incidence of postoperative complications, whereas anthropometric parameters of nutritional status were significantly associated with the severity of the complications $(p<0.05)$. Although plasma albumin was associated with the development of postoperative complications. this relation disappears after correction for the aforementioned parameters. Other factors, e.g. hemoglobin, total protein, pre-albumin, duration and type of procedure, surgical skill, and coexisting disease showed no significant association with postoperative outcome.

\subsection{Introduction}

The presence of depletion, resulting in the loss of body cell mass, is associated with impaired cell function and therefore with impaired tissue and organ function (Chapter 3). The relation of the presence of depletion with impaired outcome of a surgical trauma is not clear. If depletion indeed has an independent, significant, influence on the outcome of a surgical procedure, depletion would be an attractive focus for improvement. If nutritional support effectuates 
in improved tissue and organ functioning, and consequently in improved outcome of surgical trauma, the magnitude of these improvements are depending of the impact of depletion on outcome of surgical trauma. This idea has been the basis of the concept of perioperative nutritional support.

Studies trying to evaluate the role of depletion in the outcome of surgical trauma, mostly only evaluate parameters describing depletion. Many individual depletion parameters showed in monofactorial analyses a fair to good correlation with the incidence of postoperative morbidity and mortality ${ }^{1-17}$, and were, therefore, often used to calculate the risk for development of postoperative complications ${ }^{2-14,16,1 x}$. No single indicator has been proven better than any other ${ }^{5}$ $7,16,19$. To improve the predictive value of parameters in the individual patient combinations of parameters were suggested. Indices, derived from multiple variate regression analyses, combining anthropometric, biochemical, and immunological measurements, did not show increased sensitivity, reliability and applicability for the individual patient because of the high degree of correlation among variables (Chapter 3 ).

One of the problems of the previous analyses is that they consider only parameters, that are traditionally thought to be associated with depletion. As a consequence this has led to overemphasis of the nutrition related risk factors. In addition, it gradually became clear that some of the parameters used to identify impaired 'nutritional status', rather demonstrate the presence of metabolic stress $^{20}$. Futhermore, considerable confusion has been created because many authors defined 'nutritional status' parameters as abnormal only on the basis of their association with the development of complications (Chapter 3 ).

The emphasis on the role of nutritional status parameters as risk indicators has distracted the attention from the role that disease and surgical procedure related factors have in the development of postoperative complications. To determine the additional risk that originates from an abnormal nutritional status, we analysed prospectively preoperative nutritional status parameters, in addition to other well accepted surgical risk factors. for their association with postoperative complications. Such risk factors include type and duration of the surgical procedure, surgical skill, peroperative blood loss, type and stage of the disease, age of the patient, preoperative hemoglobin. and coexisting diseases. 


\subsection{Patients and methods}

\subsubsection{Patients}

The relation of nutritional status parameters in addition to parameters of preoperative health status and parameters of the extent of surgical trauma with the incidence of postoperative complications was prospectively studied in patients admitted to undergo surgery for recently detected gastric and colorectal carcinoma. Patients with preoperative nutritional support were excluded. Postoperative nutritional support was started only if a major complication had occurred, or starvation had continued more than 7 - 10 days.

\subsubsection{Study design and parameters}

Blood was drawn preoperatively from all patients to determine hemoglobin, white blood cell count, total lymphocyte count (TLC), total protein, albumin, pre-albumin, transferrin, electrolyte status, creatinin and urea. Preoperative anthropometric evaluation included determination of weight, height, weight loss during the preceding year, and percent weight loss (PWL). Percent ideal body weight (PIW) was calculated using tables of the Metropolitan Life Insurance Company". Peroperative blood loss, duration and type of surgical procedure were recorded.

\subsubsection{Complications}

Postoperative complications were monitored until hospital discharge or death. Postoperative complications were recorded as absent, minor or major complications (Table 5.1).

\subsubsection{Surgical skill}

Surgery was performed by senior staff surgeons, junior staff surgeons and senior residents in the presence of a senior or junior staff surgeon. Surgical procedures that were performed included:

-gastro-enterostomy

-gastric tumor resection with anastomosis

-entero-enterostomy without tumor resection

-entero-enterostomy with tumor resection

-abdominal-perineal rectum resection with end colostomy

-low anterior (rectum) resection 
Tabel 5.1: Complication definition

\begin{tabular}{|c|c|}
\hline \multicolumn{2}{|l|}{ MINOR } \\
\hline Wound infection & $\begin{array}{l}\text { Clinical aspect, positive culture or necessity for surgical } \\
\text { drainagex }\end{array}$ \\
\hline Urin & Positive culture $>10^{7}$ micro-organisms $/ \mathrm{ml}$ urine \\
\hline Pulmonary tract inf. & $\begin{array}{l}\text { positive sputum culture, abnormal chest } X \text {-ray requiring } \\
\text { treatment with antibiotics. }\end{array}$ \\
\hline \multicolumn{2}{|l|}{ MAJOR } \\
\hline Respiratory insuff. & $\begin{array}{l}\text { Ventilatory assistance for }>12 \text { hrs. postoperative or mechanical } \\
\text { renewed ventilation after detubation. }\end{array}$ \\
\hline Cardiac insuff. & $\begin{array}{l}\text { Clinical and radiological diagnosis requiring cardiotonics and/or } \\
\text { diuretics, or myocardial infarction confirmed on ECG or by } \\
\text { serum enzyme elevations. }\end{array}$ \\
\hline Renal insuff. & $\begin{array}{l}\text { Plasma urea levels elevated by } 50 \% \text { or a plasma creatinin } \\
\text { elevation with } 20 \% \text {. }\end{array}$ \\
\hline Intra-abd. abscess & $\begin{array}{l}\text { Purulent fluid collection, demonstrated by ultrasound, or CT-scan } \\
\text { guided drainage or at reoperation. }\end{array}$ \\
\hline Fistula & Diagnosis on clinical grounds or proven by fistulography. \\
\hline Anastomotic leakage & $\begin{array}{l}\text { After clinical or radiological diagnosis, necessity for operation or } \\
\text { drainage. }\end{array}$ \\
\hline Wound dehi & nce of the wound requiring surgical closure. \\
\hline Sepsis & $\begin{array}{l}\text { Positive bloodculture, persisting temperature above } 39^{\circ} \mathrm{C} \text {., } \\
\text { associated with hypotension and hypoperfusion. }\end{array}$ \\
\hline D.I.C. syndrome & $\begin{array}{l}\text { Positive FDP-test, abnormal clotting tests and decreasing } \\
\text { thrombocyte counts. }\end{array}$ \\
\hline Mortality & Any postoperative in-hospital mortality. \\
\hline
\end{tabular}

\subsubsection{Staristical analysis}

Data were summarised as means and standard deviations in each outcome group. Groups were compared on continuous parameters using ANOVA and Scheffé's post hoc t-test". After categorisation using clinically accepted cutpoints, Mantel-Haenszel chi-square tests ${ }^{23}$ for linear trend were applied to test the association with outcome (scored as 1.2, 3 for no, minor and major complications). 
The association of several parameters simultaneously with outcome was assessed with a continuation-ratio multiple logistic regression model ${ }^{23.5}$ (SAS). In this analysis the very occurrence of a complication (minor or major), and the occurrence of a major complication, given any complication, were taken as dependent variables. We assumed the same parameters to be explanatory for both, unless the coefficients were significantly different. P-values smaller than 0.05 were considered significant.

\subsection{Results}

\subsubsection{Patients}

One hundred and seventy two patients (63 female, 109 male) entered this study. In 45 patients gastric cancer and in 127 patients colorectal cancer was recently detected. The mean age was 67 years. The patients had normal mean values of hematological and biochemical parameters, a mean ideal body weight of $102 \%$, a mean weight loss of $6 \%$, and a mean blood loss of $840 \mathrm{ml}$ during the surgical procedure with a mean duration of 3 hours (Table 5.2).

Eight patients received postoperative parenteral nutritional support because of major complications (mean 21.3 days, range $8-63$ ).

\subsubsection{Complications}

An uncomplicated postoperative course was observed in $93(54.1 \%)$ patients. Minor complications occurred in $49(28.5 \%)$ patients, and major complications, including mortality $(n=11)$, in $30(17.4 \%)$ patients. Significant differences between groups were observed for preoperative plasma albumin levels, percent ideal body weight and percent weight loss, duration of surgical procedure and peroperative blood loss (Table 5.2). No significant differences were observed for age, preoperative hemoglobine, total protein, and pre-albumin values, total lymphocyte count. Also type of surgical procedure, tumor stage or tumor site showed no significant differences between groups (Chi-square $>0.1$ ) (Table 5.2).

\subsubsection{Surgical skill}

No difference was found in complications between senior staff surgeons, junior staff surgeons or senior residents supervised by a qualified surgeon. All procedures were performed in equal numbers by the three surgeon groups. 
Table 5.2: Analysis by presence of complications

\begin{tabular}{|c|c|c|c|c|c|}
\hline 3 & $\begin{array}{l}\text { Overall } \\
\text { mean (range) }\end{array}$ & $\begin{array}{l}\text { No } \\
\text { mean (SEM) }\end{array}$ & $\begin{array}{l}\text { Minor } \\
\text { mean (SEM) }\end{array}$ & $\begin{array}{l}\text { Major } \\
\text { mean (SEM) }\end{array}$ & $\begin{array}{l}\mathbf{p} \\
\text { anova }\end{array}$ \\
\hline Age (years) & $67(39-88)$ & $66(1.11)$ & $68(1.76)$ & $71(1.98)$ & ns \\
\hline $\begin{array}{l}\text { Haemoglobin } \\
(\mathrm{mmol} / \mathrm{l})\end{array}$ & $8.1(2.6-1.11)$ & $8.2(0.16)$ & $8.1(0.22)$ & $7.6(0.33)$ & ns \\
\hline $\begin{array}{l}\text { Lymphocyte count } \\
\left(10^{\circ} / \mathrm{ml}\right)\end{array}$ & $1.89(0.3-5.4)$ & $1.95(0.07)$ & $1.93(0.08)$ & $1.61(0.17)$ & $\mathrm{ns}$ \\
\hline Total protein $(\mathrm{g} / \mathrm{l})$ & $71(52-98)$ & $71(0.68)$ & $72(1.18)$ & $69(1.01)$ & ns \\
\hline Albumin $(\mathrm{g} / \mathrm{l})$ & $36(21-47)$ & $36(0.48)$ & $36(0.68)$ & $33(0.80)^{+}$ & 0.05 \\
\hline pre-albumin $(\mathrm{g} / \mathrm{l})$ & $\begin{array}{l}0.24(0.05- \\
0.44)\end{array}$ & $0.25(0.01)$ & $0.25(0.01)$ & $0.21(0.01)$ & $\mathrm{ns}$ \\
\hline $\begin{array}{l}\text { Percent ideal } \\
\text { weight }(\%)\end{array}$ & $102(62-138)$ & $103(1.32)$ & $107(1.97)^{*}$ & $93(2.55)^{+}$ & 0.0001 \\
\hline $\begin{array}{l}\text { Percent weight } \\
\text { loss }(\%)\end{array}$ & $6(-2.2-35.3)$ & $5(0.66)$ & $5(0.74)^{*}$ & $9(1.43)^{+}$ & 0.01 \\
\hline $\begin{array}{l}\text { Duration of } \\
\text { procedure (hr.min) }\end{array}$ & $\begin{array}{l}3.06(0.45- \\
7.15)\end{array}$ & $2.52(0.11)$ & $3.24(0.22)$ & $3.04(0.18)$ & 0.05 \\
\hline $\begin{array}{l}\text { Peroperative blood } \\
\text { loss }(\mathrm{ml})\end{array}$ & $840(0-6000)$ & $588(91.5)$ & $828(162.7)^{*}$ & $\left\{\begin{array}{l}1633 \\
(241.8)^{+}\end{array}\right.$ & 0.0001 \\
\hline \multicolumn{3}{|c|}{ Posthoc t-test (Scheffé) } & $P<0.05$ vs no & & \\
\hline
\end{tabular}

Procedures in gastric or colorectal cancer patients, stage of disease, nutritional status were also equally distributed over the three surgeon groups. Also there was no correlation between experience of the surgeon and duration of operative procedure, peroperative blood loss, or duration of postoperative hospital stay of the patients.

\subsubsection{Age}

Thirty one patients were over 80 years (mean 82.8 , range $80-88,4$ gastric and 27 colorectal cancer). Because advanced age is associated with impaired health status, this subgroup of the study population was analysed separately (Table 5.3). Diabets mellitus was more frequently observed in the older patients. An abnormal ECG was frequently present, but none of the patients with preoperative ECG abnormalities suffered from postoperative cardiac complications. 
Table 5.3: Comparison of parients under and over 80 years of age

\begin{tabular}{|l|l|l|l|}
\hline & $<\mathbf{8 0}$ yrs $(\mathbf{n}=\mathbf{1 4 1})$ & $>\mathbf{8 0}$ yrs $(\mathbf{n}=\mathbf{3 1})$ & $\mathbf{p}$ \\
\hline D.M. & $6(4.2 \%)$ & $5(16.1 \%)$ & 0.05 \\
Abnormal ECG & $21(14.9 \%)$ & $13(41.9 \%)$ & 0.01 \\
PIW < 95\% & $31(22.0 \%)$ & $13(41.9 \%)$ & 0.05 \\
PWL \% (mean) & 5.9 & 7.5 & $\mathbf{n s}$ \\
Pre-albumin <0.20 g/l & $51(36.2 \%)$ & $17(54.8 \%)$ & 0.01 \\
Duration $>3 \mathrm{hrs}$ & $70(49.6 \%)$ & $7(23.0 \%)$ & 0.01 \\
Mortality & $7(5 \%)$ & $4(13.0 \%)$ & $\mathbf{n s}$ \\
TLC $<1.2510 \% \mathrm{~mm}^{3}$ & $19(13.5 \%)$ & $12(46.0 \%)$ & 0.001 \\
\hline
\end{tabular}

Chronic G.I.-tract diseases, chronic obstructive pulmonary diseases (CODP) and neurological diseases were not more frequently present in the older age patients. Peroperative blood loss in patients over 80 years was not different from that in patients under 80 years of age. Hemoglobin ( $7.0 \mathrm{vs} 8.3 \mathrm{mmol} / \mathrm{l}$ ), total protein ( 67 vs $71 \mathrm{~g} / \mathrm{l}$ ), and albumin (33 vs $36 \mathrm{~g} / \mathrm{l}$ ) values were decreased compared to values in patients under 80 years, albeit not significantly. Ideal weight. prealbumin values and lymphocyte counts were significantly decreased.

Surgical procedures were shorter in patients over 80 years compared to those performed in patients below 80 years.

Mortality did not differ significantly: 4 out of $31(13.0 \%)$, as compared to 7 out of $141(5.0 \%)$ in the group below 80 years $(\mathrm{p}=0.1)$.

\subsubsection{Coexisting diseases}

In this study 6 patients suffered postoperatively from major pulmonary complications requiring special medical care. The age of all 6 patients was over 60 years. 4 were older than 70 years. Three of these patients had pre-existent C.O.P.D. and all 3 died of respiratory failure (Table 5.4). Forty eight patients had a history of cardiac disease, 23 patients complained preoperatively of coronary insufficiency, and 37 showed preoperative ECG aberrations. Six of these patients suffered major complications ( 3 deaths), while 13 patients suffered minor complications. None of the deaths was due to cardiac failure. 
Table 5.4: Association of coexistent diseases with the development of postoperative complications.

\begin{tabular}{|l|l|l|l|l|l|}
\hline & n & no & minor & major & p \\
\hline D.M. & 11 & 6 & 4 & 1 & ns \\
Hepatic diseases & 1 & 1 & - & - & ns \\
Renal diseases & 3 & 2 & - & 1 & ns \\
Coronary complaints & 23 & 14 & 8 & 1 & ns \\
Myocardial disturbances & 34 & 15 & 13 & 6 & ns \\
Neurological diseases & 19 & 10 & 7 & 2 & ns \\
Chron. G.I. tract disease & 29 & 19 & 6 & 4 & ns \\
C.O.P.D. & 24 & 11 & 5 & 8 & ns \\
Corticosteroids & 4 & - & 1 & 3 & 0.01 \\
\hline
\end{tabular}

Two patients suffered myocardial infarctions postoperatively although they had no history of cardiac complaints. Both patients suffered from postoperative sepsis, had lost a large amount of blood peroperatively, were operated for stage IV carcinoma, and were using corticosteroids preoperatively. However, none of the above associations was significant, as was the case with other preexisting diseases.

In contrast, the use of corticosteroids was significantly associated with postoperative complications $(p<0.01)$. All 4 patients using steroids preoperatively suffered postoperative complications, 3 of them suffered major complications, while 2 patients died.

\subsubsection{Multivariate analysis}

To exclude effects of confounding factors a multiple logistic analysis with complication rate as dependent factor was performed. Factors not showing significant independent association with postoperative complications were removed step by step, provided the removal of a factor did not cause a large shift in the coefficients of the remaining factors.

Peroperative blood loss was associated with postoperative complications at a high significance level (table 5.5). In addition, age was significantly associated with postoperative complications.

To determine which factors showed an independent association with progression of a complication from minor to major, the severity of the complication was analysed as a second dependent variable. Once a complication occurred not only blood loss. but also percentage ideal weight and duration of the surgical procedure were significantly associated with the severity of the complication. 
Table 5.5: Multivariate analysis

\begin{tabular}{|l|l|l|}
\hline \multicolumn{2}{|l|}{ CHI-SQ } & p \\
\hline \multicolumn{2}{|l|}{ Development of any complication } & $\mathrm{ns}$ \\
Duration of procedure & 0.43 & 0.0001 \\
Blood loss & 15.79 & $\mathrm{~ns}$ \\
P.I.W. (\%) & 0.03 & 0.05 \\
Age & 5.07 & \\
In case of occurrence of a complication & 0.05 \\
Duration & 4.61 & 0.01 \\
P.I.W. (\%) & 6.98 & $\mathrm{~ns}$ \\
Age & 3.23 & \\
\hline
\end{tabular}

Results of a stepwise (logistic) multivariate analysis with factors used as linear variables. The upper part of the table shows the factors which are associated with the development of any complication, the lower part the factors associated with the severity of a complication.

\subsection{Discussion}

The identification of a factor as a surgical risk factor largely depends on what factors in literature are analysed for their association with postoperative complications. In addition, it depends on which population is studied and to what specific surgical trauma the patients are exposed. Most studies concerning determination of surgical risk have focussed on 1 or 2 (groups of) factors. Thus, weight, ideal weight and weight loss ${ }^{23.6,6182.26,27}$, plasma total protein and albumin alone ${ }^{28}$ or in nutritional indices ${ }^{5.7 .1 .14 .6 .19 .29}$, age ${ }^{30.32}$, extent of surgical procedures, peroperative blood loss and transfusion ${ }^{6.33 .34}$, and many individual coexisting diseases have been studied for their relation with postoperative complications. For each of these factors or groups of factors a significant association with postoperative outcome has been demonstrated (Chapter 3 ).

However, an intregration of depletion parameters and other known risk factors to show the relative value of the individual or grouped parameters has not been published.

The broad interest in the field of nutrition has resulted over the past two decades in a considerable number of publications, demonstrating that aberrations of nutritional status parameters are risk factors for surgical outcome. The attractiveness of the (strong) association of nutritional status with postoperative complications has always been the suggestion that an impaired nutritional status 
can be treated, in contrast to many other risk factors.

This has led to high expectations of the ability of nutritional intervention to decreasic morbidity and mortality from surgical therapy. These expectations were, as we know now, too high. Firstly it gradually became clear that most of the parameters used to identify impaired nutritional status, rather demonstrate the presence of metabolic stress ${ }^{20}$. Secondly subsequent trials investigating the effect of nutritional intervention on outcome of surgical therapy, almost invariably failed to demonstrate a benefit.

The results of our study suggest that the extent of a surgical procedure, as reflected by blood loss and duration of the procedure, and age, are associated with the development of postoperative complications. Apart from these factors, parameters of nutritional status, as reflected by weight loss and percent ideal body weight, are associated with the severity of the occurring complication. Parameters reflecting the presence of metabolic stress, e.g. albumin, did not show an independent association with the development of postoperative complications.

We found no difference in complications, morbidity or mortality of procedures performed by senior staff surgeons, junior staff surgeons, or senior residents supervised by a staft surgeon. In the literature conflicting data have been reported on this subject. Some authors claim increased morbidity in surgical procedures performed by residents ${ }^{i 5}$, where it is not clear if they were assited or supervised by staff surgeons. Others report a higher incidence of complications in procedures performed by senior staff surgeons correlating with hospital stay and need for postoperative nutritional support". The results of the latter study can be explained by the fact that more experienced surgeons perform the more difficult procedures. Difficult procedures show a correlation with factors such as duration of procedure, need for blood transplantation and postoperative nutritional support. This illustrates the relation of these factors and the difficulty to interprete the results. This association can also be explanatory for the lack of a positive correlation between experience and complications in our study or even a negative association in other studies ${ }^{35}$.

Although none of the individual coexisting diseases was significantly associated with postoperative morbidity, the combined presence of several diseases in the old age patient group may be responsible for the observed significant association between age and morbidity.

A speculation about the underlying mechanisms of these observations should include the effects that both blood transfusions and impaired nutritional status have on the immune system ${ }^{23.4}$. Apparently the effect of a large blood loss is more important than the effect of nutritional status. If this is an intrinsic effect of blood loss, or related with a possibly greater amount of blood transfusions in 
these patients, is not subject of this study. But the use of blood transfusion is frequently associated weith factors that may alter prognosis adversely ${ }^{36}$. A deteriorated nutritional status seems to impair the ability of the host defense system to limit the progression of a complication.

\subsection{Conclusion}

The results of this study suggest that repletion by nutritional suport deminishes the severity of complications, rather than preventing their development.

\section{References}

1. Collins JP, McCarthy ID. Hill Gl. Assessment of protein nutrition in surgical patients. The value of anthropometrics.

Am.J.Clin. Nutr. 1979;32:1527-1530

2. Hickman DM, Miller RA.Rombeau JL. Twomey PL. Frey CF. Serum albumin and body weight as predictors of postoperative course in colorectal cancer.

J.P.E.N. 1980;4:314-316

3. De La Hunt . McDonald PJ. Karran SJ. Anthropometric nutritional assessment is of value in colorectal paticnts.

Dis.Col.d.Rect. 1984:27:296-298

4. Forse RA. Chrislou N. Meakins JL, MacLean LD. Shizgal HM. Reliability of skin lesting as a measurement of nutritiumal state: Arch.Surg. 1976:111:1357-1.661

5. Detsky AS, Baker JP. Menelson RA. Wolman SL. Wesson DE. Jeejeebhoy KN. Evaluating the accuracy of nutritional assessment techniques applied to hospilalized patients: Methodology and comparisons. J.P.E.N. 1984:8:153-159

6. Wamold I. Lundholm K. Clinical sigenificance of preoperative nutritional status in 215 noncancer patients.

Ann.Surg. 1984:199:299-305

7. Mullen JL, Gertner MH, Buzby GP, Goodhar GL, Rosato EF. Implications of malnutrition in the surgicial patient.

Arch.Surg. 1979:114:121-125

8. Nordenström J, Campentier YA. Askenazi J, Rohin AP. Flwyn DH, Hensle DH. Kinney JM. Metabolic utilization of intravenous fal emulsion during tulal parintural nutrition. Ann. Surg. 1982:196:221-231

9. Bellantone R. Doglietto GB,Bossola M. Pacelli F, Negro F, Sofo L, Cruciti F. Preoperative parenteral nutrition of malnourished surgical patients.

Acta Chir.Scand. 1988:22:249-251

10. DeMatteis R. Herman RE. Supplementary parenteral nutrition in patients with malignant disease.

Cleveland Clinic Quarterly 1973:40:139-145 


\section{Chapter 5}

11. Mtullen JL. Complications of total parenteral nutrition in the cancer patient

Cancer Treat.Rep. 1981,65:107-113

12. Daly JM. Use of parenteral nutrition in the patient with cuncer.

Surgery 1985:97:756-758

13. Muefler JM. Keller HW. Brenner U. Walter M. Holzmueller W. Indications and effects of preoperative parenteral nutrition.

World J Surg. 1986:10:53-63

14. Klidjian AM. Foster KJ. Kammerling RM. Karran S3. Relation of anthropometric and dynamometric variables to scrious pestuperative complications.

Brit.Med.J. 1980:281:899-901

15. Sutton G. Karran SJ. The diagnusis of malnutrition: nutritional parameters.

Cum.Op.Gastrent 1985:1:281-287

16. Multen JL, Buzby GP, Waldman MT, Gerner MH, Hohhs CL, Rosato EF. Prediction of operative morbidity and mortality by preoperative nutritional assessment.

Surg. Forum 1979;30:80-82

17. Mueller JM, Brenner U, Diest C. Pichimaier H. Preoperative parenteral feeding in patients with gastrointestinal carcinoma.

The Lancet 1982:1:68-71

18. Windsor JA, Hill GL. Weight loss with physiologic impaiment. A basic indicator of surgical risk. Ann.Surg. 1988:207:2\%0-296

19. Dionigi R. Cremaschi RE, Jemos V, Dominioni L. Monico R. Nutritional assessment and severity of illness classification systems: A critical review on their clinical relevance.

World J.Surg. 1986;10:2-11

20. Editorial. Indicators of surgical risk.

The Lancet 1986:1:1422-1423

21. Association of life insurance medical directors: Medico-actuarial mortality investigations

Ass.Life Ins.Med.Dir and Actuarial Soc.Am. 1912;vol.1

Scheffe H. The analysis of variance. New York, John Wiley \& Sons. 1959

23. Mantel N, Haenszel W. Staristical aspects of the analysis of data from reuospective studies of disease. J.Natl.Cancer Inst. 195():22:719-748

24. Agresti A. Analysis of ordinal categorical data, New York, John Wiley \& Sons 1984:112.117

Cox C. Multinominal regression models bilsted on continuation ratios

Statistics in Medicine 1988: $: 435-41$

26. Elwyn DH. Nutritional requirements of adult surgical patients.

Crit.Cure Med. 1980;8:9-19

27. Ennis CE, Andrussy RJ. Nutritional management of the surgical parient. A.O.R.N.J. 1980:31:1217-1224

28. Starker PM. Askenazi J, Lasala PA. Elwyn DH. Gump FE. Kinncy JM. The effect of parenterd nutritional repletion un muscle water and electrolytes. Implicatums for body composition. Asm. Surg. 1983:198:213-217 
29. Harvey KB, Moldawer LL, Bristrian BR, Blackbum (iL. Biological measures for the formulation of a hospital prognostic index.

Am.J.Clin.Nutr. 1981;34:2013-2022

30. Starker PM, Lasala PA, Askenazi J, Gump FE, Forse RA, Kinney JM. The response to TPN. A form of nutritional assessment.

Ann.Surg. 1983:198:720-724

31. Harbrecht PJ. Garrison RN. Fry DE. Role of infection in increased mortality associated with age in laparotomy.

Am.Surg. 1983:49:173-178

32. Limn BS. Rohinson DS, Klimas NG. Effects of age and nutritional status on surgical outcome in head and neck cancer.

Ann.Surg. 1988:207:267-273

33. Szczepanski KP. Skaarup P. Stear-Johansen T. Pleuropulmonary complications following major surgery (Thoracic surgery excluded).

Acta Chir.Scand 1973:139:425-430

34. The Norwegian Gastro-Intestinal Group (NORGAS). Infectious problems after elective surgery of the alimentary tract: the influence of perioperative factors.

Curr.Med.Res.Op. 1988;11:179-195

35. Keigly MRB, Winslet MC. Flinn R. Kmiot W. Multivariate analysis of factors influencing the results of restorative prociocolectomy.

Br.J.Surg 1989:76:740-744

36. Francis DMA. Relationship between blood transfusion and tumour behaviour. Br.J.Surg. 1991:78: 1420-1428 
Chapter 6

\section{The influence of perioperative nutritional intervention on postoperative complications}

\subsection{Abstract}

Ever since methods of artificial nutritional support became available, attempts have been made using this form of treatment to reduce mortality and morbidity in surgical patients. Many trials have addressed this question, but very few have given a meaningful answer because of conceptual and methodological flaws. We therefore undertook a prospective randomised trial investigating the effects of at least 10 days preoperative total parenteral nutrition (TPN) (n=51) or total enteral nutrition (TEN) ( $n=50)$ providing $150 \%$ BEE non-protein energy, to reduce major postoperative complications or mortality in a homogeneous patient group with signs of depletion. Fifty parients served as a depleted control group (D) and 49 patients served as a non-depleted reference group and were operated upon without delay.

Depleted control patients suffered significantly more septic complications than patients in the non-depleted reference group did $(p<0.05)$. There was no significant difference, however, in septic complications between either of the nutritional support groups and the non-depleted control group. In high risk patients, with weight loss $>10 \%$ of body weight and over $500 \mathrm{ml}$ blood loss during operation, a significant decrease $(p<0.05)$ in major complications was observed as a result of nutritional support.

We conclude that preoperative nutritional support, in patients with severe depletion, results in a reduction of major complications to a degree that justifies its routine use in this selected group of patients.

\subsection{Introduction}

Many studies have demonstrated that parenteral nutrition can correct the effects of starvation ${ }^{1.16}$. That depletion and loss of body cell mass induces loss of tissue function and are associated as single factors with a less favourable outcome of treatment of disease is well accepted. On the other hand, in surgical patients it is 
often one of many factors determining surgical outcome. Whether correcting nutritional depletion under these circumstances influences outcome is less certain, although it has been the subject of several trials which have particularly addressed the effectiveness of preoperative parenteral nutrition in reducing postoperative morbidity and mortality. Unfortunately, most of these trials do not fulfill the minimum criteria with regard to design and number of randomised patients $^{17}$. A recent large multi-centre trial ${ }^{18}$ of preoperative nutritional support suggested that the effectiveness of this treatment was confined to a limited group of patients with severe depletion. This study was designed to assess the clinical efficacy of preoperative nutrition in a relatively homogerneous group of patients studied in a single centre. The question of whether efficacy is confined to a subgroup of severly depleted patients was particularly addressed.

\subsection{Patients and methods}

\subsubsection{Patients}

Patients with newly detected, histologically proven gastric or colorectal carcinoma requiring surgical treatment, who had not undergone treatment for other malignant tumors were eligible to enter the trial.

As it was considered unethical to include patients over 80 years of age and patients with a normal nutritional status, patients in these categories were excluded from randomisation.

The study was reviewed and approved by the Human Studies Committee of the University Hospital Maastricht.

\subsubsection{Nutritional assessment}

The presence of depletion was determined in all patients using the following parameters: albumin (ALB), total lymphocyte counts (TLC) and percent ideal body weight (PIW), calculated from body length, body weight and wrist circumference using the Metropolitan Life tables ${ }^{19}$. These parameters were combined in a nutritional index $(\mathrm{NI}=0.14 \times \mathrm{ALB}+0.03 \times \mathrm{PIW}+0.73 \times \mathrm{TLC}$ 8.9) that has been demonstrated in a previous study ${ }^{20}$ to allocate correctly patients to groups that were on clinical grounds considered to be depleted or not. Values above the mean of the non-depleted group from that study (1.31) were considered to reflect a normal nutritional status.

\subsubsection{Study design}

After stratification for percent weight loss (PWL) $(<, \geq 15 \%)$, age $(<, \geq 65$ years) and tumor localisation (gastric/colorectal), patients were randomised to receive 
preoperative parenteral nutrition (TPN) (group 1), preoperative enteral nutrition (TEN) (group 2) or to undergo surgery without delay (group 3). Non-depleted patients, with a nutritional index $>1.31$, served as a reference group and were monitored according to the trial guidelines (group 4). Patients in this group also underwent surgery without delay.

\subsubsection{Nutritional support}

Patients in group 1 were planned to receive $150 \%$ of basal energy expenditure (BEE), calculated using the Harris and Benedict equation"1, as non-protein calories from a parenteral nutrition stock solution that contained $7 \mathrm{~g} \mathrm{~N} / \mathrm{l}$ (Synthamin $14^{\mathrm{R}}$ ) and $25 \%$ dextrose. Trace elements and vitamins (MVI ${ }^{\mathrm{K}}$ ) were added conform today's standards. Electrolytes were added according to the individual patient's needs. Five hundred $\mathrm{ml}$ of an intravenous fat emulsion (Intralipid $^{\mathrm{K}} 20 \%$ ) was administered at least three times per week. Preoperative nutritional support lasted at least 10 days.

Patients in group 2 received enteral nutrition (Precitene ${ }^{k}$ or Isotein ${ }^{k}$ ) either by nasogastric tube or by mouth. Caloric intake was planned to contain $150 \%$ of the calculated BEE during at least 10 days preoperatively.

Parenteral nutritional support was continued postoperatively in group 1 until the patients had resumed an oral diet providing $120 \%$ BEE. Postoperatively. patients in groups 2, 3 and 4 were allowed increasing amounts of liquids and solids as tolerated. Only in the event of a major postoperative complication, parenteral nutrition was started in these groups.

\subsubsection{Morbidity and mortality}

Complications, summarised in table 6.1, were monitored daily. The presence of each complication was evaluated separately. Finally, patients were categorised within each trial group as having suffered no complications, at least one minor complication (and no major complications) or at least one major complication. Mortality was evaluated separately.

\subsubsection{Statistics}

All patients in the trial groups were analysed according to the intention-to-treat principle. Data were summarised as means and standard deviations. Results were evaluated using Chi-square and Mantel Haenszel Chi Square tests for the complication frequency in the trial groups and an ANOVA procedure for comparison of the distribution of risk factors between trial groups. P-values smaller than 0.05 were considered to be significant. 
Table 6.1: Complication definition

\begin{tabular}{|c|c|}
\hline \multicolumn{2}{|l|}{ MINOR } \\
\hline Wound infection & Clinical aspect, positive culture or necessity for surgical drainage \\
\hline Urinary tract inf. & Positive culture $>10^{7}$ micro-organisms $/ \mathrm{ml}$ urine \\
\hline Pulmonary tract inf. & $\begin{array}{l}\text { positive sputum culture, abnormal chest } \mathrm{X} \text {-ray requiring } \\
\text { treatment with antibiotics }\end{array}$ \\
\hline \multicolumn{2}{|l|}{ MAJOR } \\
\hline Respiratory insuff. & $\begin{array}{l}\text { Ventilatory assistance for }>12 \text { hrs. postoperative or mechanical } \\
\text { renewed ventilation after detubation. }\end{array}$ \\
\hline Cardiac insuff. & $\begin{array}{l}\text { Clinical and radiological diagnosis requiring cardiotonics and/or } \\
\text { diuretics, or myocardial infarction confirmed on ECG or by } \\
\text { serum enzyme elevations. }\end{array}$ \\
\hline Renal insuff. & $\begin{array}{l}\text { Plasma urea levels elevated by } 50 \% \text { or a plasma creatinin } \\
\text { elevation with } 20 \% \text {. }\end{array}$ \\
\hline Intra-abd. abscess & $\begin{array}{l}\text { Purulent fluid collection, demonstrated by ultrasound, or CT- } \\
\text { scan guided drainage or at reoperation. }\end{array}$ \\
\hline Fistula & Diagnosis on clinical grounds or proven by fistulography. \\
\hline Anastomotic leakage & $\begin{array}{l}\text { After clinical or radiological diagnosis, necessity for operation or } \\
\text { drainage. }\end{array}$ \\
\hline Wound dehiscence & Dehiscence of the wound requiring surgical closure. \\
\hline Sepsis & $\begin{array}{l}\text { Positive bloodculture, persisting temperature above } 39^{\circ} \mathrm{C} \text {., } \\
\text { associated with hypotension and hypoperfusion. }\end{array}$ \\
\hline D.I.C. syndrome & $\begin{array}{l}\text { Positive FDP-test, abnormal clotting tests and decreasing } \\
\text { thrombocyte counts. }\end{array}$ \\
\hline Mortality & Any postoperative in-hospital mortality. \\
\hline
\end{tabular}

\subsection{Results}

\subsubsection{Patients}

Hundred-and-fifty-one patients entered the trial. Fifty-one patients were randomised to receive TPN and 50 patients to receive TEN, while 50 patients received no nutritional support and underwent surgery without delay. Forty nine patients served as a 'normal' reference group. The trial groups were comparable with respect to age, weight loss and the ratio gastric/colorectal cancer (Table 6.2). 
The trial groups $(1-3)$ and the reference group 4 were also comparable in terms of blood loss during operation and duration of the surgical procedure.

In group 1 more patients had advanced disease (stage IV cancer). The higher values of PIW, serum albumin and TLC and the lower PWL values in group 4 (reference group) were a consequence of the way this group was selected.

\subsubsection{Nutritional support}

In TPN patients (group I) average preoperative energy intake ( $\pm \mathrm{sd}$ ) was 1783 $( \pm 350) \mathrm{kcal}$ per day with $11.9( \pm 2.5)$ gram nitrogen per day and $9.4( \pm 5.7) \%$ fat; the $\mathrm{N} / \mathrm{kcal}$ ratio was $1: 168( \pm 20)$. The average $( \pm \mathrm{sd})$ preoperative caloric intake in TEN patients (group 2) was 1458 ( \pm 444) kcal per day with 20.5 ( \pm 5.5) gram nitrogen per day, $27.4( \pm 8.3) \%$ of total energy intake as fat and a

\section{Table 6.2: Study population}

\begin{tabular}{|c|c|c|c|c|c|}
\hline & & T.P.N. & T.E.N. & Depleted & $\begin{array}{l}\text { Non } \\
\text { depleted }\end{array}$ \\
\hline \multirow{3}{*}{\multicolumn{2}{|c|}{$\begin{array}{l}n \\
\text { age (mean }+s t d) \\
\text { age (range) }\end{array}$}} & 51 & 50 & 50 & 49 \\
\hline & & $67(10)$ & $66(9)$ & $66(7)$ & $61(10)$ \\
\hline & & $41-80$ & $39-78$ & $49-79$ & $39-77$ \\
\hline \multicolumn{2}{|l|}{ G/CR cancer } & $15 / 36$ & $13 / 37$ & $14 / 36$ & $10 / 39$ \\
\hline \multicolumn{2}{|l|}{$\mathrm{M} / \mathrm{F}$ ratio } & $29 / 22$ & $32 / 18$ & $32 / 18$ & $33 / 16$ \\
\hline \multirow[t]{5}{*}{ STAGE n (\%) } & I & $13(26 \%)$ & $12(24 \%)$ & $15(30 \%)$ & $24(48 \%)$ \\
\hline & II & $5(10 \%)$ & $7(14 \%)$ & $3(6 \%)$ & $3(6 \%)$ \\
\hline & III & $15(30 \%)$ & $20(40 \%)$ & $19(38 \%)$ & $14(29 \%)$ \\
\hline & IV & $18(36 \%)$ & $11(22 \%)$ & $13(26 \%)$ & $8(17 \%)$ \\
\hline & & mean (std) & mean (std) & mean (std) & mean (std) \\
\hline \multicolumn{2}{|l|}{ P.I.W. (\%) } & $95(12)$ & $98(12)$ & $98(11)$ & $113(12)$ \\
\hline \multicolumn{2}{|l|}{ P.W.L. $(\%)$} & $8(6)$ & $6(7)$ & $6(6)$ & $4(6)$ \\
\hline \multicolumn{2}{|l|}{ Albumin $(\mathrm{g} / \mathrm{l})$} & $34(4)$ & $36(4)$ & $34(4)$ & $39(3)$ \\
\hline \multicolumn{2}{|l|}{ T.L.C. $\left(/ \mathrm{mm}^{3}\right)$} & $1.7(0.5)$ & $1.7(0.5)$ & $1.8(0.6)$ & $2.5(0.7)$ \\
\hline \multicolumn{2}{|l|}{ Blood loss (ml) } & $770(760)$ & $820(1030)$ & $830(1030)$ & $990(1350)$ \\
\hline \multicolumn{2}{|c|}{$\begin{array}{l}\text { Duration of } \\
\text { procedure (hr.min) }\end{array}$} & $2.50(1.2)$ & $2.50(1.1)$ & $3.00(1.0)$ & $3.30(1.4)$ \\
\hline
\end{tabular}


$\mathrm{N} / \mathrm{kcal}$ ratio of 1:102 $( \pm 26)$. The ranges of the nutritional support data are summarised in table 3 : the lower values indicating the values at the start of nutritional support, the higher ones indicating the level reached after the initial 2 days (Table 6.3).

\subsubsection{Complications}

\subsubsection{Technical complications}

Complications resulting from the nutritional intervention itself include: in the TPN group: 1 arterial puncture and 1 pneumothorax requiring drainage

Table 6.3: Nutritional support

\begin{tabular}{|l|l|l|}
\hline & T.P.N. & T.E.N. \\
\hline preoperative support days & $11.8(10-23)$ & $11.4(10-15)$ \\
kcal/N & $157-173$ & $102-109$ \\
\% fat & $5-12$ & $26-27$ \\
carbohydrates (kcal/day) & $1375-1885$ & $1345-1575$ \\
fat (kcal/day) & $85-250$ & $535-555$ \\
$\mathrm{~N}$ (g/kg BW/day) & $0.16-0.20$ & $0.31-0.34$ \\
Prot (g/kg BW/day) & $0.97-1.25$ & $1.90-2.09$ \\
\hline
\end{tabular}

as a result of the catheter insertion procedure: and 4 clinically or bacteriologically proven episodes of catheter sepsis, requiring removal of the catheter. Complications in the TEN group included diarrhoea requiring treatment in 3 patients, vomiting in a further 3 patients, and a delayed gastric emptying in 2 patients, resulting in gastric retention of the administered food. No episodes of ileus, or aspiration were observed. 
Table 6.4: Postoperative complications

\begin{tabular}{|l|l|l|l|l|}
\hline complications & T.P.N. & T.E.N. & Depleted & Non-depleted \\
\hline $\mathbf{n}$ & 51 & 50 & 50 & 49 \\
Woundinfection & 8 & 7 & 8 & 13 \\
Urinary tract infection & 16 & 10 & 10 & 9 \\
Resp. tract infection & 14 & 8 & 7 & 6 \\
Wound dehiscence & 2 & 1 & 2 & 1 \\
Anastomotic leakage & 5 & 4 & 7 & 3 \\
Fistula & 2 & 2 & 1 & 0 \\
Intra abd. abscess & 4 & 4 & $8 *$ & $0 *$ \\
Sepsis & 1 & 1 & $4 *$ & $0 *$ \\
Resp. insuff. & 0 & 2 & 2 & 2 \\
Circ. insuff. & 1 & 1 & 0 & 0 \\
Renal insuff. & 0 & 0 & 0 & 0 \\
Mortality & 2 & 4 & 2 & 1 \\
sepsis related mortality & 1 & 2 & 2 & 0 \\
$*$ p $<0.05 x^{2}$-test & & & & \\
\hline
\end{tabular}

\subsubsection{Postsurgical complications}

The number of complications per study group is summarised in table 6.4. No significant differences were present between study groups for most complications. Complications categorised as minor or major are summarised in table 6.5 while mortality is shown separately. If summarised in this way no significant differences were observed between the groups (Table 6.5). The number of complications occurring in each patient is summarised in table 6 . There were fewer patients with more than 1 complication in the non-depleted, T.P.N. and T.E.N. groups than in the depleted group. If the number of complications is given a separate weight (e.g. 1 complication eq 1,2 complications eq 2,3 complications eq 3 ) the distribution of number of complications is significantly different between groups: TPN and TEN seem to reduce the number of complications per patient, compared to the depleted control group 3. 
Table 6.5: Postoperative complication groups

\begin{tabular}{|c|c|c|c|c|c|c|c|c|}
\hline \multirow[b]{2}{*}{ complications } & \multicolumn{2}{|c|}{ T.P.N. } & \multicolumn{2}{|c|}{ T.E.N. } & \multicolumn{2}{|c|}{ Depleted } & \multicolumn{2}{|c|}{ Non-depleted } \\
\hline & n & $\%$ & n & $\%$ & $n$ & $\%$ & $n$ & $\%$ \\
\hline no & 24 & 47.1 & 26 & 52.0 & 32 & 64.0 & 28 & 57.2 \\
\hline minor & 19 & 37.2 & 14 & 28.0 & 9 & 18.0 & 17 & 34.7 \\
\hline mijor & 6 & 11.8 & 6 & 12.0 & 7 & 14.0 & 3 & 6.1 \\
\hline mortality & 2 & 3.9 & 4 & 8.0 & 2 & 4.0 & 1 & 2.0 \\
\hline \multicolumn{4}{|c|}{ Chi-square and Mantel-Haenszel } & $\mathrm{p}\left(\mathrm{x}^{2}\right)$ & & \multicolumn{3}{|c|}{$\mathbf{p}(\mathbf{M H})$} \\
\hline \multicolumn{4}{|l|}{ Total group } & 0.45 & & \multicolumn{3}{|l|}{0.16} \\
\hline \multicolumn{4}{|c|}{ Group TPN vs TEN vs Depleted } & 0.24 & & \multicolumn{3}{|l|}{0.29} \\
\hline \multicolumn{4}{|c|}{ Group TPN vs Depleted } & 0.19 & & \multicolumn{3}{|l|}{0.39} \\
\hline \multicolumn{4}{|c|}{ Group TEN vs Depleted } & 0.48 & & \multicolumn{3}{|l|}{0.33} \\
\hline \multicolumn{4}{|c|}{$\begin{array}{l}\text { Group TPN and TEN and Depleted } \\
\text { vis Non-depleted }\end{array}$} & 0.40 & & \multicolumn{3}{|l|}{0.26} \\
\hline \multicolumn{4}{|c|}{ Group Depleled vs Non-depleted } & 0.20 & & \multicolumn{3}{|l|}{0.76} \\
\hline
\end{tabular}

p-Values of $x^{2}$-test and Mantel-Haenszel for combinations of intervention groups versus depleted patients of reference groups. In non of the combinations a significant difference is observed.

Table 6.6: Number of multiple major septic postoperative complications

\begin{tabular}{|l|l|l|l|l|}
\hline & T.P.N. & T.E.N. & Depleted & Non-depleted \\
\hline no/minor complications & 43 & 40 & 41 & 45 \\
pat. with 1 complication & 1 & 3 & 0 & 1 \\
pat with 2 complications & 3 & 3 & 5 & 2 \\
patient with 3 complications & 1 & 0 & 3 & 0 \\
\hline
\end{tabular}

Significunt reduction ( $x^{2}: p<0.05$ ) of major septic complications in supported groups.

The stratification for weight loss allowed for performance of a subset analysis in the patient group displaying more severe depletion. This analysis showed a significant decrease in the number of patients developing an intraabdominal abscess in the TPN and TEN groups to become significant (Table 6.7). The differences between the intervention groups and the depleted control group became more pronounced in the subset of patients suffering major peroperative 
blood loss (Table 6.8). The patient characteristics as described in table 2 were not different between groups in either of these subset analyses.

Table 6.7: Postoperative complications in patients with $P W L>10 \%$.

\begin{tabular}{|l|l|l|l|l|}
\hline & T.P.N. & T.E.N. & Depleted & Non-depleted \\
\hline $\mathrm{n}$ & 18 & 13 & 11 & 8 \\
Anastomotic leakage & 1 & 2 & 3 & 2 \\
Intra-abd. abscess & $0^{*+}$ & $2^{*+}$ & $4^{*+}$ & $2 *$ \\
Sepsis & 0 & 1 & 2 & 0 \\
${ }^{*} \mathrm{p}<0.05$ TPN vs TEN vs Depleted vs Non-depleted & & \\
$+p<0.05$ TPN and TEN vs Depleted & & & \\
\end{tabular}

Table 6.8: Postoperative complications in patients with peroperative blood loss $>500 \mathrm{ml}$.

\begin{tabular}{|l|l|l|l|l|}
\hline & T.P.N. & T.E.N. & Depleted & Non-depleted \\
\hline $\mathrm{n}$ & 25 & 21 & 20 & 23 \\
Anastomotic laekage & 3 & 3 & 6 & 3 \\
Intra-abd. Abscess & $2^{*+}$ & $3^{*+}$ & $7^{*+\#}$ & $2^{* \#}$ \\
Sepsis & $1^{*+}$ & $1^{*+}$ & $4^{*+\#}$ & 0 \\
${ }^{*} \mathrm{p}<0.05$ TPN vs TEN vs Depleted vs Non-depleted & & \\
$+\mathrm{p}<0.05$ TPN and TEN vs Depleted & & \\
$\#$ \#<0.05 Depleted vs Non-depleted & & \\
\hline
\end{tabular}

\subsubsection{Hospital stay}

Total hospital stay of the reference group 4 was significantly shorter than that of the other groups. Total hospital stay in the TPN group was $36.3( \pm 17.7)$ days, in the TEN group 33.3 ( \pm 20.2 ) days, in depleted control group $31.7( \pm 22.1$ ) days. This difference was not significant. In the reference group this was $24.8( \pm 11.3)$ days and differed significantly from the trial groups (ANOVA $p<0.01$ ). Hospital stay in both the TPN and TEN group was no longer than that of the untreated group 3, even though a longer preoperative hospital stay was present in the nutritional support groups (1 1.5 days in group $\mid$ and 9.9 days in group 2, compared to 5.0 days in the depleted control patients. This would suggest a shorter postoperative hospital stay in the TPN and TEN groups. Due to a large variation in these data the difference did not become statistically significant. As 
was to be expected, postoperative hospital stay increased significantly in patients with minor or major complications $(p<0.001)$. Analysis of the patients with complications as a group did not reveal a beneficial effect of perioperative nutrition on total hospital stay. Postoperative hospital stay was shorter, albeit not signicantly, for both TPN and TEN groups if patients had suffered a major complication.

\subsection{Discussion}

Cancer patients frequently show signs of depletion as a result of an often prolonged disturbance of energy balance. Although increased energy expenditure has long been thought a major contribution to the disturbance of energy balance, most physicians now agree that decreased energy intake, is most cases, the more important determinant of the development of cancer associated depletion.

Parameters describing depletion have been identified as surgical risk factors. Thus weight loss and ideal weight, plasma proteins and various derived nutritional indices have all shown a significant association with operative outcome 0.711 .22 .35 . The availability of various forms of artificial nutrition has resulted in efforts to demonstrate a clinical benefit of perioperative nutritional support ${ }^{3,+6-18,13,36-40}$. Most trials suffer from major conceptual flaws ${ }^{17}$ and have ioncluded non depleted patients. Our trial has overcome most of these problems by testing the effects of 10 days of perioperative nutritional support in depleted patients only, in a prospective randomised design against immediate operation, without nutritional support. The results of our trial suggest a small benefit with fewer episodes of sepsis and less intra-abdominal abscess formation. This effect was more pronounced in the more severely depleted patients and was not obtained at the cost of increased morbidity of the nutrional support technique itself.

Depletion was defined in this study by means of a "nutritional index' ${ }^{\prime \prime}$. This index is derived from serum albumin, total lymphocyte count and percent ideal weight, which reflect the disease process as well as nutritional depletion. Plasma albumin concentrations remain normal even during prolonged periods of simple starvation ${ }^{+1}$, but decrease rapidly in the presence of disease, due to changes in distribution. Although little is known concerning the total lymphocyte count in starvation, TLC values decrease rapidly in septic conditons. Any antropometric parameter is influenced by fluctations in fluid retention. As none of these patients suffered from severe metabolic stress or fluid retentions, low PIW values may reflect nutritional depletion as well as the presence of cancer. 
The results of the current trial are in line with the two most important trials performed in this field ${ }^{6.1}$. The data from the trial reported by Mueller et al. " have never been considered convincing enough to cause preoperative nutrition to become common practice. Patients in that trial were not stratified for depletion and the control group stayed in hospital for preoperative work-up for almost as long a period as the nutritional intervention group. The results of that trial may be interpreted as suggesting that prolonged starvation results in a worse outcome than if nutritional support is administered. Our observation that nutritional support reduced infectious complications in severely depleted patients, confirms the observation in the Veterans Administration trial ${ }^{18}$ that was not statistically significant possibly because of the number of patients showing severe depletion was too small. That our results are significant in contrast to those of the VAtrial's may be explained by the fact that we investigated a more homogeneous patient group, operated in only one hospital, by a limited number of surgeons, with a reasonable result ( $5 \%$ mortality vs $10 \%$ in the VA-trial).

The ability to respond to intrusions is only in part dependent on 'nutritional status'. Other facors such as cardio-respiratory status are far more crucial in many cases. Nutritional support, therefore, is only one factor affecting outcome and is of varying importance in different patients. Nutritional depletion increases the risk of perioperative complications, but not to the extent that all depleted patients develop complications. It is, therefore, unreasonable to expect complete eradication of all postoperative complications by nutritional support.

\subsection{Conclusion}

From the results of this trial we therefore advocate that only patients with signs of (severe) depletion (i.e. weight loss $>10 \%$ ) receive nutritional support prior to surgery. The benefit of such treatment increases with the degree of the intial depletion. These observations may possibly be extended to other conditions where patients are planned to undergo chemotherapy, radiotherapy and surgery.

\section{References}

1. Copeland EM III, Daly JM. Ota DM, Dudrick SJ. Nutrition, cancer. and intravenous hyperalimentation. Cancer 1979:43:2108-21:6

2. Moghissi K, Homshaw J. Teasdale PR. Dawes EA. Parenteral nutrition in carcinoma of the oesophagus treated by surgery: nitrogen balance and clinical studies. Br.J.Surg, 1977:64:125-128 


\section{Chapter 6}

3. Fasth S. Hulten L, Magnusson O, Nordgren S, Wamold I, Postoperative complications in colorectal surgery in relation to preoperative clinical and nutritional state and postoperative nutritional treatment. int.J.Colorect.Dis. 1987:2:87-92

4. Mullen JL, Buzby GP, Matthews DC, Smale BF, Rosato EF. Reduction of operative morbidity and montality by combined preoperative and postoperative nutritional suppor. Ann.Surg. 1980:192:604-613

5. Multen JL. Consequences of malnutrition in the surgical patient Surg.Clin. North Am. 1981;61:465-487

6. Mueller JM, Brenner U, Dicnst C, Pichlmaier H. Preoperative parenteral feeding in patients with gastrointestinal carcinoma.

Lancet 1982:1:68-7!

7. Bellantone R, Doglietto GB, Bossola M, Pacelli F. Negro F. Crucitti F. Preoperative parenteral nutrition in malnourished surgical patients. Acta Chir.Scand 1988:22:249-251

8. Holter AR, Fisher JE. The effects of perioperative hyperalimentation on complications in patients with carcinoma and weight loss. J.Surg.Res. 1977:23:31-34

9. Holter AR. Rosen HM, Fisher JE. The effects of hyperalimentation on major surgery in patients with malignant disease: a prospective study.

Acta Chir.Scand (suppl) 1977:466:86-87

10. Lim STK, Choa RG. Lam KH. Wong J, Ong GB. Total parenteral nutrition vs gastrostomy in the preoperative preparation of patients with carcinoma of the esophagus. Br.J.Surg. 1981:68:69-72

11. Mueller JM, Keller HW. Brenner U. Walter M. Holtzmueller W. Indications and effects of preoperative parenteral nutrition.

World J.Surg. 1986:10:53-63

12. Allison SP. Nutritional support: Efficacy versus cost. Nutr.lnt. 1987:3:19-24

13. Preshaw RM, Attisha RP. Hollingsworth WJ. Todd JD. Randomized sequential trial of parenteral nutrition in healing of colonic anastomoses in man.

Can.J.Surg. 1979:22:437.439

14. Nordenstrom J. Askanazi J. Elwyn DH. et al. Nitrogen balance during total parenteral nutrition. Ann.Surg. 1983:197:27-33

15. Bower RH. Talamini MA, Sax HC. Hamilton F. Fisher JE. Postoperitive enteral vs parenteral nutrition. Arch.Surg. 1986:121:1040-1045

16. Starker PM. LaSala PA. Askanazi J. Gump FE. Forse RA, Kinney JM. The response to TPN: a form of nutritional iscisiment.

Am. Surg. 198: $: 198: 720-724$.

17. Canjpos ACL. Meguid MM. A critical appraisal of the usefulness of perioperalive nutrilional support. Am.J.Clin. Nutr. 1992:55:117-30

18. The Veterans Affilis tolal parenteral nutrition cooperative sludy group. Perioperative total parenteral nutrition in surgical patticnts.

N.1:.1.M. $1991: 325: 525-532$ 
19. Association of life insurance medical directors: Medico-actuarial morality investigations. Ass.litic Ins.Med.Dir and Actuarial Soc.Am. 1912:vol.1

20. de Jong PCM, Wesdorp RIC, Volovies A, Roulflart M, Greep JM. Sceters PB. The value of objective measurements to select patients who are malnourished.

Clin. Nutr. 1985;4:61-66

21. Harris JA, Benedict FG. A biometric study of basal metabolism.

Washington. Carnegie institution of Washington 1919

22. Wamold I. Lundholm K. Clinical significince of preoperative nutritional status in 215 noncancer patients.

Ann.Surg. 1984:199:299-305

23. Detsky AS. Baker JP. Meneison RA, Wolman SL, Wesson DE, Jecjeebhoy KN. Evaluating the accuracy of nutritional assessment techniques applied to hospitalized patients: Methodology and comparisons. J.P.E.N. 1984:8:153-159

24. Mullen JL, Gertner MH, Buzby GP. Goodhar GL, Rosato EF. Implications of malnutrition in the surgical patient.

Arch.Surg. 1979:114:121-125

25. Mullen JL, Buzby GP. Waldman MT. Gerner MH. Hobbs CL. Rosato EF. Prediction of operative morbidity and mortality by preoperative nutritional assessment.

Surg. Forum 1979:30:80-82

26. Klidjian AM. Foster KJ, Kammerling RM, Kartan SJ, Relation of anthropomelric and dynamometric variables to serious postoperative complications.

Bril.Med.J. 1980:281:899-901

27. Hickman DM. Miller RA,Rombeau JL. Twomey PL, Frey CF. Serum albumin and body weigh! as predictors of postoperative course in colorectal cancer J.P.E.N. 1980:4:314-316

28. De La Hunt L. MCDonald PJ, Karran SJ. Anthropometric nutritional assessment is of value in colorectal patients.

Dis.Col.\&Rec1. 1984:27:296-298

29. Collins JP. McCarthy ID, Hill GL. Assessment of protein nutrition in surgical patients. The value of anthropometric's.

Am.J.Clin.Nutr. 1979:32:1527-1531

30. Forse RA, Christou N, Meakins JL. MacLean LD. Shizgal HM. Reliability of skin testing as a measurement of nutritional state.

Arch.Surg. 1976;111:1357-1361

31. Nordenström J. Carpentier YA. Askenazi J. Robin AP, Elwyn DH. Huısle DH, Kinney JM. Meratolic utilization of intravenous fat emulsion during tolal parenteral nutrition.

Ann.Surg. 1982:196:221.231

32. DeMatteis R. Herman RE. Supplementary parenteral nutrition in patients with malignant discase. Cleveland Clinic Quanerly 1973:40:139-145

33. Mullen JL. Complications of total parenteral nutrition in the cancer patient Cancer Treat.Rep. 1981:65:107-113

34. Daly JM. Line of parcnteral nutrition in the paticnt with cancer.

Surgery 1985:97:756-758 


\section{Chupter 6}

i.5. Sutton G, Kartan SJ. The diagnosis of malnutrition: nutritional parameters.

Curr.Op.Gastrent. 1985:1:281-287

36. Willians RHP, Heatley RV, Lewis MH, Hughes LE. A randomised trial of preoperative intravenous nurrition in parients with stomach cancer.

Br.J.Surg. 1976:63:667

37. Collins JP. Hill GL. Oxby CB. Intravenous aminoacids and intravenous hyperalimentation as protein spuring therapy after major surgery.

Lancet 1978;2:788-790

38. Heatley V. Lewis MH, Williams RHP. Preoperative intravenous feeding, a controlled trial. Posgrad.Med.J. 1979;55:541-545

39. Thompson BR. Julian BJ, Stremple JF. Perioperative TPN in patients with gastrointestinal cancer. J.Surg.Res. 1981:30:497-500

40. Shizgal HM. Spanier AH, Kunz RS. Effect of parenteral nutrition on body composition in the critically ill patient. Am.J.Surg. 1976:131:156-161

41. Cahill F. Starvation: some biological aspects. In: Kinney JM. Jecjeebhoy KN. Hill GL. Owen OE (eds.). Nutrition and metabolism in patient care. Saunders, Philadelphia. 1988. pp 193-204. 


\section{The relation of preoperative surgical risk parameters with long term survival of patients with gastric and colorectal} cancer

\subsection{Abstract}

Indicators of depletion and surgical risk have prognostic significance with regard to the response to medical or surgical therapy. Several studies suggested after monofactorial analyses a significant association of depletion and other surgical risk indicators with long term survival. It has been questioned, however, whether these significant associations are independent associations. We therefore analysed in a prospective study the effect of parameters commonly ued to assess preoperative depletion on long term survival in 201 consecutive patients admitted for surgical treatment of gastric or colorectal cancer. Stage of disease, preoperative percent weight loss, percent ideal body weight, plasma protein, plasma albumin, plasma pre-albumin concentration and blood loss were significantly correlated with long term survival (Kaplan-Meier, log rank $p<0.05$ ) in both gastric and colorectal cancer.

A Cox regression analysis yielded independent effects for depletion related parameters (ideal weight, albumin, hemoglobine) and blood loss. We conclude that depletion has an adverse effect on long term survival of patients with gastric or colorectal carcinoma, that is independent from the stage of disease.

\subsection{Introduction}

Parameters that indicate depletion are of prognostic significance with regard to the response to medical therapy and risk for postoperative complications. Already in 1936 a markedly increased mortality rate was observed after surgical treatment of chronic peptic ulcer patients who had suffered a more than 20 per cent weight loss'. Furthermore, weight loss and decreased levels of albumin have been associated with increased postoperative morbidity and mortality': (Chapter 3). 
Few studies have addressed the prognostic significance of depletion indicators on long term survival. DeWys et al." found a significantly decreased median survival of colorectal cancer and gastric cancer patients who had experienced more than $10 \%$ weight loss compared to weight stable patients. Lanzotti ${ }^{5}$ found weight loss to be the most important prognostic indicator of survival in patients with inoperable lung cancer. Wiggers ${ }^{6}$ demonstrated significantly decreased survival after surgical treatment of colorectal cancer in patients with serum total protein values under $65 \mathrm{gr} / \mathrm{l}$. Phillips ${ }^{7}$ showed low 'pre-disease' albumin values to be associated with increased mortality rates of cardiovascular disease and cancer in a large population.

It has been questioned, however, whether the effect of depletion on long term survival is an independent effect. The aim of the current study was to analyse prospectively the associations of depletion, stage of disease, and surgical procedure related factors with long term survival after surgical treatment of gastric or colorectal cancer.

\subsection{Patients and methods}

\subsection{Patients}

Two hundred and one consecutive patients (126 males, 75 females) admitted to undergo surgery for newly detected and pathologically confirmed gastric $(n=52)$ or colorectal $(n=149)$ cancer entered this study. Patients aged over 80 years were excluded.

The study was reviewed and approved by the Human Studies Committee of the University Hospital Maastricht and informed consent was obtained from each subject. The study was started in oktober 1983 and lasted until januari 1988.

\subsubsection{Study design}

On admission blood was drawn from all patients to determine hemoglobin, white blood cell count, total lymphocyte count, total protein, albumin, prealbumin, transferrin, electrolyte status, creatinin, urea. Preoperative anthropometric evaluation included determination of weight, weight loss during the previous year, and height. Percent ideal body weights (PIW) and percent weight loss were calculated. Peroperative blood loss was estimated and postoperative complications were scored until hospital discharge. Postoperative complications were categorised as absent, minor (including woundinfection, urinary or pulmonary tract infections) or major complications (including respiratory, renal, hepatic or cardiac failure, intra-abdominal abscess or fistula formation, anastomotic leakage, wounddehiscence. sepsis, diffuse-intravascular-coagula- 
tion-syndrome and mortality).

Part of the patients had participated in a prospective randomised trial investigating the efficacy of perioperative nutritional support to reduce postoperative complications in depleted paticnts. Therefore, the administration of nutritional support was taken into account. The results of perioperative nutritional support on long term survival are reported in chapter 8.

Records of all patients were reviewed to assess survival and cause of death in may 1991, after a follow-up period of at least 42 months. Survival was recorded from the time of surgery until death from any cause.

\subsubsection{Statistical analysis}

Parameters among groups were tested by ANOVA, complication ratios were analysed using Chi-Square analysis. Life table (actuarial) survival analyses for all patients as well as for subgroups were performed using the Kaplan-Meier method". The survival curves of groups of patients were compared using the logrank test ${ }^{16}$.

The combined and independent effects of the predictor variables on survival were analysed using a Cox (proportional hazards) non-parametric multiple regression model" for censored survival data (BMDP2L). This model allows simultaneous estimation of the relative effect on survival of each variable, adjusted for the effects of correlations with the other prognostic variables included in the model. This regression model included all preoperative parameters which appeared to be important in the log-rank analysis $(p<0.05)$, and the depletion parameters. Factors not showing significant independent association with long term survival were removed step by step, provided the removal of a factor did not cause a large shift in the coefficients of the reamining factors. Perioperative nutritional support parameters were always kept in the model to exclude confounding effects. P-values smaller than 0.05 were considered significant.

\subsection{Results}

\section{4.l Patients}

Hundred-and-fifty patients were randomised into three groups. Fifty patients received on average 21 days of perioperative parenteral nutritional support, and 50 patients received 10 days of preoperative enteral nutrition (Chapter $6 \& 8$ ). Preoperative parameters of both groups are listed in table 7.1. The administration of perioperative nutritional support did not affect the complication rate in overall patients groups (chi-square ns, Chapter 6). 
All deaths were G.I. cancer related, except for 3 patients; one died in a traffic accident, one of a primary lung carcinoma, and one patient committed suicide.

Table 7.1: Preoperative characteristics

\begin{tabular}{|l|l|l|l|l|}
\hline & \multicolumn{2}{l|}{$\begin{array}{l}\text { Gastric cancer } \\
\text { n=52 }\end{array}$} & \multicolumn{2}{l|}{$\begin{array}{l}\text { Colorectal cancer } \\
\text { n=149 }\end{array}$} \\
\hline & mean & std & mean & std \\
Total protein $(\mathrm{g} / \mathrm{l})$ & 70 & 8 & 71 & 7 \\
Albumin $(\mathrm{g} / \mathrm{l})$ & 35 & 4 & 36 & 5 \\
Pre-albumin $(\mathrm{g} / \mathrm{l})$ & 0.25 & 0.08 & 0.24 & 0.07 \\
Hemoglobin (mmol/l) & 8.0 & 1.6 & 8.0 & 1.5 \\
Lymphocyte count $\left(/ \mathrm{mm}^{3}\right)$ & 1.90 & 0.83 & 1.92 & 0.62 \\
Age & 64 & 11 & 65 & 9 \\
P.I.W. & 97 & 14 & 101 & 15 \\
P.W.L. & 11 & 16 & 6 & 8 \\
Duration of procedure (hr.min) & 3.20 & 1.33 & 2.55 & 1.15 \\
Peroperative blood loss (ml) & 910 & 980 & 820 & 1080 \\
\hline
\end{tabular}

\subsubsection{Survival}

Overall 5-year survival in the current study was $45 \%$ in the colorectal cancer patients and $40 \%$ in the gastric cancer group. This difference was not significant.

Figure 7.1 shows the overall survival curves for patients with gastric and colorectal cancer. Figure 7.2 shows the survival curves for patients with different tumor stages in gastric and colorectal cancer patients. We found a $80 \%$ 5-year survival of gastric cancer and 70\% 5-year survival in colorectal cancer in stage 1 and 11 , a 45\% 5-year survival in stage 1 II both gastric and colorectal cancer and no 5-year survival in stage IV gastric and colorectal cancer. 


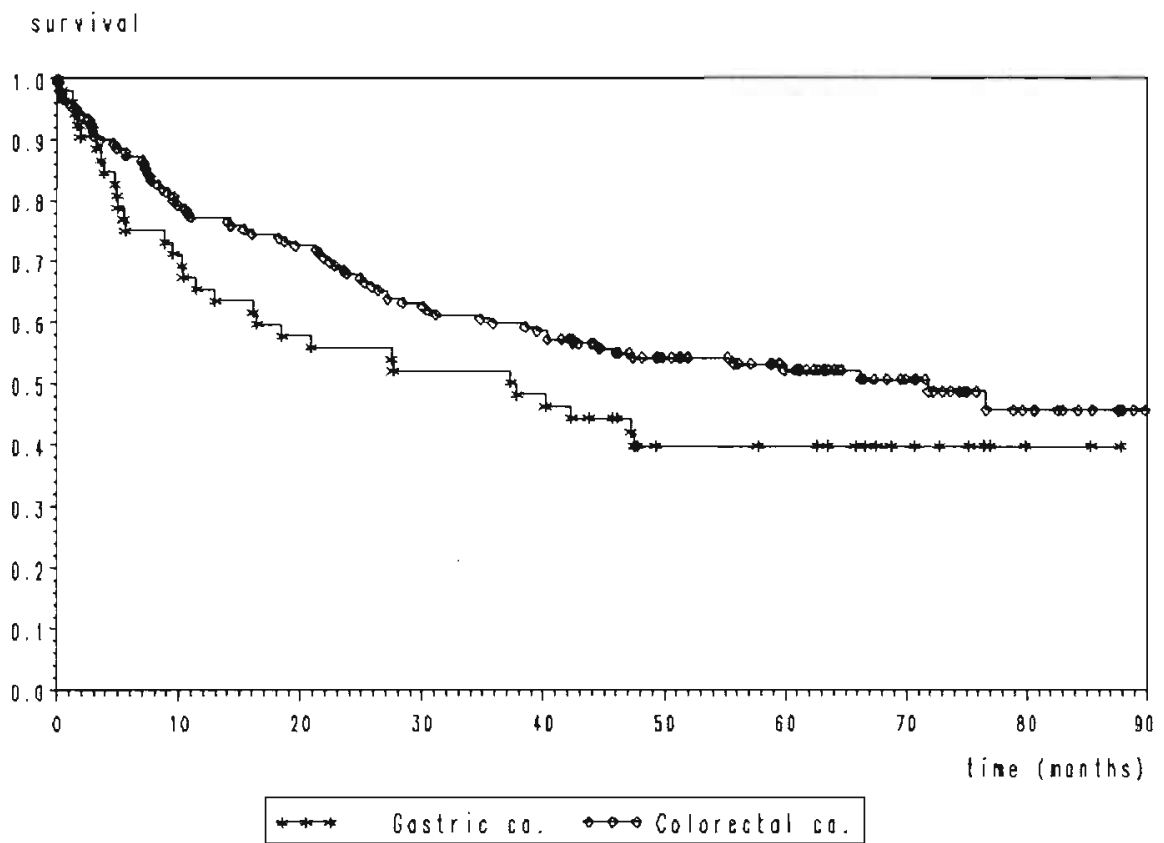

Figure 7.1: Overall survival for gastric and colorectal cancer patients as estimated with the Kaplan-Meier method. (log rank ns)

The results of comparisons of the survival curves for several individual parameters with given cut-off points are summarised in table 7.2. Significant differences in survival curves for groups of patients defined by tumorstage (stage I to IV), albumin ( $<, \geq 35 \mathrm{gr} / \mathrm{l})$, total protein $(<, \geq 60 \mathrm{gr} / \mathrm{l})$, pre-albumin $(<, \geq 0.20 \mathrm{~g} / \mathrm{l})$, weight loss $(<, \geq 10 \%)$, percent ideal weight $(\leq,>95 \%)$, and blood loss $(<500,500-1000,1000-1500,>1500)$ were observed. 
safiral

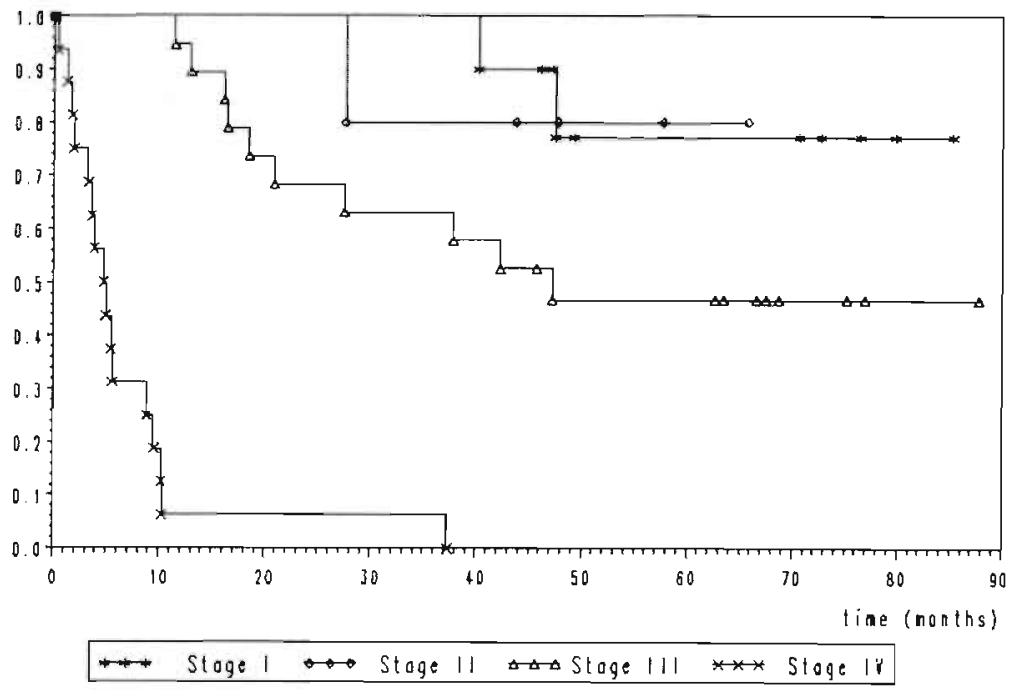

sutrivol

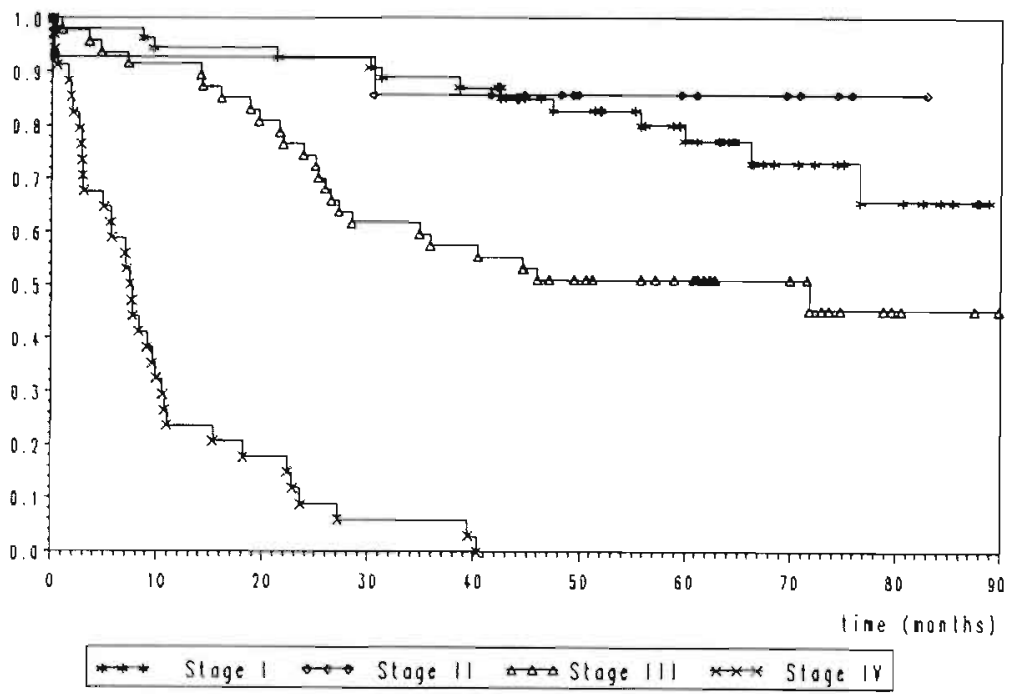

Figure 7.2: Orerall survival for separate stages of gastric (top) and colorectal cancer (bottom) as estimated with the Kaplan-Meier method. Stage III (log rank $p<0.01)$ and stage IV (log rank $p<0.0001)$ differ significantly from stage I and II. 
Figure 7.3 shows the influence of PIW above and below $95 \%$ on survival in GI cancer patients. Median survival is 48 months in gastric cancer patients and 76 months in colorectal cancer patients with a PIW above $95 \%$. Median survival is 13 months in gastric cancer patients and 42 months in colorectal cancer patients in the group below $95 \%$ of ideal weight.

Figure 7.4 shows the influence of albumin above and below $35 \mathrm{~g} / \mathrm{l}$ on survival in GI cancer patients. Median survival was over 90 months in patients with an albumin above $35 \mathrm{~g} / 1$ both in gastric and colorectal cancer and 20 months in gastric cancer patients and 36 months in the colorectal cancer patients in the group below $35 \mathrm{~g} / \mathrm{l}$.

Figure 7.5 shows the influence of blood loss in GI cancer patients. The patients with higher amounts blood loss showed decreasing survival rates. 


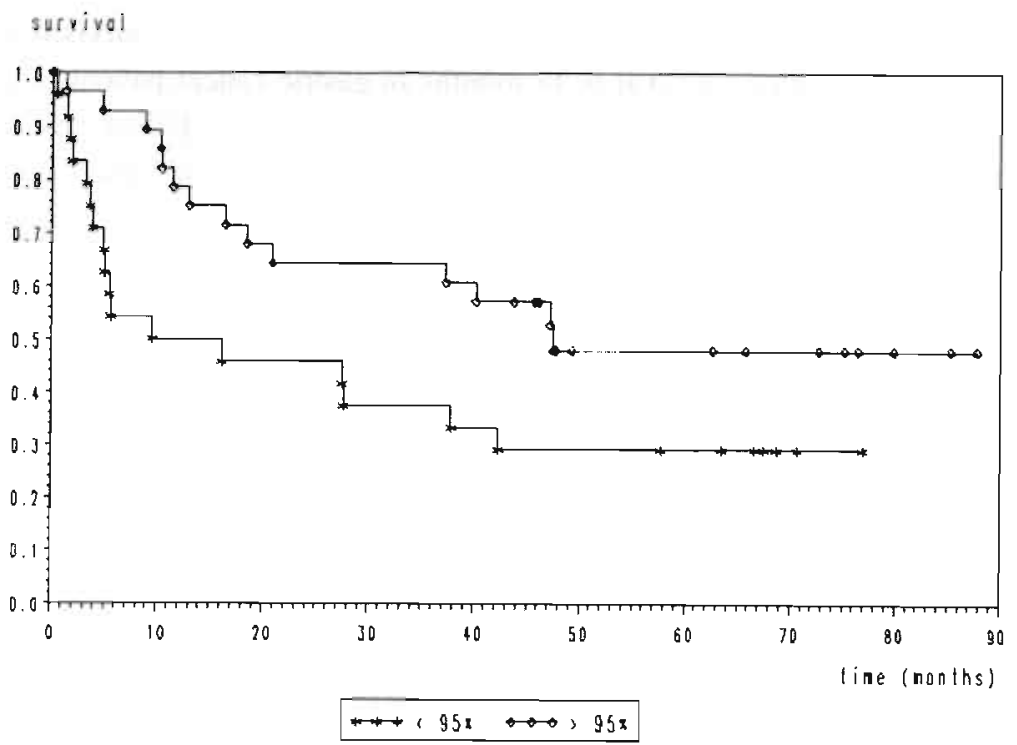

survival

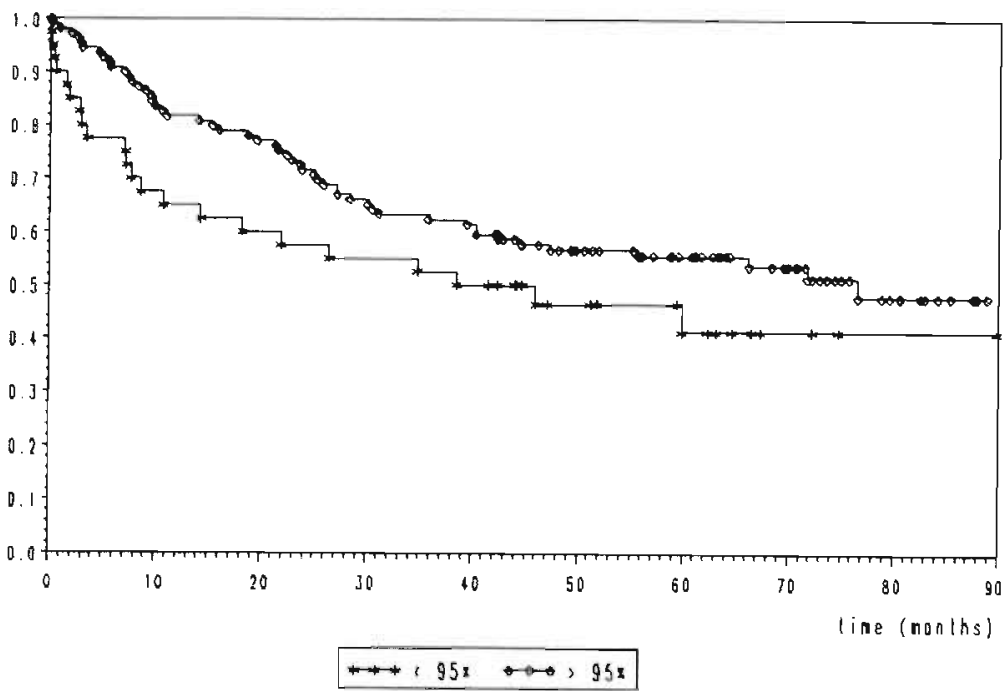

Figure 7.3: The association of ideal body weight ( $\leq>>95 \%$ ) with survival of gastric (top) and colorectal cancer patients (bottom) in all stages of disease. (log rank $p<0.05$, resp Wilcoxon $p<0.05$ ) 

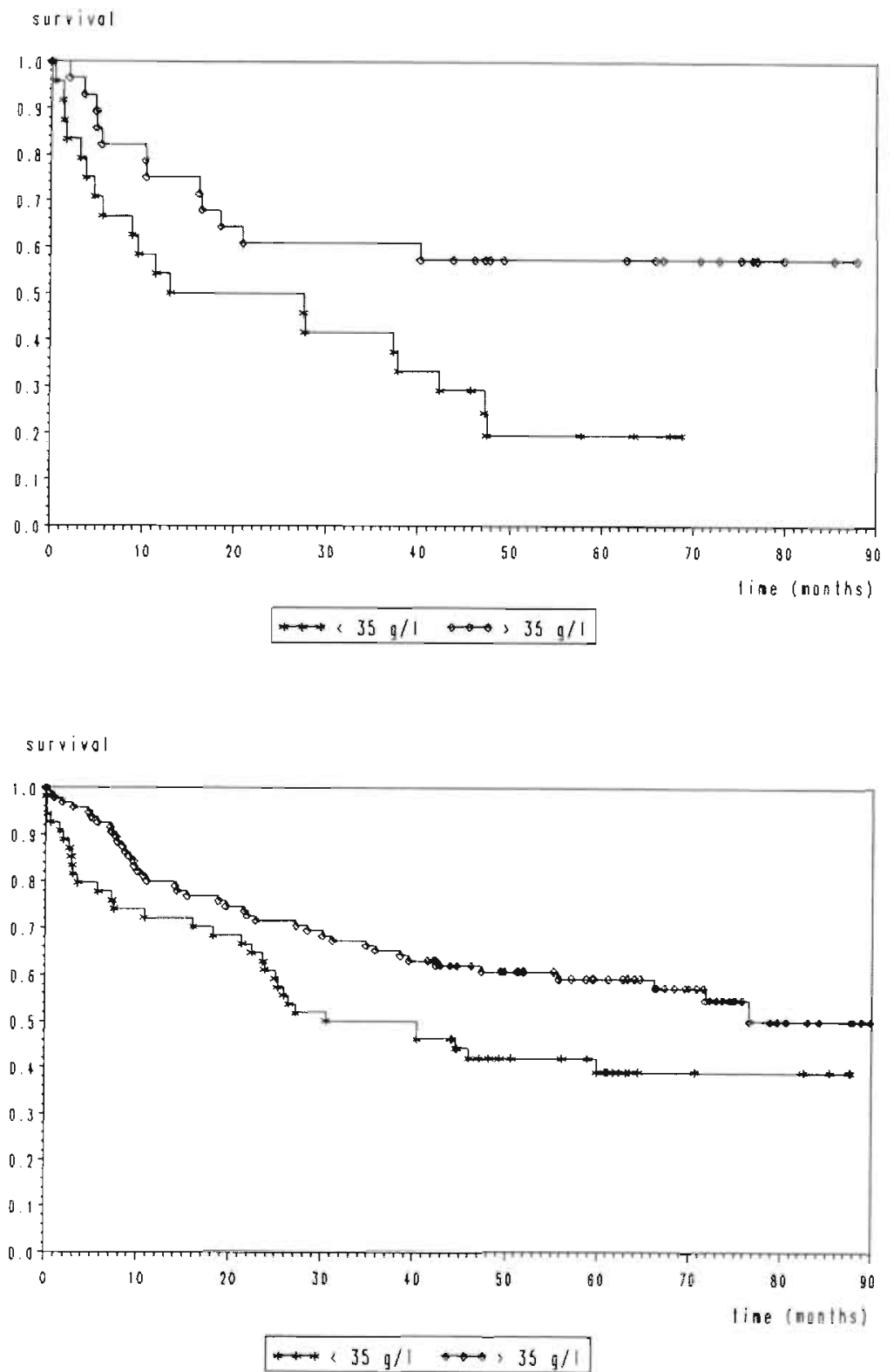

Figure 7.4: The association of albumin above and below $35 \mathrm{~g} / \mathrm{l}$ with survival of gastric (top) and colorectal cancer patients (botrom) in all stages of disease. (log rank $p<0.01$, resp. $p<0.025$ ) 


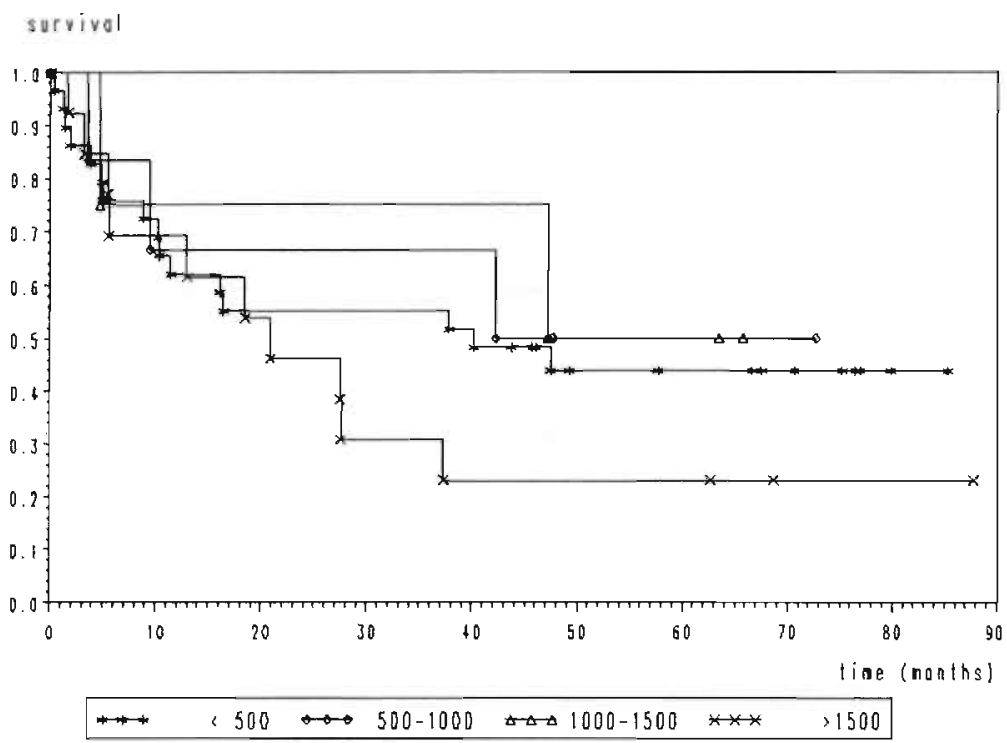

survivol

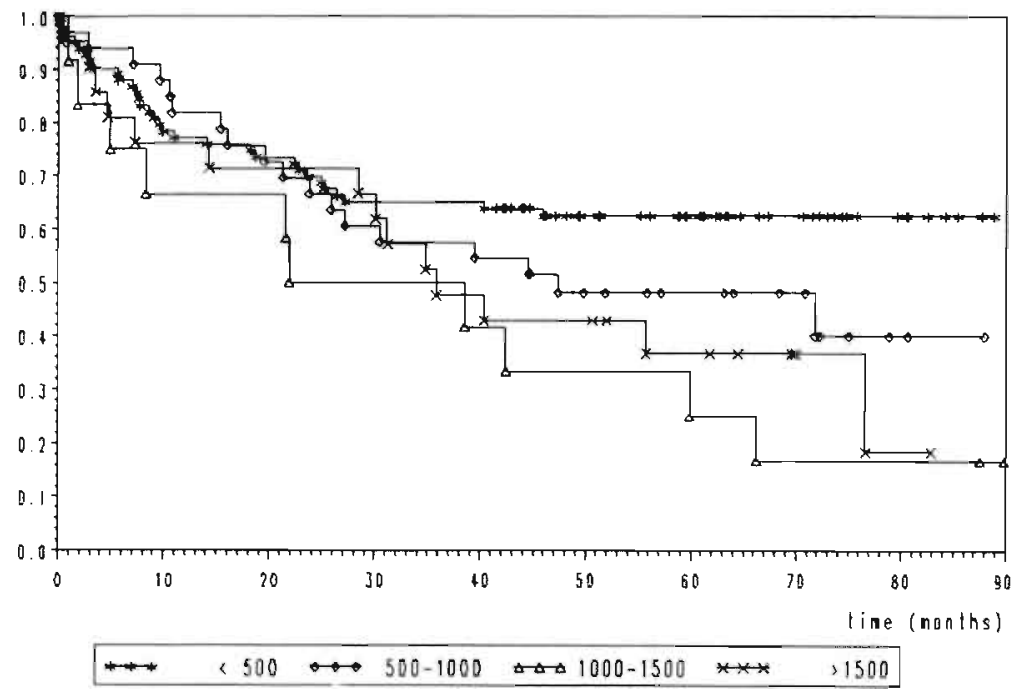

Figure 7.5: The association of peroperative hlood loss $1<500,500-1000,1000$ $1500,>1500 \mathrm{ml}$ ) with the survival of gastric (top) and colorectal cancer patients (bottom) in all slages of disease. (log rank $n s$, resp. $p<0.01)$ 
Table 7.2: Results of log-rank tests for comparison of survival curves.

\begin{tabular}{|c|c|c|c|}
\hline & \multirow{2}{*}{$\begin{array}{l}\text { Group definition } \\
\text { cut-off points }\end{array}$} & \multicolumn{2}{|c|}{ Log rank test p-value } \\
\hline & & gastric & colorecta \\
\hline Tumor stage & stage I-IV & 0.0001 & 0.0001 \\
\hline Albumin & $35 \mathrm{~g} / \mathrm{l}$ & 0.01 & 0.05 \\
\hline Total protein & $60 \mathrm{~g} / \mathrm{l}$ & 0.05 & 0.0 .5 \\
\hline Pre-albumin & 0.20 & 0.05 & $0.0(0) 1$ \\
\hline P.W.L. & $10 \%$ & 0.05 & $0.0(0) 0.5$ \\
\hline P.I.W. & $95 \%$ & 0.05 & 0.0 .5 \\
\hline Hemoglobin & $6 \mathrm{mmol} / \mathrm{l}$ & $\mathrm{ns}$ & 0.01 \\
\hline Lymphocyte count & & ns & ns \\
\hline Peroperative blood & $<500,500-1000$ & ns & 0.01 \\
\hline loss & $1000-1500,>1500 \mathrm{ml}$ & & \\
\hline Duration of operation & & ns & ns \\
\hline Postoperative complications & no. minor, major & 0.01 & 0.01 \\
\hline Nutritional support & no. TPN, TEN & ns & ns \\
\hline Age & & ns & ns \\
\hline Sexe & Male, Female & ns & IIS \\
\hline
\end{tabular}

For each significant different parameter the group defining cut-off points are given.

\subsubsection{Cox-regression}

The parameters yielding a significant result in the log-rank test summarised in table 7.2, as well as the indicators of nutritional support, tumor localisation and depletion parameters, were subsequently considered as explanatory variables in a Cox-regression model. Stepwise reduction of factors, deleting the least significant factor, resulted in a list of factors with a significant association with survival. Table 7.3 shows the result of this analysis. As expected, the most important factor was tumorstage. Comparison of stage II, III and IV with stage I showed an increasing risk of dying in higher stages. Stage II was not associated with a significantly increased risk of dying compared to stage I, whereas stage III and stage IV were. The analysis furthermore showed that at any point in time the risk of dying in stage IV was about 53 times (exp(coeff)) that of stage I. The occurrence of postoperative complications did not show significant effects on long term survival. Futhermore, PIW and albumin were significantly associated with long term survival. The proportional risk of dying is reduced by two/thirds in patients with a PIW above $95 \%$ compared with patients with a PIW below 
$95 \%$. The proportional risk of dying is reduced with 0.92 with every increasing unit of albumin: a patient with a plasma albumin concentration of $40 \mathrm{~g} / \mathrm{l}$ has a reduced hazard of dying amounting to $(0.92)^{5}=0.66$ compared to a patient with an albumin value of $35 \mathrm{~g} /$.

The administration of perioperative nutrition was included in the model as a possible confounder. There was no improvement of long term survival by routine perioperative feeding on long term survival in the total population, nor was there an adverse effect on long term survival by perioperative nutrition.

Preoperative hemoglobin levels were also significantly associated with long tern survival (Figure 7.6).

Table 7.3: Stepwise multivariate analysis

\begin{tabular}{|l|l|l|l|}
\hline & Coeff/se & Exp(coeff) & p \\
\hline Stage II & - & - & ns \\
Stage III & 2.1788 & 2.9793 & 0.025 \\
Stage IV & 7.0863 & $52.85 I I$ & 0.0001 \\
Preop. nutrit. support & - & - & ns \\
TPN/TEN & - & - & ns \\
Tumor localisation & - & - & ns \\
Hemoglobin & 2.6030 & 1.2789 & 0.01 \\
Albumin & -2.2666 & 0.9218 & 0.025 \\
PIW (<,> 95\%) & -1.7154 & 0.6383 & 0.05 \\
Blood loss & 2.4175 & 1.3030 & 0.01 \\
\hline
\end{tabular}

The table lists in the first column estimated coefficient/standard error (coeffise) or the z-statistics. The second column of data lists the relative risk estimate (equal to exp(coeff)), while the last column of the table lists the p-lalue of the likelihood ratio test for significance of the factor (afier correction for the other factors). 
surpirol

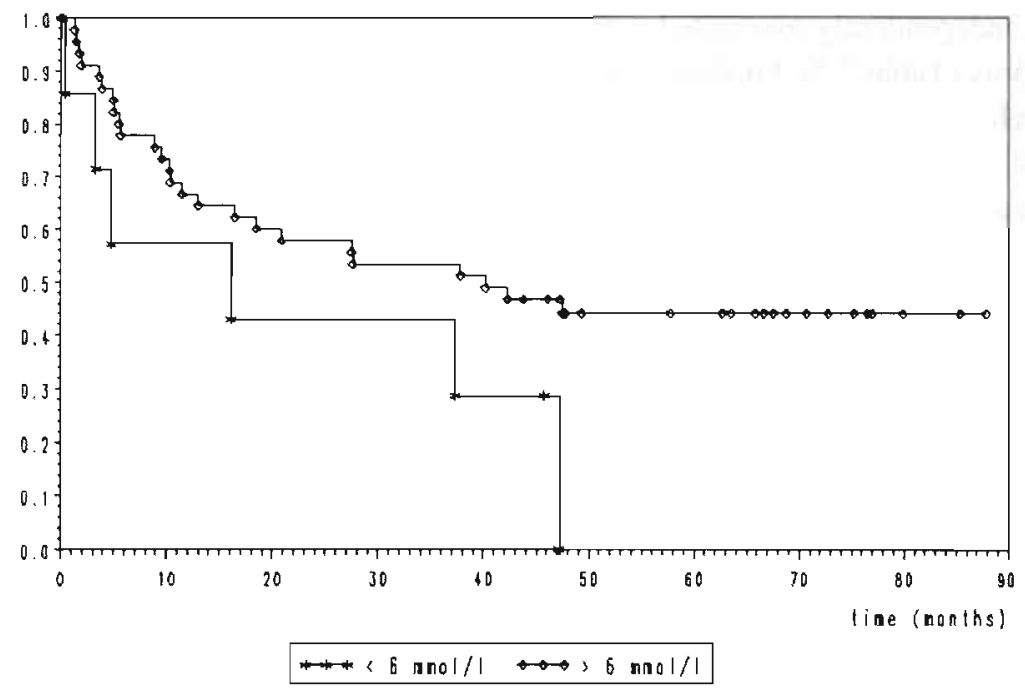

sarvivol

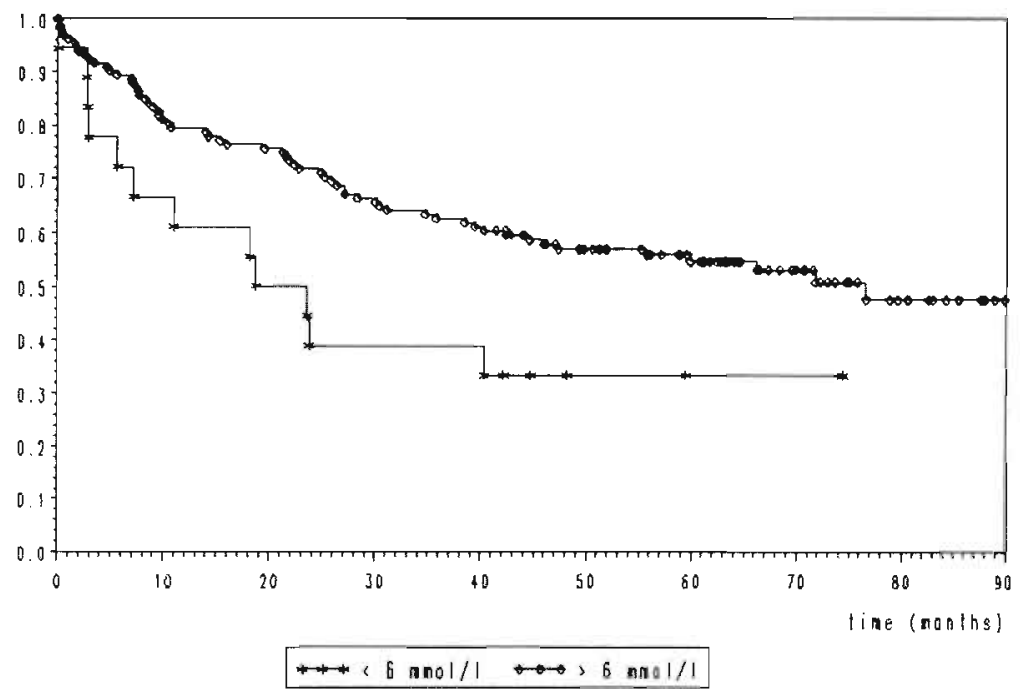

Figure 7.6: The association of preoperative hemoglobin levels $(<, \geq 6$ mmol/l) with the survival of gastric (top) and colorectal cancer patients (bottom) in all stages of disease. (log rank ns, resp. log rank $p<0.01)$ 
However, not a low hemoglobin, but the presence of high hemoglobin levels was independently associated with a decreased survival in the Cox-regression analysis (Table 7.3). Further analysis of this unexpected effect showed a strong correlation of preoperative hemoglobin levels and albumin levels with tumor stage, specifically with stage IV. It appears that the high coefficient for the stage IV variable 'overshoots' the risk ratio for low albumin, high hemoglobin patients. The presence of low albumin $(<35 \mathrm{~g} / \mathrm{l})$ and low hemoglobin $(<6$ $\mathrm{mmol} / \mathrm{l}$ ) was observed in 17 patients, with 12 patients in stage IV (Figure 7.7). The high additional negative influence of stage IV in this subgroup of patients $(\mathrm{Hb}<6, \mathrm{Alb}<35)$ pulls the coefficient of hemoglobin to a positive value. The lower rectangle in each quadrant shows the relative risk $(\log R R)$ of hemoglobin and albumin in each subgroup, the upper polygonal the contribution of the relative risk $(\log R R)$ of stage I, II, III and IV, with the widths of the bars relative to the numbers of patients in each stage. The total area represents the mean log RR for the quadrant. The coefficient, after taking into account the stage of disease, shows then the highest hazard of dying was observed in the group with preoperative hemoglobin levels $<6 \mathrm{mmol} / \mathrm{l}$ and albumin levels $<35 \mathrm{~g} / \mathrm{l}$, mainly due to the large contribution of stage IV patients. This is shown also in figure 7.8 where hemoglobin levels, plasma albumin values and survival are plotted for each separate stage. Low hemoglobin levels and low albumin values have shorter survival then high hemoglobin levels and albumin values, but nearly all patients are in stage IV of disease. The same is illustrated in figure 7.9 where a three dimensional regression surface is drawn for the data shown in figure 7.8. Low hemoglobin and low albumin values show the shortest survival. 


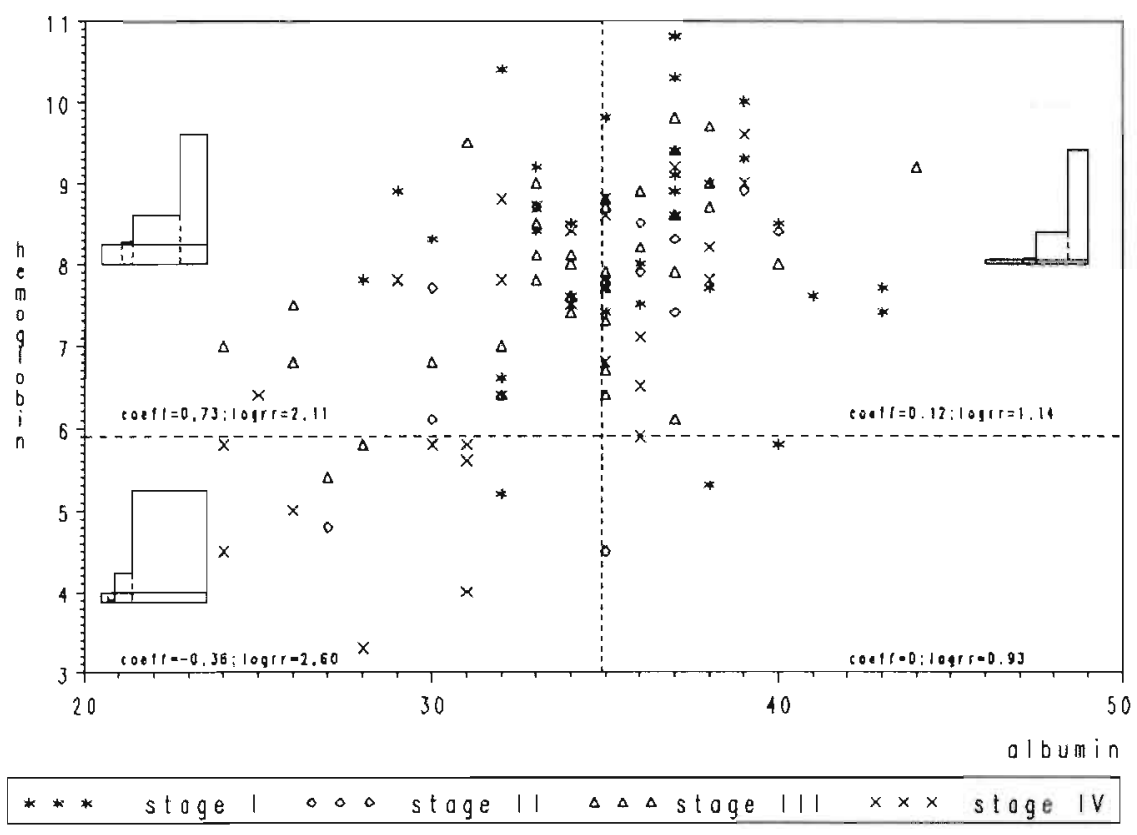

Figure 7.7: The relative contributions to the $\log R R$ (relative risk) in each quadrant of hemoglobin levels, plasma albumin values and stage (see text for explanation). 


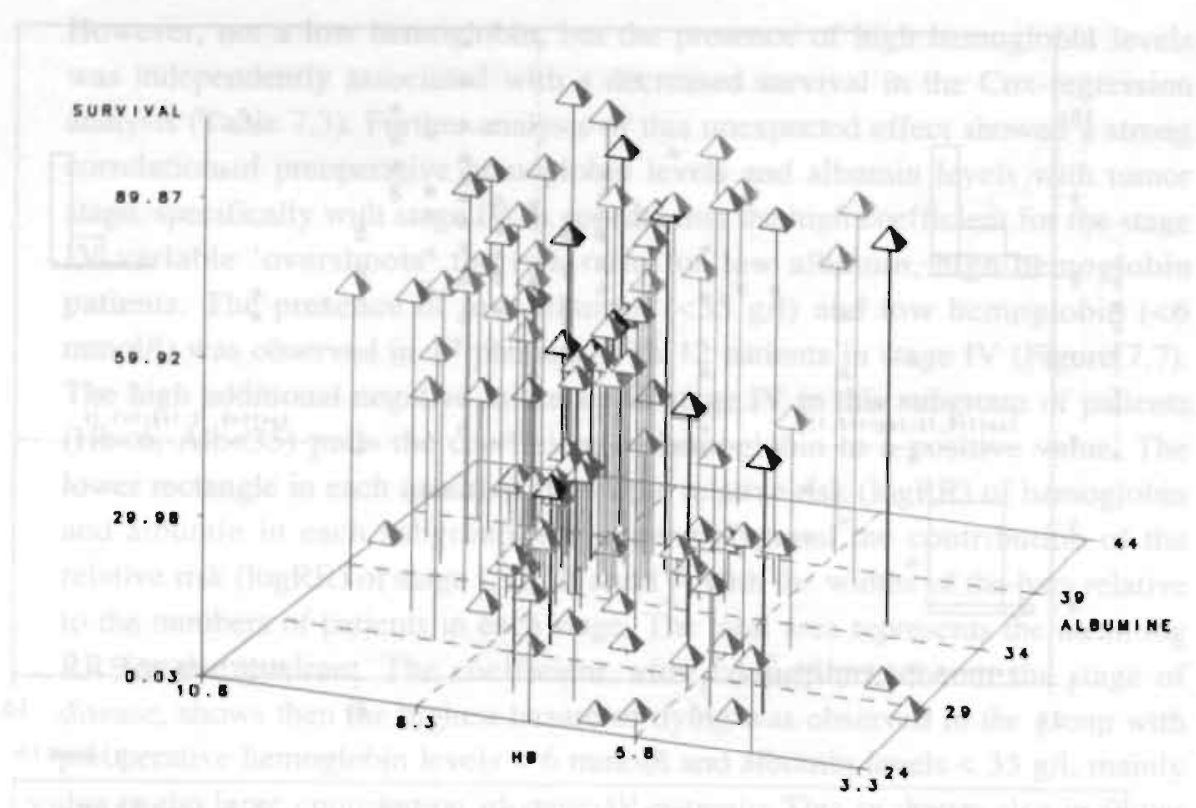

Figure 7.8: $3 D$ scatter plot of survival for stage. plasma albumin values and hemoglobin levels. Clearly is shown that low plasma albumin values, low hemoglobin levels, and especially the combination of both have the shortest survival as can be expected from clinical experience. 


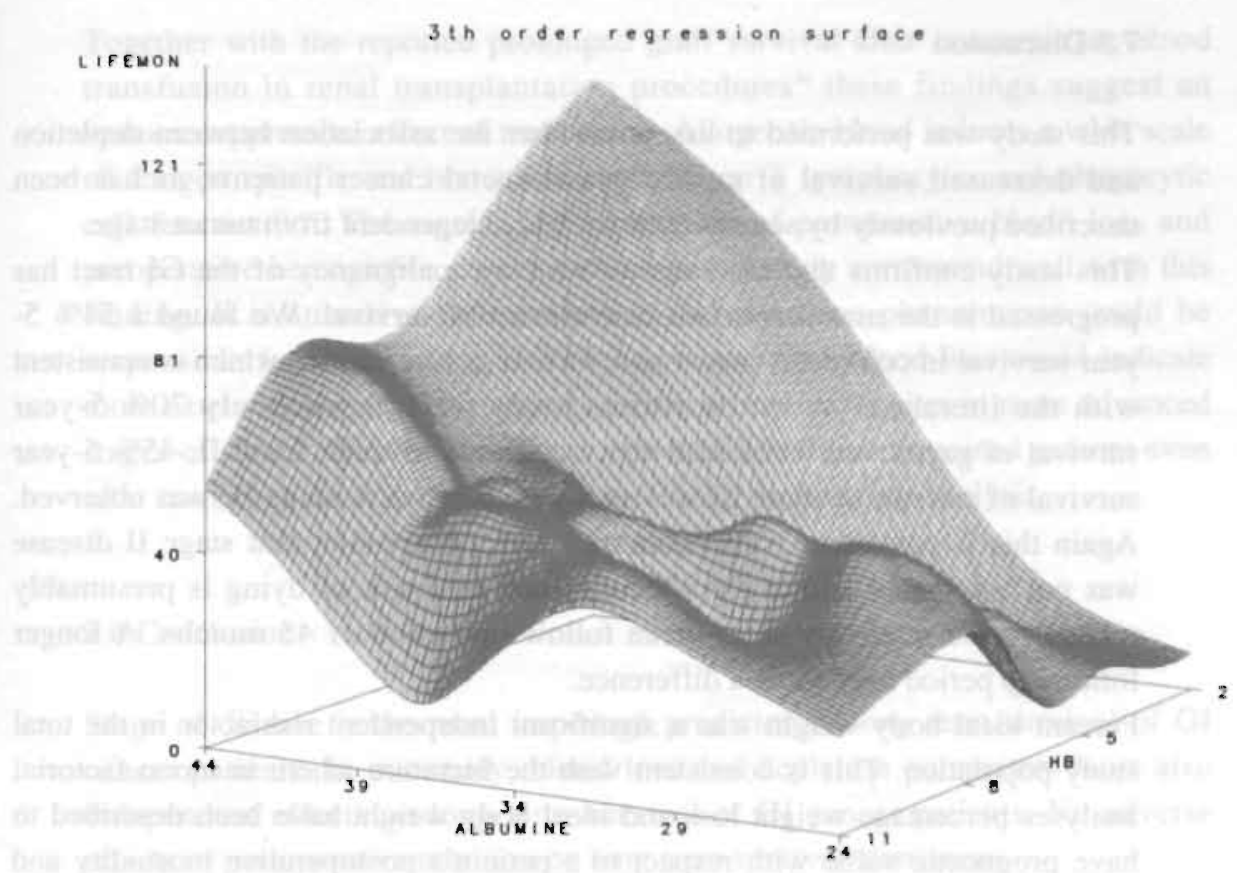

Figure 7.9: The same data analysis of figure 7.8 is shown in this third order regression surface drawn though the points of figure 7.8 . 


\subsection{Discussion}

This study was performed to assess whether the association between depletion and decreased survival of gastric or colorectal cancer patients, as has been described previously by several authors" ", is independent from tumor stage.

This study confirms that the stage to which a malignancy of the GI tract has progressed is the most important determinant of survival. We found a 54\% 5year survival in colorectal cancer and $40 \%$ in gastric cancer, which is consistent with the literature ${ }^{12-14}$. In the current study $80 \%$, respectively $70 \% 5$-year survival of gastric and colorectal cancer patients in stage I and II, 45\% 5-year survival of patients in stage III and no 5-year survival in stage IV was observed. Again this is consistent with literature ${ }^{15}$. Our observation that stage II disease was not associated with a significantly increased risk of dying is presumably related to the relatively short mean follow up period of 45 months. A longer follow-up period may show a difference.

Percent ideal body weight was a significant independent riskfactor in the total study population. This is consistent with the literature where in mono factorial analyses percentage weight loss and ideal body weight have been described to have prognostic value with respect to a patient's postoperative morbidity and mortality ${ }^{16-19}$, and long term survival ${ }^{4,5,7.20}$. Weight loss is not a significant predictor in the Cox regression analysis because of the high correlation with ideal body weight. Weight loss is a common feature of cancer, negatively influencing treatment results and survival. Weight loss, and eventually cachexia, may be caused by several mechanisms ${ }^{22-25}$. Although it has long been thought that the association of weight loss and low plasma albumin levels with long term survival reflects progressing tumor stages, we now demonstrate this phenomenon to be independent from tumor stage. It is possible that weight loss and cachexia are epiphenomena of the metabolic relation between host and tumor.

In addition, low plasma albumin values showed in the current study a significant independent association with decreased survival. Most likely hypoalbuminaemia does not reflect depletion, but rather the metabolic response elicited by the presence of a tumor, in which plasma albumin behaves as a negative (acute) phase protein"1.

In the Cox-regression analysis blood loss was significantly correlated with long term survival of these patients. Blood transfusion ${ }^{3 .-20}$ has been claimed to correlate significantly with long term survival. An association between perioperative blood transfusions and decreased long term survival of colorectal cancer patients ${ }^{20: 87,29030}$ as well as breast cancer patients ${ }^{28}$, has been reported for some time, other studies failed to prove a relationship between transfusion and survival or recurrence rate of colonic cancer $^{3+-3:}$ or breast cancer ${ }^{\text {is }}$ patients. 
Together with the reported prolonged graft survival after concomittant blood transfusion in renal transplantation procedure ${ }^{34}$ these findings suggest an immunosuppressive effect of transfusion. Allogeneic blood induces a wide scale of antigen specific and non-specific effects on $T$ lymphocytes and phagocytic cell function ${ }^{35+4}$. The significant association of peroperative blood loss and preoperative hemoglobin concentrations in our study correspond well with this finding. It is attractive to hypothesise that the same phenomenon could be responsible for this finding. Otherwise peroperative blood loss could indicate more extensive surgical procedures at difficult attainable sites in more advanced stages of cancer. But the significant effect of blood loss remained present even after correction for some of these factors in the multivariate analysis.

\subsection{Conclusion}

Stage of disease is the most important predictor of long term survival of GI cancer patients. In our study, blood loss and depletion parameters have also independent effects on long term survival of Gl cancer patients. No adverse effects of perioperative nutrition on long term survival were seen.

The impaired nutritional status possibly reflects a quality of the impact the tumor has on the host, resulting in decreased long term survival. In the future it is of interest to investigate whether manipulation of this metabolic relationship, e.g. by nutritional intervention, results in improved long term survival. Further trials investigating the impact of nutritional intervention on long term survival are therefore warranted.

\section{References}

1. Studley HO. Percentage of weight loss: A basic indicator of surgicat risk in patients with chronic peptic ulcer. J.A.M.A. $1336 ; 106: 458-460$

2. Rhoads JE, Alexander CE. Nutritional problems of surgituil patients Ann.N.Y.Acad.Sci. 1955:63:265-275

3. Hickman DM. Miller RA. Rombeau JL. Twomey PL, Frey CF. Senum albumin and body weight as predictors of postoperative course in colorectal cancer. J.P.E.N. 1980:4:314-316

4. DeWys WD, Begg C. Lavin PT et al. Prognostic effect of weight loss prior to chemotherapy in cancer patients. Am.J.Med. 1980;69:491-497

5. Lanzori VJ, Thomas OR, Boyle LE, Smith TL. Getan E.A. Samue1s ML. Survival with inoperable lung cancitr.

Cancer 1977:39:303-313 


\section{Chapter 7}

6. Wiggers T, Arens JW, Volovics A. Regression analysis of prognostic faciors in colorectal cancer after curative resections.

Dis. Colon Rectum 1988:31:33-41

7. Phillips A. Shaper AG, Whincup PH. Association between serum albumin and mortality from cardiovaseular disease, cancer, and other causes.

The Lancet 1989:II:1434-1436

8. Association of life insurance medical directors: Medico-actuarial mortality investigations. Ass.Life Ins.Med. Dir, and Actuarial Soc.Am. 1912:vol.1

9. Kaplan EL, Meier P. Nonparametric estimation from incomplete observations.

J.Am.Statist Ass. 1958:53:457-481

10. Mantel N. Evaluation of survival data and two new rank order statistics arising in its consideration. Cancer Chemotherapy Reports 1966;50:163-170

11. Cox DR. Regression models and life tables (with discussion).

J.R.Statist.Soc.B. 1972;34:187-220

12. Dukes CE. Histlogical grading of reclal cancer

Proc.R.Soc. Med. 1937:30:371-376

13. Jackson BR. Contempory management of rectal cancer. An overview. Cancer 1977:40:2365-2374

14. Nolthenius HW. Manual of oncology. Urban and Schwartzenberg. Baltimore, Munich 1981.

15. Woxd DA. Robbins GF. Zippin C. Lum D. Stearns M. Staging of cancer of the colon and cancer of the reclum.

Cancer 1979:43:961-966

16. Klidjian AM, Foster KJ. Kammerling KM. Cooper A. Karan SJ. Relation of antropometric and dynamometric variables to serious postoperative complications.

Brit.Med.J. 1980:281:899-901

17. Collins JP, McCarthy ID. Hill GL. Awswment of protein nutrition in surgieal patients: the value of antropomstrics.

Am.J.Clin.Nutr. 1979:32:1527-1530

18. De la Hunt. McDonald PJ. Karran SJ. Antropometric nutritional assessment is of value in colorectal paricuts.

Dis.Culon Rectum 1984:27:296-298

19. Windsor JA. Hill GL. W. ight loss with physiologic impairment. A basic indicator of surgical risk, Ann.Sug. 1988:207:290-293

20. Costa G. Lane W. Vincent R. Weight loss and cachexia in lung cancer. Nurrition and cancer 1980;2:98-103

21. liditurial. Indicators of surgical risk. The Lancet 1986:1:1422-1443

22. Hinswll DT, Davies JWL. Burns HJG. The relationship between resting energy expenditure and weigh loss in berigul and malignant disease.

Ann. Surg (1) \&: $2013: 240-245$ 
23. Bozetti F, Fagnoni AM. Del Veccio M. Excessive caloric expenditure as a course of malnutrition in patients with cancer.

Surg.Gynec.Obstet. 1980:150:229-234

24. Hansell DT. Davies JWL. Bums HJG. The cftects on resting energy expenditure of different tumor types. Cancer 1986;58:1739-1744

25.

Fredrix EWHM, Socters PB. Wouters EFM. Deerenberg IM, von Meyenfeldi MF, Saris WHM. Effeci of different tumor types on resting energy expenditure.

Cancer Res. 1991;51:6128-6141

Voont PJ, Velde vd CJH. Brand A, et al. Perioperative blood transfusion and cancer prognosis. Different effects of blood transfusion on prognosis of colon and breast cancer patients.

Cancer 1987:836:836-843

Foster RS, Costanza MC. Foster JC. MC Wanner, Foster CB. Adverse selationship berween blood transfusions and survival after colectomy for colon cancer.

Cancer 1985:55:1195-1201

28. Tarter Pl, Burrows L. Papatestas AE. Lesnick G, Aufses AH. Perioperative blood transfusion has prognostic signilicance for breast cancer.

Surgery 1985:97:225-229

29. Blumberg N, Agarwal MM. Chuang C. Relation between recurtence of cancer of the colon and blood transfusion.

Br.Med.J. 1985:291): 1037.1039

30. Parrot NR, Lennard TWJ, Taylor RMR. Proud G. Shenton BK. Johnston IDA. Effect of perioperative blood triunsfusion on recurrence of colorectal cancer.

Br.J.Surg. 1986:73:970-973

31. Francis DMA. Judson RT. Blood transfusion and recurtence of cancer of the colon and rusum. Br.J.Surg. 1987:74:26-30

32. Vente JP, Wiggers Th. Weidema WF. Jeekel J. Obertop H. Perioperative blood Iransfusions in colorectal cancer.

Eur.J.Surg.Oncol. 1989:15c:371-374

33. Nathanson SD. Tilley BC. Schulız L. Smith RF. Perioperative allogenic blood transfusions: Survival in patients with resected carcinomas of the colon and rectum.

Arch.Surg. 1985; 120:734-738

34. Opelz G. Sengar DDS. Mickey MR, Til asaki PI. Effect of blood transfusions on subsequent kidney transplants.

Transplanr Proc. 1973-5:25:-259

35. Smith MD. Williams JD. Coles GA, Salaman JR. The effect of blood transfusion on T suppressor cefls in renal dialysis patients.

Transplanı Proc. 1981:13:181-183

36. Marquet RL. Heyslek GA. Niessen GJCM, Jeekel J. Induction of suppressor cells by a single bloml transfusion in rats.

Transplant Proc. 1982;14:397-399

37. Kerman RH. Buren van CT. Payne W. et al. Influence of blood transfusions on immune responsiteness Transplant Proc. 1982:14:335-337 
38. Singal DP, Joseph S, Szewcruk MR. Possible mechanism of the bencficial effect of pre-transplant blood transfusion on renal allograft survival in man.

Transplant Proc. 1982:14:316-318

39. Keown PA, Descamps B. Improved renal allograft survival after blood transfusion: A non-specific erythrocyte mediated immunoregulatory process?

Lancet 1979;: :20-22

40. Linden vd CJ. Buurman WA, Vegt PA. In: Opelz G, Persijn GG, ed. Blood rransfusion in renal transplantation.

Transplant Proc. 1981:13:1556-1558 
Chapter 8

\section{Influence of perioperative nutritional intervention on long term survival of patients with advanced colorectal cancer}

\subsection{Abstract}

Indicators of depletion have prognostic value with regard to the incidence of postoperative complications and to long term survival. The effects of perioperative nutrition on tumor growth and long term survival of GI tract cancer patients have not been documented.

In this prospective randomised controlled study the effect of perioperative nutritional intervention on long term survival is investigated in 149 consecutive patients (62 females, 87 males) admitted for surgical treatment of newly detected colorectal cancer. Depleted patients in stage IV colorectal cancer survived significantly shorter than non-depleted patients. Depleted stage IV colorectal cancer patients receiving perioperative nutritional support survived significantly longer than depleted patients who received no nutritional support $(\log$ rank $\mathrm{p}<0.05)$. No differences were observed in stage I, II and III. No differences among groups were observed with regard to tumorlocalisation, tumorload, age, sex and preoperative depletion indicators.

We therefore conclude that perioperative nutritional support has a beneficial effect on survival of stage IV colorectal cancer patients showing signs of depletion.

\subsection{Introduction}

Nutritional status parameters have prognostic value with regard to the incidence of postoperative complications and to long term survival's. Perioperative nutritional support in depleted cancer patients has resulted in improved postoperative recovery ${ }^{t-8}$. However, a potential hazard of nutritional support of a cancer patient is enhanced tumor growth. Increased tumor growth and fat storage have been demonstrated in parenterally fed tumor bearing rats". The response to nutritional support seems to be dependent on tumor load: repletion of serum protein levels and body weight, and reversed anergy have been 
reported to occur in tumor bearing rats with a tumor load of less than $5 \%$, while a tumor Joad of more than $25 \%$ inhibited repletion of these parameters ${ }^{10.1}$.

No data are available conceming the effect of perioperative nutrition on long term survival of depleted cancer patients. We therefore performed a prospective study to investigate these effects on long term survival of colorectal cancer patients.

\subsection{Patients and methods}

\subsubsection{Patients}

The effect of perioperative nutritional support was prospectively studied in 149 consecutive patients (62 females, 87 males) admitted to undergo surgery for newly detected colorectal cancer between oktober 1983 until january 1988. Patients aged over 80 years were excluded.

\subsubsection{Study design}

Because it was considered ethically unjustified to subject patients having a normal percentage ideal body weight (PIW), plasma albumin (Alb) and total lymphocyte count (TLC) to nutritional intervention, these patients were excluded from randomisation. In 1985 we computed an index ${ }^{12}$ consisting of these parameters which could distinguish patients that were on clinical grounds judged to be nutritionally depleted, from a healthy control group by using the next formula:

$(0.14 \times \mathrm{Alb}(\mathrm{g} / \mathrm{l}))+(0.03 \times \mathrm{PIW}(\%))+\left(0.73 \times \mathrm{TLC}\left(10^{4} / \mathrm{mm}^{3}\right)-8.90\right.$

In the current study all cancer patients who had an index below the mean of the healthy reference group (1.31) were randomised. Thirty-nine (26 males, 13 females) had an index value above 1.31 and were therefore excluded from randomisation. They served as non-depleted control group (ND). Of the remaining 110 patients (49 males. 61 females) with a value below the cut-off point, 36 were randomised to receive T.P.N., 37 enteral nutrition (T.E.N.), while 37 served as depleted controls (D).

\subsubsection{Data collection}

Blood was sampled preoperatively from all patients to determine hemoglobin, WBC, TLC, total protein, albumin, and pre-albumin. Preoperative anthropometric evaluation included determination of weight. height, weight loss during the preceeding year, and percent weight loss (PWL). PIW was calculated 
using the Metropolitan Life tables ${ }^{13}$.

Peroperative blood loss was estimated. Postoperative complications, scored until hospital discharge, were categorised as absent, minor (including woundinfection, urinary or pulmonary tract infections) or major (including respiratory, renal, hepatic or cardiac failure, intra-abdominal abscess or fistula formation, anastomotic leakage, wounddehiscence, sepsis, diffuse intravascular coagulation-syndrome, and mortality).

Records of all patients were reviewed to assess survival and cause of death in may 1991, after follow-up period of at least 42 months. All deaths were cancer related, except for 3 patients; one died in a traffic accident (stage III, enteral group), one of a primary lung carcinoma (stage III, depleted control group), and one patient committed suicide (stage I, non-depleted group).

\subsubsection{Nutritional support}

As preoperative nutritional support patients received at least $150 \%$ of their basal energy expenditure (BEE) as calories, calculated with the Harris-Benedict formula ${ }^{14}$, during at least 10 days. Patients in both control groups were operated without delay. Postoperative parenteral nutrition was continued in the T.P.N. group until patients were able to take $120 \%$ BEE orally.

T.P.N. solutions were prepared in the hospital pharmacy according to current standards. Basis solutions contained 7 gr N per liter (Synthamin $14^{\mathrm{k}}$ ), $25 \%$ glucose per liter. Intravenous lipid emulsions were administered at least 3 times weekly $\left(500 \mathrm{ml}\right.$ Intralipid ${ }^{R} 20 \%$ ). Vitamins $\left(M V I^{R}\right)$ and trace metals (zinc, copper, manganese, selenium, chromium, and iodine) were supplemented daily. Electrolytes (potassium, sodium, magnesium, calcium, chloride, phosphate) were supplemented according to the individual patient's needs.

Enteral nutrition, (Precitene $N$ or Isotein ${ }^{k}$ ( $N$ :kcal ratio 1:92, protein $107 \mathrm{gr} / \mathrm{l}$. $1575 \mathrm{kcal} / \mathrm{l})$ ), was administered by naso-gastric tube or orally.

\subsubsection{Statistical analysis}

All patients were analysed according to the intention-to-treat principle. Parameters among groups were tested by ANOVA, complication ratios were analysed using Chi-Square analysis. Survival was analysed using the KaplanMeier method ${ }^{15}$. The survival curves of groups of patients were compared using the log-rank test ${ }^{i b}$. The combined and independent effects of the predictor variables on survival were analysed using a Cox (proportional hazards) nonparametric multiple regression model $^{17}$ for censored survival data (BMDP2L). This model allows simultaneous estimation of the relative effect on survival of each variable, adjusted for the effects of correlations with the other prognostic variables included in the model. This regression model included all preoperative 
parameters which appeared to be important in the log-rank analysis $(p<0.05)$, the nutritional status parameters, and depletion parameters. P-values smaller than 0.05 were considered significant.

\subsection{Results}

\subsection{Nutritional support}

Six patients in the T.P.N. group refused participation in the trial (non in stage IV). In one patient (stage IV) the catheter was removed on the second day after signs of catheter sepsis. The other patients in the T.P.N. group received an average of 12.3 days (range 10 - 18 days) of preoperative parenteral nutritional support. On average patients in the T.P.N. group received 11.2 days (range 7 36 days) of postoperative parenteral nutritional support.

Six patients in the T.E.N. group refused participation in the trial (one stage IV), one patient was unable to receive enteral nutrition because of bowel obstruction. The other patients in the T.E.N. group received 10.5 days (range $9-14$ days) of preoperative enteral nutritional support. After operation, the patients in the T.E.N. group received regular i.v. fluids until oral intake could be resumed.

Three patients in the T.E.N.-group (one stage IV) and 6 patients in the depleted control group (one stage IV) received T.P.N. after operation because of their inability to resume oral nutrition (table 8.1 ). 
Table 8.1:Perioperative nutritional support

\begin{tabular}{|c|c|c|c|c|c|c|c|}
\hline & $\begin{array}{l}\text { TPN } \\
\text { mean }\end{array}$ & $\begin{array}{l}=36 \\
\text { range } \\
\end{array}$ & $\begin{array}{l}\text { TEN } \\
\text { mean }\end{array}$ & range & $\begin{array}{l}\text { Deple } \\
\mathrm{n}=37 \\
\text { mean }\end{array}$ & $\begin{array}{l}\text { ed } \\
\text { range }\end{array}$ & $\begin{array}{l}\text { Non depleted } \\
n=39\end{array}$ \\
\hline $\begin{array}{l}\text { Preop. support } \\
\text { days } \\
\text { patients with } \\
\text { postop. TPN }\end{array}$ & $\begin{array}{l}12.3 \\
n=35\end{array}$ & $9-18$ & $\begin{array}{l}10.5 \\
n=3\end{array}$ & $9-14$ & $n=6$ & - & - \\
\hline $\begin{array}{l}\text { Postop. TPN } \\
\text { days }\end{array}$ & 11.2 & $7-36$ & 34.3 & $26-42$ & 25.8 & $10-66$ & \\
\hline $\begin{array}{l}\text { Stage IV } \\
\text { patients } \\
\text { postop. TPN }\end{array}$ & $\begin{array}{l}n=11 \\
n=10\end{array}$ & & $\begin{array}{l}n=7 \\
n=1\end{array}$ & & $\begin{array}{l}n=8 \\
n=1 \\
66\end{array}$ & - & $n=6$ \\
\hline $\begin{array}{l}\text { postop. TPN } \\
\text { days }\end{array}$ & 11.6 & $8-17$ & 42 & 42 & 66 & 66 & - \\
\hline
\end{tabular}

Duration of pre-and postoperative nutritional support and the number of patients with parenteral nutrition. Patients in the enteral, depleted and nondepleted group resumed oral regimen according to normal postoperative standards.

No difference in preoperative biochemistry and anthropometric data was observed between the trial groups (table 8.2). The non-depleted reference group had significant better preoperative parameters. 
Table 8.2: Pre-and peroperative parameters

\begin{tabular}{|c|c|c|c|c|c|c|c|c|}
\hline \multirow{2}{*}{ 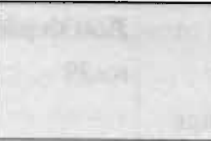 } & \multicolumn{2}{|c|}{ TPN $n=36$} & \multicolumn{2}{|c|}{ TEN $n=37$} & \multicolumn{2}{|c|}{$\begin{array}{l}\text { Depleted } \\
\mathrm{n}=37\end{array}$} & \multicolumn{2}{|c|}{$\begin{array}{l}\text { Non depleted } \\
n=39\end{array}$} \\
\hline & mean & range & mean & range & mean & range & mean & range \\
\hline $\begin{array}{l}\text { Total protein } \\
(\mathrm{g} / \mathrm{l})\end{array}$ & 69 & 5 & 70 & 8 & 69 & 6 & $75^{*}$ & $6^{-}$ \\
\hline $\begin{array}{l}\text { Albumin } \\
(\mathrm{g} / \mathrm{l})\end{array}$ & 34 & 4 & 35 & 4 & 34 & 4 & $39 *$ & 3 \\
\hline $\begin{array}{l}\text { Pre-albumin } \\
(\mathrm{g} / \mathrm{l})\end{array}$ & 0.22 & 0.08 & 0.23 & 0.06 & 0.22 & 0.08 & 0.30 & 0.05 \\
\hline $\begin{array}{l}\text { Hemoglobin } \\
(\mathrm{mmol} / \mathrm{l})\end{array}$ & 7.6 & 1.5 & 7.6 & 1.4 & 8.0 & 1.5 & $8.9^{*}$ & 1.3 \\
\hline $\begin{array}{l}\text { Lymphocyte } \\
\text { count }\left(/ \mathrm{mm}^{3}\right)\end{array}$ & 1.73 & 0.51 & 1.66 & 0.52 & 1.82 & 0.56 & $2.42 *$ & 0.59 \\
\hline Age (yrs) & 69 & 8 & 66 & 9 & 66 & 7 & $61^{*}$ & 9 \\
\hline P.I.W. (\%) & 96 & 12 & 98 & 11 & 97 & 18 & $113 *$ & 11 \\
\hline P.W.L. (\%) & 9 & 12 & 5 & 6 & 6 & 7 & $3^{*}$ & 4 \\
\hline $\begin{array}{l}\text { Duration } \\
\text { (hrs.min) }\end{array}$ & 2.47 & 1.15 & 2.47 & 0.94 & 2.41 & 0.77 & $3.31 *$ & 1.45 \\
\hline $\begin{array}{l}\text { Perop. blood } \\
\text { loss }(\mathrm{ml})\end{array}$ & 700 & 670 & 830 & 1040 & 740 & 1030 & 1020 & 1440 \\
\hline
\end{tabular}

Pre-and peroperative parameters are not significantly different between the trial groups. P.I.W.. duration of surgical procedure, and lymphocyte counts are in the non-depleted group significantly different from the values of the (depleted) trial groups. (*ANOVA $p<0.05)$

\subsubsection{Complications}

The immediate overall postoperative in hospital complication rate and mortality were not different between the 4 groups. In stage IV no major complicatons and 2 minor complications were observed in the non-depleted colorectal cancer patients. while in all other groups major complications were observed. Two patients in stage IV T.E.N. group died in the hospital and 3 others suffered major complications. No major complications occurred in the ND controls (table 8.3)(Chapter 6). 
Table 8.3: Tumor stage and tumor spread

\begin{tabular}{|c|c|c|c|c|}
\hline & TPN $n=11$ & TEN $n=7$ & $\begin{array}{l}\text { depleted } \\
\mathrm{n}=8\end{array}$ & $\begin{array}{l}\text { non-depleted } \\
n=6\end{array}$ \\
\hline \multicolumn{5}{|c|}{ TNM-classification } \\
\hline $20+$ & 1 & - & - & 1 \\
\hline $2++$ & 1 & 1 & 1 & 3 \\
\hline $30+$ & - & - & - & 1 \\
\hline $3++$ & 4 & - & 4 & 1 \\
\hline $40+$ & 1 & 1 & 2 & - \\
\hline $4+0$ & 2 & 2 & - & - \\
\hline $4++$ & 2 & 3 & 1 & - \\
\hline \multicolumn{5}{|l|}{ Sexe } \\
\hline Male & 9 & 3 & 4 & 4 \\
\hline Female & 2 & 4 & 4 & 2 \\
\hline \multicolumn{5}{|l|}{ Complication rate } \\
\hline no & 2 & 1 & 4 & 4 \\
\hline minor & 6 & 1 & 3 & 2 \\
\hline major (mortality) & $3(1)$ & $5(2)$ & $1(1)$ & $0(0)$ \\
\hline
\end{tabular}

Tumor stage and tumor spread in stage IV colorectal cancer patients.
$2 / 3 / 4$
T-stage
Ol+ Negativelpositive lymph nodes
$0 /+\quad$ Absencelpresence of distant metastases

In addition, sexe, localisation, and complication rates in stage IV colorectal trial groups are summarised. The number of parients in each cell is given. No statistically significant difference between the depleted trial groups is observed. In the non-depleted group there was a smaller tumor load as expressed by lower TNM-scores and no major complications were observed $(p<0.05)$.

\subsubsection{Survival}

Overall survival at 90 months in the current study was $45 \%$. The effect of perioperative nutritional support on survival of patients in all stages of disease is depicted for each trial group in figure 8.1. No difference in survival between nutritional support and control groups was seen. 


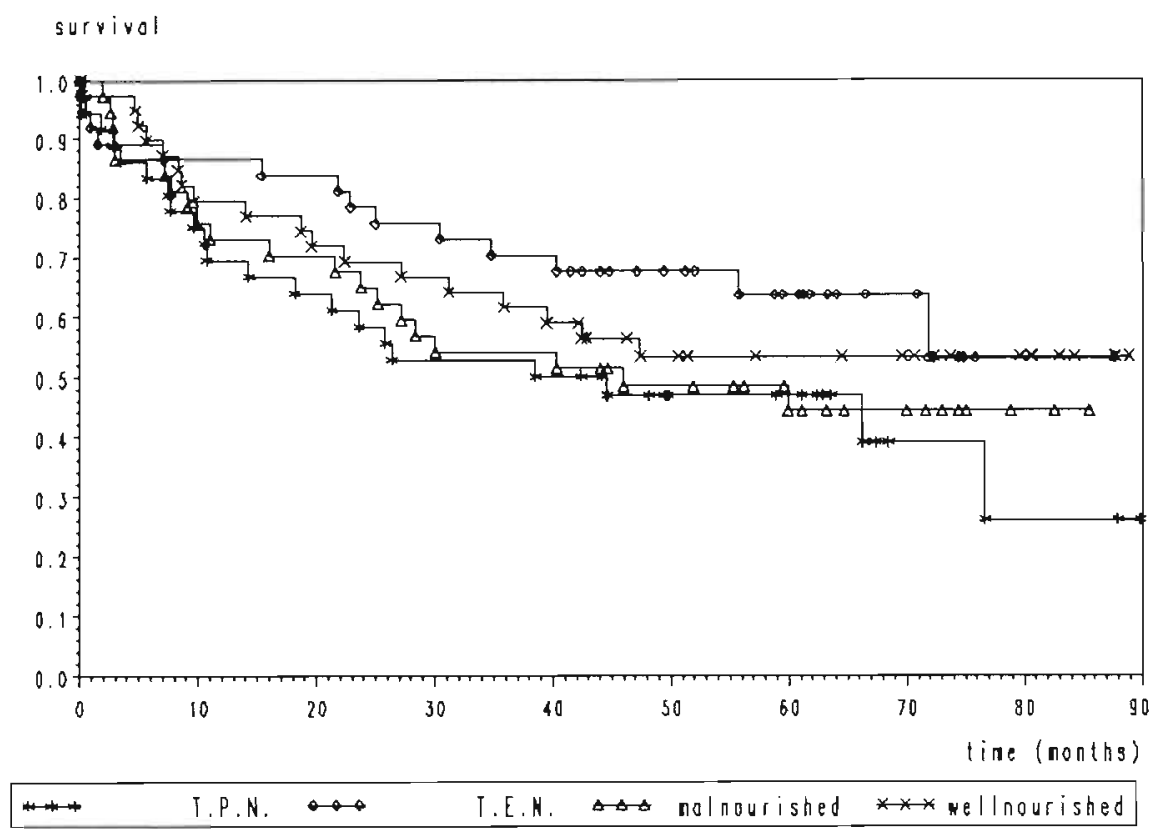

Figure 8.l: The association of nutritional intervention with long term survital in colorectal cancer patients in all stages of disease. (log rank ns)

\subsubsection{Stage I/II and III}

As disease stage is the most prominent determinant of survival, separate analyses per stage were performed. Analyses for the separate stages I to III demonstrated no difference in mortality between study groups for nutritional intervention.

A stepwise Cox-regression analysis, deleting the least significant parameter step by step was performed for stage I/II, III and IV. The first column in table 8.4 summarises the results of the Cox regression for stage I/II disease. The second column shows the results for stage III-cancer patients. In both analyses peroperative blood loss showed an independant association with survival, as did hemoglobin levels in stage I and II. In stage III preoperative plasma albumin levels and total lymphocyte count also showed a significant association with survival.

\subsubsection{Stage IV}

Figure 8.2 displays the effect of perioperative nutritional support on survival of patients with stage IV-carcinoma. Curves of the depleted patient groups that 
survivol

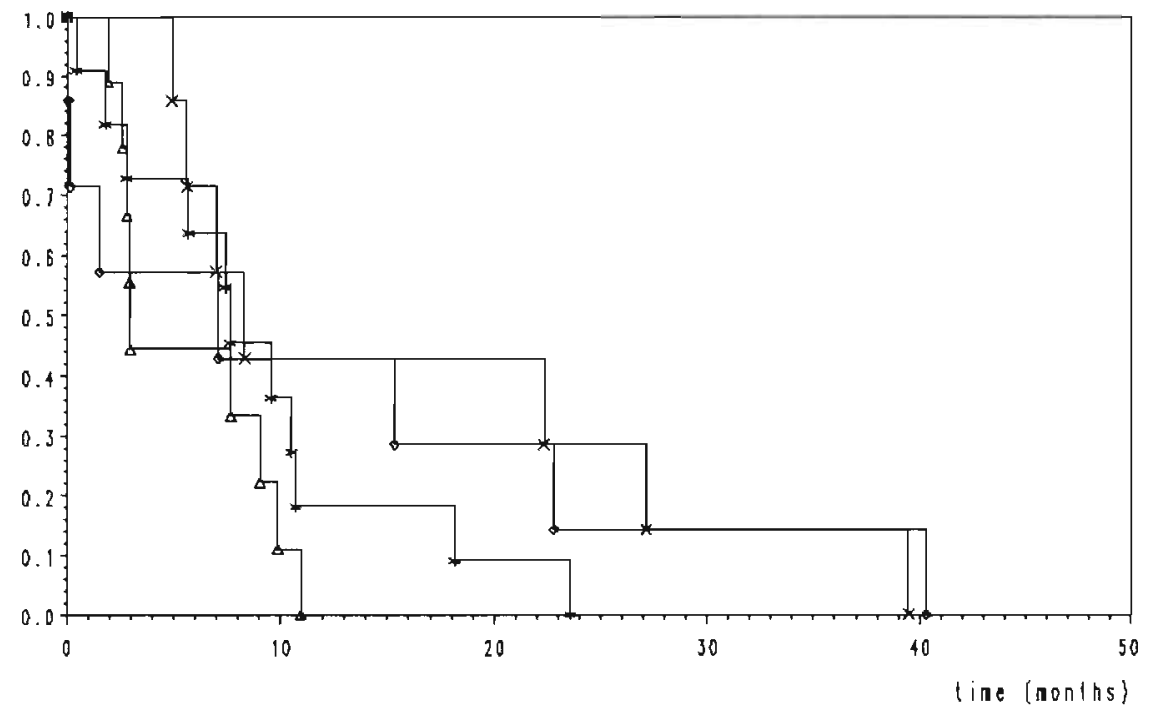

T.P.K. T.E.K. $\Delta \Delta$ nolnourished $* * *$ vellnourished

Figure 8.2: The association of nutritional support with long term survival of stage IV colorectal cancer patients. The curve of the depleted patients with nutritional intervention mimics the curve of the non-depleted control patients. The curves of the depleted patients receiving nutritional support differ significantly from the curve of the depleted patictns without nutritional support. (log rank $p<0.05$ )

received parenteral $(n=11)$ or enteral $(n=7)$ nutritional support nearly mimic the curve of the non-depleted control patients $(n=7)$. There is a significant difference between survival of the depleted control patients $(n=9)$ and the survival of the non-depleted patients ( $\log$ rank $p<0.05)$. Median survival of depleted control patients was 3 months, of enterally fed patients 7 months, of parenterally fed patients 7.5 months, while non-depleted control patients had a median survival of 8.5 months. The Cox-regression revealed in stage IV colorectal cancer patients a significant association with percent ideal body weight $(p<0.05)$, total lymphocyte count $(p<0.05)$ and perioperative nutritional support $(p<0.05$ ) (table 8.4). Hemoglobin, albumin, or type of nutritional support were not significantly related with survival. 
Table 8.4: Cox-regression model

\begin{tabular}{|l|l|l|l|l|l|}
\hline Stage & I/II & III & IV & \\
& $\mathrm{p}$ & $\mathrm{p}$ & coeff/se & $\exp$ (coeff) & $\mathrm{p}$ \\
\hline Preop. nutrit. support & $\mathrm{ns}$ & $\mathrm{ns}$ & -1.8195 & 0.3633 & 0.05 \\
TPN/TEN & $\mathrm{ns}$ & $\mathrm{ns}$ & - & - & $\mathrm{ns}$ \\
blood loss & 0.01 & 0.05 & - & - & $\mathrm{ns}$ \\
Hemoglobin & 0.01 & $\mathrm{~ns}$ & - & - & $\mathrm{ns}$ \\
Albumin & $\mathrm{ns}$ & 0.01 & - & - & $\mathrm{ns}$ \\
lymphocyte counte & $\mathrm{ns}$ & 0.05 & 1.9063 & 2.2079 & 0.05 \\
PIW (<>> 95\%) & $\mathrm{ns}$ & $\mathrm{ns}$ & -1.9653 & 0.2701 & 0.05 \\
Postop. complications & $\mathrm{ns}$ & $\mathrm{ns}$ & - & - & $\mathrm{ns}$ \\
Sexe & $\mathrm{ns}$ & $\mathrm{ns}$ & - & - & $\mathrm{ns}$ \\
\hline
\end{tabular}

Results of Cox-regression model for each separate stage of disease. For stage IIII and stage III the significant parameters are shown by their p-value. For stage $I V$ in the first column the estimated coefficients/standard error (coeff/se) or the z-statistics are given. The second column of data lists the relative risk estimate (exp(coeff)), while the last column lists the p-value of the likelihood ratio test for significance of the factor (after correction for the other factors).

Table 8.5 shows characteristics of all patients with stage IV carcinoma. They were comparable with respect to age, preoperative biochemical parameters, peroperative blood loss, tumor load and tumor spread. In addition, PIW, PWL and age were not different between trial groups. Tumor localisation, locoregional tumor spread and pattern of distant metastases were not different between trial groups either (table 8.2). Non-depleted stage IV cancer patients, however, showed better preoperative parameters (table 8.2 ) and a smaller extent of tumor (table 8.3). 
Table 8.5: Pre-and peroperative parameters stage IV colorectal cancer patients

\begin{tabular}{|c|c|c|c|c|c|c|c|c|}
\hline \multirow{2}{*}{$\begin{array}{l}\text { Stage IV } \\
\text { colorectal } \\
\text { cancer }\end{array}$} & \multicolumn{2}{|c|}{ TPN $n=11$} & \multicolumn{2}{|c|}{ TEN $n=7$} & \multicolumn{2}{|c|}{ Depleted $n=8$} & \multicolumn{2}{|c|}{$\begin{array}{l}\text { Non-depleted } \\
n=6\end{array}$} \\
\hline & mean & range & mean & range & mean & range & mean & range \\
\hline Total protein & 68 & 5 & 68 & 8 & 71 & 7 & 74 & 5 \\
\hline Albumin & 33 & 4 & 33 & 5 & 32 & 4 & 39 & 4 \\
\hline Pre-albumin & 0.17 & 0.06 & 0.21 & 0.07 & 0.16 & 0.06 & $0.29 *$ & 0.06 \\
\hline Hemoglobin & 7.0 & 1.6 & 6.8 & 1.7 & 7.5 & 1.7 & 8.9 & 0.9 \\
\hline $\begin{array}{l}\text { Lymphocyte } \\
\text { count }\end{array}$ & 1.71 & 0.76 & 1.84 & 0.57 & 2.11 & 0.73 & 2.09 & 0.46 \\
\hline Age & 69 & 9 & 70 & 7 & 68 & 5 & 61 & 8 \\
\hline P.I.W. & 94 & 9 & 95 & 17 & 98 & 8 & $116^{*}$ & 6 \\
\hline P.W.L. & 9 & 6 & 9 & 7 & 14 & 8 & $3^{*}$ & 4 \\
\hline $\begin{array}{l}\text { Duration of } \\
\text { procedure }\end{array}$ & 2.23 & 1.39 & 2.49 & 0.95 & 2.16 & 0.80 & 2.4 & 1.5 \\
\hline $\begin{array}{l}\text { Peroperative } \\
\text { blood loss }\end{array}$ & 568 & 488 & 871 & 821 & 637 & 1275 & 583 & 585 \\
\hline
\end{tabular}

Pre-and peroperative parameters in stage IV colorectal cancer patients differ not significantly among the trial groups. The non-depleted reference group had significant better preopeative parameters $(* p<0.05)$.

\subsection{Discussion}

The stage to which a malignancy of the GI tract has progressed is the most important determinant of survival. Other determinants of long term survival are indicators of depletion (Chapter 7). Whether correction of depletion by means of nutritional support is associated with enhanced tumor growth and, therefore, decreased survival in humans is not known. Only Weisdorf ${ }^{18}$ showed a positive effect of pre-treatment TPN on long term outcome of bone marrow transplantation patients.

Perioperative nutritional support of stage IV colorectal cancer patients who showed signs of depletion significantly prolonged survival, to a level similar to that of non-depleted control patients. These effects were not (yet) present in stage I, II, and III colorectal cancer patients.

It is known for some time that percentage weight loss and ideal body weight have prognostic value with respect to postoperative morbidity and mortality ${ }^{1922}$, 
and long term survival ${ }^{1,423}$. In addition, total protein correlates significantly with long term survival ${ }^{24}$.

Few studies have addressed the effects of other nutritional status parameters on long term survival ${ }^{1,45}$ and none the effect of perioperative nutritional support in this respect. Administration of routine T.P.N. as adjuvant to chemotherapy or radiation therapy has not resulted in a beneficial effect with respect to tolerance to therapy, morbidity, mortality or survival ${ }^{5226}$.

Suggestions that nutritional support would stimulate tumor growth, and consequently impair long term survival, have not been confirmed. A recent review concluded that no clinical evidence was present to support this suggestion ${ }^{27}$.

Our observation that nutritionally supported stage IV cancer patients tolerated palliative surgical trearment better, as expressed by a significant improvement of long term survival, can not be explained by differences between study groups regarding type of operative procedure, degree of tumor spread or preoperative parameters. Perioperative morbidity data were also similar. We therefore must assume that this finding is truly associated with nutritional support.

\subsection{Conclusion}

We conclude from this study that in depleted patients with stage IV colorectal cancer perioperative nutritional support significantly improved long term survival.

The differences between the results of trials investigating the role of nutritional repletion as an adjuvant to chemotherapy, and the results of the studies by Weisdorf ${ }^{2 x}$ and our study, can be explained by the fact that nutritional repletion was given prior to the trauma.

The effect seems to be superior to even very aggressive systemic palliative treatment ${ }^{3 \times 2}$. A prospective randomised controlled trial to confirm our results is therefore warranted. Such a study offers the possibility to investigate mechanisms that may be causally related to our observation.

References

1. DeWys WD. Begg C. Lavin PT, et al. Prognostic effect of weight loss prior to chemotherapy in cancer paltients.

An.J.Med. 1980:69:491-497

2. Clamon GH. Feld R. Evans WK. et al. Effect of adjuvant central intravenous hyperalimentation on the survival and response to treatment of patients with small lung cincer: a randomized trial. Cancer Treat.Rep. 1985:69:167-177 
3. Nixon DW, Lawson DH, Kutner MH, et al. Effect of total parenteral nutrition on survival in advanced colon cancer.

Cancer Detect Prev, 1981:4:421-427

4. Lanzotti VJ, Thomas DR, Boyle LE, Smith TL, Gehan EA. Samuels ML. Surviyal with inoperable lung cancer.

Cancer $1977 ; 39: 303-313$

5. Wiggers T. Arens JW, Volovics A. Regresision analysis of prognostic factors in colorectal cancer after curative resections.

Dis.Colon Recturn 1988:31:33-41

6. Megujd MM, Mughal MM, Debonis D, Meguid V, Terz JJ. Influence of nutritional status on the resumption of adequate food intake in patients recovering from colorectal cancer operations. Surg.Clin.North.Am. 1986:66:1167-1176

7. Brennan MF. Total parenteral nutrition in the cancer patient N.Engl.J.Med. 1981:305:375-382

8. Nixon DW, Lawson DH, Kutner MH et al. Hyperalimentation of the cancerpatient with protein calorie undernutrition.

Cancer Res. 1981:41:2038-2045

9. Popp MB, Kirkemo AK, Morrison SD. Brennan MF. Tumor and host carcass changes during total parenteral nutrition in an anorectic rat-tumor system.

Ann.Surg. 1984: 199:205-210

10. Daly JM, Copeland EM, Dudrick SJ, Delaney JM. Nutritional repletion of malnourished tumor beuring and non-tumor bearing rats: Effects on body weight, liver, muscle and tumor.

J.Surg.Res. 1980:28:507-518

11. Daly JM, Copeland EM, Dudrick SJ. Effect of intravenous nutrition on tumor growth and host immunocompetence in malnourished animals.

Surgery 1978:84:655

12. de Jong PCM, Wesdorp RIC, Volovics A. Rouflart M. Greep JM. Soeters PB. The value of objeclive measurements to select patients who are malnourished.

Clin.Nutr. 1985:4:61-66

13. Association of life insurance medical directors: Medico-actuarial montality investigations. Ass.Life Ins.Med.Dir. and Actuarial Soc.Am. 1912; vol.1

14. Harris JA. Benedict FG. A biometric study of basal metabolism. Washington. Camegie institution of Washington 1919

15. Kaplan EL, Meier P. Nonparametric estimation from incomplete observations. J.Am.Statist.Ass. 1958:53:457-481.

16. Mantel N. Evaluation of survival data and two new rank order statistics arising in its consideration Cancer Chemotherapy Reports 1966:50:163-170

17. Cox DR. Regression models and life tables (with discussion). J.R.Statist.Soc. B. 1972; 34:187-220

18. Weisdorf SA, Lysne J, Wind D. et al. Positive effect of prophylactic total parenteral nutrition on longlerm outcome of bone marrow transplantation.

Transplantation 1987:43:833-838 


\section{Chapter 8}

19. Klidjian AM, Foster KJ, Kamnerling KM, Cooper A, Karran SJ. Relation of anthropometric and dynamometric variables to serious postoperative complications.

Brit.Med.J. 1980:281:899-90 I

20. Collins JP, McCarthy ID, Hill GL. Assessment of protein nutrition in surgical patients: the value of antropometrics.

Am.J.Clin.Nutr. 1979;32:1527-1530

21. De la Hunt, McDonald PJ, Karran SJ. Anthropometric nutritional assessment is of value in colorectal patients.

Dis.Colon Rectum 1984;27:296-298

22. Windsor JA. Hill GL. Weight loss with physiologic impairment, A basic indicator of surgical risk. Ann.Surg. 1988:207:290-293

23. Costa G. Lane W. Vincent $R$. Weight loss and cachexia in lung cancer. Nutrition and cancer 1980:2:98-103

24. Wiggers T. Arens JW, Volovics A. Regression analysis of prognostic factors in colorectal cancer after curative resections.

Dis.Colon Reclum 1988:31:33.41

25. American College of Physicians. Parenteral nutrition in patients recieving cancer chemotherapy. Ann.Int.Med. 1989:110:734-736

26. Valerio D, Overelt L, Malcolm A. Blackbum GL. Nutritional suppon for cancer patients recieving abdominal and pelvic radiotherapy. A randomized prospective clinical experiment of intravenous versus oral feeding.

Surg.Fonum 1978:29:145-148

27. Brennan MF. Panel report on nutritional support of patients with cancer. Am.J.Clin.Nutr. 1981:34:1199-1205

28. Klein HO, Dias Wickramanayake P. Bedeutung der Chemotherapy in der Behandlung des metastasierten Magenkarzinums. Fortschrite in der Chirurgie 2: Magenkarzinom. Gall FP. Hermanek P ed. 1986.

Zuckschwerdt Verlag Munchen Bern Wien San Fransisco

29. Sugarbaker PH. Gunderson LL. Wittes RE. Colorectal cancer.

Cuncer Principles and Practice of Oncology. Ed. DeVita VT. Hellman S. Rosenberg SA. Philadelphia, PA. Lippincon. 1985:pp 795-884 


\section{Chapter 9}

\section{Final discussion}

\subsection{Depletion parameters}

As discussed in chapter 3 the goal of the assessment of the presence of depletion is to identify patients that are unable to stage a normal response to a disease or (surgical) trauma. This inability results in an additional risk in these patients for development of complications of their disease or of the treatment of their disease.

In the current study we used the Nutritional Index', developed in our hospital, for stratification of depletion. This index is composed of the parameters albumin, total lymphocyte count and percent ideal weight. Originally these parameters were thought to indicate malnutrition. However, at present we have good reasons to suggest that the nutritional index rather identifies depletion, resulting from metabolic stress.

Plasma albumin concentrations certainly correspond with the presence of metabolic stress. Plasma albumin concentrations were shown to be normal in long term starvation without presence of disease ${ }^{2}$. But in patients with signs of sepsis, plasma albumin concentrations decrease within a few days, even in healthy young trauma patients. The clinical importance of plasma albumin concentrations is illustrated by the prognostic value for long term survival in Gl cancer patients (as shown in chapter $7 \& 8$ ).

Total lymphocyte counts are also more affected by the presence of disease than by the presence of starvation, although few data are available regarding lymphocyte counts in starvation experiments. In septic conditions total lymphocyte counts decrease rapidly. Like plasma albumin concentrations, total lymphocyte counts were shown to have prognostic value in predicting survival of these cancer patients. The central role of the immune system in the natural history of cancer $^{3}$ and in recurrence of cancer $^{+6}$ has since long been accepted.

Weight parameters are less clearly associated with metabolic stress. In starving conditions without presence of disease, weight is gradually decreasing. The loss of weight is principally body fat mass, used as energy source. Lean body mass is affected only slightly, because of protein sparing mechanisms during starvation. However, in the presence of disease and especially in septic conditions, not only body fat mass is affected, but specifically body cell mass decreases. This is reflected by negative protein balances, despite adequate (parenteral) nutrition. 
Weight loss is in these conditions often masked by increasing extracellular water.

Weight loss, therefore, reflects both starvation and disease. It has been suggested that the assessment of fat free mass, or loss of fat free mass more accurately defines the presence of depletion. Fat free mass is currently fairly easily measured by impedance techniques in healthy individuals, albeit that validation in various (septic) disease conditions is only in its early phase. The accumulation of extracellular water may jeopardise the validity of the technique.

\subsection{Prerequisites of trials}

In chapter 4 the prerequisites are defined that should be met in trials investigating the effect of nutritional therapy.

- Nutritional status parameters should identify a patient group that is relevant. According to the index we used to identify patients as depleted, about threequarter of the study population was depleted. It is, therefore, likely that these criteria were too mild. The absence of clear-cut answers in chapter 6 may be the result of this phenomenon. Subanalysis of the severely depleted patients where a positive effect of preoperative nutrition on the incidence of postoperative complications was observed, underlines this point.

- Advance calculations should define the group size required to reach significance of the expected differences. Interim analyses are necessary to avoid treatment which has already been shown to be inferior to the other treatment. Interim analyses after admitting 201 patients in our study revealed no benefit for one of both nutritional intervention therapies. Consequently, the trial was discontinued at that moment. One of the possible explanations for the absence of significant effects is that all major complications were analysed as one group. The group of major complications encompasses a variety of complications, including some which are not believed to be influenced by nutritional therapy.

Detailed analyses showed, as reported in chapter 6 , and in some other trials in the literature, a benefit of nutritional therapy in the severely depleted patient group. However, the number of patients in this group is rather small.

\subsection{Nutritional intervention}

As shown in chapter 5, factors indicating depletion influence the severity of complications. It seems as if in depleted patients minor complications will progress to a major complication more often or a major complication will result 
in a sequence of multiple complications. The capability to respond to intrusions is only in part dependent on 'nutritional status', and nutritional support, therefore, can only partly influence or modify outcome of therapy. Depletion increases the risk of perioperative complications, but not to the extent that all depleted patients develop complications. Similarly it is unreasonable to expect complete eradication of all postoperative complications by nutritional support. The acknowledgement of the limited role of depletion in the development of postoperative complications, and the difficulty to demonstrate nutritional support as effective therapy in reducing complications illustrates that the expectations of the effects of nutritional therapy in the past two decades were too high.

In this study we confirm the hypothesis that preoperative nutritional therapy supports severely depleted patients with a significant reduction of postoperative complications. This intervention must contain suffient amounts of nutrients and must last a sufficient time period. Nearly all trials supporting patients shortly before or only after operation, failed to demonstrate positive effects of nutritional therapy. It is warranted to extend the conclusions of this study to other situations where severely depleted patients are subjected to (aggressive) therapy: pre-treatment nutritional support could also have beneficial effects in other treatment modalities. However, the option of nutritional intervention prior to chemotherapy and radiation therapy has not been tested. None of the studies concerning nutritional therapy in these two treatment modalities showed a beneficial effect if given during or after the treatment therapy had started.

\subsection{Survival}

Long term survival is first of all influenced by stage of disease. Apart from this, depletion related parameters, like ideal weight, plasma albumin levels and preoperative hemoglobin values, showed a significant association with long term survival. 'Correction' of these parameters by preoperative nutritional support failed to show beneficial effects in the total group. This is probably due to the stage to which the disease has progressed, and, as explained above, the relative role of depletion and rather mild inclusion criteria for the trial. However, preoperative nutrition did not show any adverse effects on long term survival.

Analysis per stage of disease showed beneficial effects of preoperative nutrition in stage IV colorectal cancer disease. The discontinuation of the study is responsible for the small number of stage IV colorectal cancer patients as described in chapter 8 . In such a small patient group (34 patients) it is difficult to draw firm conclusions concerning the influence of nutritional therapy on long 
term survival. To address this question a multicenter trial should be initiated, confirming the strong suggestions of a positive effect on long term survival of nutritional intervention in depleted patients with advanced stages of cancer.

\subsection{Blood loss}

Blood loss was shown to be of major importance in predicting outcome of therapy. Loss of more than $500 \mathrm{ml}$ of blood was highly correlated with the presence of postoperative complications. Because of the correlation and the improved outcome of surgical therapy after nutritional repletion in depleted patients that lost over $500 \mathrm{ml}$ of blood, one should like to take blood loss into account when making decisions with regard to the start of nutritional support. But, more than an preoperative estimate of blood loss is not possible.

Blood loss probably also reflects the need for blood transfusion. Both loss of blood and transfusion of blood have been claimed to have detrimental effects on the immune system resulting in a variety of immunosuppressive actions ${ }^{7.12}$ and decreased survival ${ }^{1 \cdots 19}$. Accepting very low hematocrit values has not been shown detrimental, and the effect of transfusions of homologous blood products as opposed to heterologous blood products is currently under investigation. Of course blood loss during surgical procedures should be kept to a minimum during surgical procedures. This is common practice to every surgeon. It is not yet known which blood component(s) induce(s) the immunosuppressive effect. It is certainly not always necessary to replenish volume deficits with whole blood. It is not yet established if replenishment of volume deficits with other products will have less detrimental effects.

Further investigations are necessary to explain the claimed detrimental effects of transfusions on survival: are they caused by transfusion itself, or are these detrimental effects an epiphenomenon of other confounding effects such as the size of the tumor, vascularisation of the tumor, resectabilty and site of the tumor, duration and extension of surgical procedure or surgical skill.

\subsection{Clinical implication}

The results of the trial described in this thesis have resulted in policy changes in day-to day clinical practice: depleted patients showing a recent weight loss of more than $10 \%$ receive preoperative nutritional support. In this group of severely depleted patients we demonstrated that postoperative complications are reduced, and the severity of complications is limited. 
1. de Jong PCM. Wesdorp RIC. Volovics A, Roulflar M, Greep JM. Soeters PB. The value of objective measurements to select patients who are malnourished.

Clin.Nutr. 1985:4:61-66

2. Russel DM. Prendergast PJ, Darby PL. Garfinkel PE, Whitwell J, Jeejeebhoy KN. A comparison between muscle function and body composition in anorexia nervosa: the effect of refeeding. Am.J.Clin.Nutr. 1983;38:229-237

3. Bumet FM. The concept of immunological surveillance. Progr.Exp.Tumor Res. 1970:13:1-27

4. Haffejee AA, Webster DJT, Paterson AG, et al. E-rosette inhibition and tumour recurnence in early breast cancer. Br.J.Surg. 1983;70:319-321

5. Anthony HM, Kirk JA, Madsen KE, Mason MK. Temple MAN. E and EAC rosetting: lymphocytes in patients with carcinoma of the bronchus. II A sequential study of thirty parients: Fillul of BCG. Clin.Exp. Immunol. 1975:20:41-54

6. Cochran AJ, Mackie RM, Grant RM, et al. An examination of the immunology of cancer patients Int.J.Cancer 1976; 18:298-309

7. Smith MD. Williams JD, Coles GA. Salaman JR. The effect of blood transfusion on T suppressor cells in renal dialysis patients.

Transplant Proc. 1981;13:181-183

8. Marquet RL. Heystek GA. Niessen GJCM, Jeekel J. Induction of suppressor cells by a single blood transfusion in rats.

Transplant Proc. 1982:14:397-399

9. Kerman RH, Buren van CT, Payne W, el al. Influence of blood transfusions on immune responsiveness. Transplant Proc. 1982:14:335-337

10. Singal DP, Joseph S, Szewczuk MR. Possible mechanism of the beneficial effect of pre-transplant blood transfusion on renal allograft survival in man.

Transplant Proc. 1982;14:316-318

11. Keown PA, Descamps B. Improved renal allograft survival after blood transfusion: A non-specific erythrocyle mediated immunoregulatory process?

Lancet 1979:I:20-22

12. Linden vd CJ, Buurman WA. Vegt PA. In: Opelz G. Persijn GG. ed. Blood transfusion in renal transplantation.

Transplant Proc. 1981:13:1556-1558

13. Voogt PJ. Velde vd CJH. Brand A. el al. Perioperative blood transfusion and cancer prognosis. Different effects of blood transfusion on prognosis of colon and breast cancer patients.

Cancer 1987:836:836-843

14. Foster RS, Costanza MC. Foster JC, MC Wanner, Foster CB. Adverse relationship between blood transfusions and survival after colectomy for colon cancer.

Cancer 1985:55:1195-1201

15. Tanter PI, Quintero S. Barton DM. Perioperalive blood transfusion associated with infectious complications after colorectal cancer operations.

Am.J.Surg. 1986:152:479-482 
Chapter 9

16. Parrot NR. Lennard TWJ, Taylor RMR, Proud G. Shenton BK, Johnston IDA. Effect of perioperative blood transfusion on recurrence of colorectal cancer.

BrJ.Surg. 1986;73:970-973

17. Tanter PI, Burrows L, Papatestas AE, Lesnick G, Aufses AH. Perioperative blood transfusion has prognostic significance for breast cancer.

Surgery 1985:97:225-229

18. Burrows L. Tartter P. Effect of blood transfusions on colonic malignancy recurrence rate. Lancet 1982;11:662

19. Blumberg N, Agarwal MM. Chuang C. Relation between recurrence of cancer of the colon and blood transfusion.

Br.Med.J. 1985:290:1037-1039 


\section{Summary}

Malnutrition or depletion has since long been associated with an increased incidence of mortality and morbidity of surgical therapy. The fact that depleted patients develop more postoperative septic complications requires careful preoperative detection of depletion. There is no agreement, however, in the literature how depletion should be detected and which parameters of depletion are most predictive of the development of postoperative complications. The confusion is evenmore increased because the relative contribution of all potential conceivable risk factors has never been assessed together. If depletion indeed has an independent, substantial influence on surgical outcome, then repletion might improve outcome. The magnitude of these improvements are depending of the impact of depletion on outcome of surgical trauma. Therefore, if nutritional support effectuates in improved tissue and organ functioning it is a tool to reverse depletion, and consequently to improve outcome of surgical therapy. This concept has been the basis of perioperative nutritional support.

Aim of this thesis was to analyse surgical riskfactors together and weighing their relative contribution on postoperative complications and long term survival. The influence of perioperative nutrition was analysed on short term effects on postoperative complications and long term effects on survival.

When patients are metabolically stable, body composition is kept constant over longer periods of time through maintenance of a balance between intake and losses of energy, protein, and other essential nutrients. Deficiencies are the result of a derangement of the balance, either on the intake side or on the expenditure side, and lead to changes in body composition and disturbed organ functioning.

Nutritional assessment signifies detection of abnormal body composition and organ function resulting from insufficient nutritional intake; including energy and protein intake, and intake of other essential nutritients.

However, the actual intake of energy, protein and other nutrients by depleted patients is not always decreased. Some studies in cancer patients revealed a normal food intake compared to a control group. Nutritional assessment in these patients is used to detect abnormal body composition and disturbed organ function resulting from increased loss: increased energy expenditure, increased protein degradation, increased loss of total body nitrogen, and increased loss of essential nutrients, result of metabolic derangements. In most cases a mixture of 
both conditions is present, both resulting in depletion. The recognition that depletion has a nutritional origin and a metabolic origin may explain why nutritional intervention is not always succesful in reversing 'malnutrition'. The metabolic side of depletion is probably not easily reversed with 'ordinary' nutritional intervention.

The broad interest in the field of nutrition has resulted over the past two decades in a considerable number of publications, demonstrating that aberrations of nutritional status parameters are risk factors for surgical outcome. Many individual nutritional status parameters have been suggested to describe depletion and the degree of malnutrition. Many of these parameters show a significant correlation with postoperative morbidity and mortality and are therefore often used to calculate the risk for development of postoperative complications. In monofactorial analyses these parameters showed a fair to good correlation with the incidence of postoperative complications. But no single indicator has been proven better than any other. Combination of parameters has not been shown to increase sensitivity, reliability and applicability for the individual patient because of the high degree of correlation among variables. Indices, derived from multiple variate regression analyses, combining anthropometric, biochemical, and immunological measurements, did not show a further improvement either. The lack of a gold standard, and the index being developed in a specific patient group, explains why the results of application of these indices to other patient groups are so disappointing. Because of the way patients are selected when indices are established, not only the influence of depletion is considered, but also the influence of the underlying disease on outcome of surgical therapy. In addition, indices are frequently only composed of parameters, that are traditionally thought to be associated with depletion. As a consequence the role of nutrition related risk factors has been overemphasised, distracting the attention from the role that disease related factors and surgical therapy play in the development of postoperative complications. The outcome of surgery is the result of many factors e.g. patient related factors, including depletion, but also extent and type of the surgical procedure, skill of the surgeon, and the underlying disease itself.

Depletion increases the risk of perioperative complications, but not to the extent that all depleted patients develop complications. It is, therefore, unreasonable to expect complete eradication of all postoperative complications by nutritional support.

The attractiveness of the association of nutritional depletion with postoperative complications has always been the suggestion that depletion can be treated, in 
contrast to many other risk factors. This has led to high expectations of the ability of nutritional intervention to decrease morbidity and mortality from surgical therapy. These expectations were, as we know now, too high. Firstly it gradually became clear that most parameters thought to represent depletion and depletion associated surgical risk represent the presence of metabolic stress. Secondly, subsequent trials investigating the effect of nutritional intervention on outcome of surgical therapy, almost invariably failed to produce a positive result. Reasons for this failure include the fact that most trials do not fulfil the minimum criteria with regard to design and number of randomised patients. A further criticism is that in most trials the criteria that designate patients as 'malnourished' are rather mild and that non-depleted patients are not excluded from randomisation. In most studies surgery was not performed in the control group a few days after admission. These patients were left on a normal hospital diet, sometimes resulting in starvation. Furthermore, patients admitted for elective minor surgery as well as cancer patients undergoing extensive surgery were included.

In this thesis we determined the additional risk that originates from an abnormal nutritional status, depletion parameters, in addition to other well accepted surgical risk factors were analysed prospectively, for their association with postoperative complications. Other risk factors included type and duration of the surgical procedure, surgical skill, peroperative blood loss, type and stuge of the disease, age of the patient, and the presence of coexisting diseases. Nearly all parameters in this study showed in monofactorial analyses (ANOVA or ('hiSquare) a significant correlation with outcome, as has also been shown in literature. However, a multiple logistic regression analysis, with complication rate as dependent factor, revealed peroperative blood loss to be the most important factor associated with the development of postoperative complications. In addition, age was significantly associated with the occurrence of postoperative complications. When a complication occurred, percentage ideal weight and duration of the operative procedure were associated with the severity of the complication. Parameters reflecting the presence of metabolic stress, e.g. albumin, did not show an independent association with the development of postoperative complications. The results of this study suggest that repletion deminishes the severity of complications, rather than preventing their development.

We therefore undertook a prospective randomised trial to investigate the effects of at least 10 days preoperative total parenteral nutrition $(n=51)$ or total enteral nutrition $(n=50)$, on the rate of major postoperative complications or mortality 
in a homogeneous patient group with signs of depletion. Fifty patients served as a depleted control group and 49 patients served as a non-depleted reference group and were operated without delay.

Depleted control patients suffered significantly more septic complications than patients in the non-depleted reference group $(p<0.05)$. There was no significant difference, however, in septic complications between either of the nutritional support groups and the non-depleted control group. In high risk patients, with weight loss $>10 \%$ of body weight and over $500 \mathrm{ml}$ blood loss during operation, a significant decrease $(p<0.05)$ in major complications was observed as a result of nutritional support.

The results of our nutritional intervention trial in a homogeneous cancer patient group, suggest a benefit with fewer episodes of sepsis and less intra-abdominal abscess formation. This effect was more pronounced in the more severely depleted patients and was not obtained at the cost of increased morbidity of the nutrional support technique itself. We conclude that preoperative nutritional support in patients with severe depletion, results in a reduction of major complications to a degree that justifies its routine use in the selected group of patients with signs of severe depletion (i.e. weight loss $>10 \%$ ) prior to surgery.

In addition, the effect of depletion parameters on long term survival was analysed to assess whether the association between depletion and decreased survival of gastric or colorectal cancer patients is independent from tumor stage. Stage of disease, preoperative percent weight loss, percent ideal body weight, plasma protein, plasma albumin, plasma pre-albumin concentration and blood loss were significantly correlated with long term survival (Kaplan-Meier, log rank $p<0.05$ ) in both gastric and colorectal cancer. No adverse effects of perioperative nutrition on long term survival were seen.

A Cox multiple variate analysis with survival as dependent variable yielded, besides stage of disease, independent effects of percent ideal body weight, plasma albumin values and blood loss. Although it has long been thought that the association of weight loss and low plasma albumin levels with long term survival reflects progressing tumor stages, we now demonstrate this phenomenon to be independent from tumor stage. It is possible that weight loss and cachexia are epiphenomena of the metabolic relation between host and tumor. We conclude that depletion has an adverse effect on long term survival of patients with gastric or colorectal carcinoma, that is independent from the stage of disease.

The effects of perioperative nutrition on tumor growth and long term survival of Gl tract cancer patients have not been documented. Whether correction of 
depletion by means of nutritional support is associated with enhanced tumor growth and, therefore, decreased survival in humans is not known. Administration of routine T.P.N. as adjuvant to chemotherapy or radiation therapy has not resulted in a beneficial effect with respect to tolerance to therapy, morbidity, or survival. In 149 consecutive patients (62 females, 87 males) admitted for surgical treatment of newly detected colorectal cancer the long term effect of perioperative nutrition was analysed. Depleted patients in stage IV colorectal cancer survived significantly shorter than non-depleted stage IV cancer patients. Depleted stage IV colorectal cancer patients receiving perioperative nutritional support survived significantly longer than depleted patients who received no nutritional support ( $\log$ rank $\mathrm{p}<0.05)$. Such effects were not observed in stage I, II and III. In a Cox multivariate regression analysis this beneficial effect of perioperative nutrition showed to be an independent observation.

We therefore conclude that perioperative nutritional support improved long term survival after surgical treatment in stage IV colorectal cancer patients. This effect can not be explained by differences between study groups regarding type of operative procedure, degree of tumor spread or preoperative parameters. We must assume, therefore, that this finding is truly associated with nutritional support.

In daily practice, the results of this thesis have led to policy changes in clinical preoperative care of depleted (cancer) patients. In patients with weight loss over $10 \%$ of usual body weight, 10 days of preoperative nutritional support is indicated, provided the surgical treatmentcan be delayed without adverse effects. The results of this trial may possibly be extended to all depleted surgical patients. The finding that perioperative nutritional support improves long term survival in depleted stage IV cancer patients needs confirmation in a larger trial. 
Chapter 11

\section{Samenvatting}

Depletie is sinds lang geassocieerd met een verhoogde incidentie van postoperatieve chirurgische complicaties en mortaliteit.

Het feit dat een gedepleerde patiënt meer postoperatieve complicaties ontwikkelt, maakt een goede preoperatieve evaluatie van depletie noodzakelijk. Er is echter in de literatuur geen consensus over hoe depletie moet worden gedetecteerd en welke parameters de grootste predictieve waarde hebben bij het voorspellen van postoperatieve complicaties. De verwarring wordt nog vergroot doordat de onderlinge relatie van al deze parameters nog nooit is bekeken. Als het zo is dat depletie een onafhankelijke, substantiële invloed heeft op het postoperatieve beloop, dan moet repletie het beloop verbeteren. De mate waarin dit zal gebeuren is afhankelijk van de invloed van depletie op het postoperatieve beloop. Als perioperatieve voeding een middel is om depletie te verminderen en daarmee leidt tot een verbetering van orgaanfuncties, dan zou perioperatieve voeding het chirurgische resultaat verbeteren kunnen. Dit concept is de basis geweest van perioperatieve voedingstherapie.

Het doel van deze studie was het analyseren van chirurgische risicofactoren, om hun onderlinge samenhang en ieders individuele invloed op postoperatieve complicaties en lange termijn effecten vast te stellen.

In metabool stabiele patiënten is de lichaamssamenstelling over langere tijd constant. Er is een balans tussen inname en verlies van energie, eiwitten en andere nutriënten. Deficiënties treden op als er een dyshalans ontstaat tussen enerzijds de inname en anderzijds de verliezen. Een langer durende disbalans leidt tot veranderingen in lichaamssamenstelling en verstoorde orgaanfunctie.

'Nutritional assessment' betekent het vaststellen van de voedingstoestand en abnormale lichaamssamenstelling van een patient als resultaat van een verminderde inname van voedingsstoffen, van zowel energie, eiwit als andere essentiële nutriënten. Echter langdurige hongering kan door een gezonde persoon langdurig volgehouden worden, zonder dat dit leidt to grote veranderingen in lichaamssamenstelling.

De inname bij gedepleerde patiënten is niet altijd afgenomen. Sommige studies toonden een normale voedselinname aan bij gedepleerde kankerpatiënten. Het vaststellen van een abnormale lichaamssamenstelling onder deze omstandigheden bij gedepleerde patiënten met een normale inname, is het vaststellen van metabole ontregelingen door toegenomen verliezen van energie, eiwit en 
andere essentiële nutriënten.

Omdat de term 'ondervoeding' vaak alleen de innamezijde belicht is het beter te spreken over depletie, een term die beide oorzaken dekt. Het erkennen van de twee oorzaken van depletie, verklaart ook al waarom voedingstherapie niet altijd succesvol is in het omkeren van 'ondervoeding'. In ziekte is er bijna altijd een combinatie van beide condities, waardoor er een abnormale of verminderde respons op ziekte ontstaat. Deze veranderde respons vormt een additioneel risico voor het ontwikkelen van complicaties. Het is echter niet synoniem voor de ontwikkeling van complicaties of synoniem voor een gestoord postoperatief beloop. De metabole kant van depletie zal door de normale voedingsondersteuning niet gemakkelijk verholpen worden. Zo zal een gedepleerde patiënt met een morbus Crohn met chronische activiteit en septicemie niet herstellen van depletie zolang de actieve infectie met metabole en hormonale veranderingen niet verholpen is. Een vergelijkbaar gedepleerde patiënt met een stenose van de darm op basis van zijn morbus Crohn, zonder actieve ontsteking, zal daarentegen met voedingstherapie snel herstellen van zijn depletie.

In de literatuur zijn er de laatste twee decennia vele publicaties verschenen die aantonen dat afwijkingen in de parameters van de 'voedingsstatus' geassocieerd zijn met postoperatieve complicaties. In monofactoriële analyses hebben de meeste van deze parameters een redelijke tot goede correlatie met de incidentie van postoperatieve complicaties. Niet één van die afzonderlijke factoren had echter een bewezen betere predictieve waarde. Bovendien zijn er bijna geen patiënten zonder minstens één abnormale waarde voor alle in de literatuur genoemde parameters. Dat leidde tot de ontwikkeling van velerlei indices met een combinatie van antropometrische, biochemische en immunologische parameters. Deze indices, veelal gebaseerd op regressieanalyses, lieten echter geen toename van sensitiviteit, betrouwbaarheid of toepasbaarheid zien. Dit komt mede door de hoge correlaties tussen de gebruikte parameters. Het ontbreken van een gouden standaard en het feit dat de index in een specifieke patiëntengroep ontwikkeld is, verklaart al grotendeels de matige resultaten van de indices, wanneer deze toegepast worden op een andere patiëntengroep. Door die patiëntenselectie meten deze indices niet alleen het effect van depletie, maar tevens de invloed van de onderliggende ziekte op de uitkomst van chirurgische therapie. Meestal bevatten deze indices alleen parameters die geassocieerd zijn met depletie. Dit legt een te grote nadruk op depletie. Die nadruk leidt de aandacht af van de rol die ziekte en andere therapie-gerelateerde factoren hebben op het postoperatieve beloop. Depletie is echter maar één van de vele factoren voor het uiteindelijke resultaat, naast vele andere factoren, die minstens zo belangrijk zijn. De rol van die andere factoren werd vergeten of ontkend. 
Om de predictieve waarde van indices te vergroten mocten er ook andere factoren meegenomen worden, die van invloed zijn op het postoperatieve beloop. Zulke factoren zijn de leeftijd van de paliënt, coëxistunte ziekten, de duur en de uitgebreidheid van een ingreep, het peroperatieve bloedverlies, het soort anesthesie en de vaardigheid van de chirurg. Depletie is maar één van de risico-factoren voor de uitkomst, van zowel chirurgische, chemotherapeutische als radiotherapeutische therapie. Voedingsinterventie zal daarom ook slechts gedeeltelijk de uitkomst kunnen beinvloeden. Dit verklaart voor een deel de tegenvallende resultaten van voedingsinterventietrials. Depletie vergroot het risico op postoperatieve risico's, maar niet in die mate dat alle gedepleerde patiënten een complicatie ontwikkelen. Het is dan ook niet te verwachten dat door middel van voedingstherapie de postoperatieve complicaties grotendeels voorkomen kunnen worden.

Het aantrekkelijke van een sterke samenhang tussen de voedingstoestand en postoperatieve complicaties is het idee dat de voedingstoestand door middel van voedingstherapie beinvloed kan worden, in tegenstelling tot vele andere factoren. Dit heeft geleid tot veel te hoog gespannen verwachtingen van het effect van voedingstherapie met betrekking tot het terugdringen van postoperatieve morbiditeit en mortaliteit. Dat deze verwachtingen gestoeld waren op verkeerde uitgangspunten, blijkt uit het feit dat de meeste parameters die gebruikt werden ter identificatie van voedingstoestand steeds meer gezien worden als indicatoren van metabole stress. De opeenvolgende interventietrials faalden nagenoeg allen in het geven van een éénduidig antwoord door conceptuele en methodologische fouten. De grootste kritick op de nueste trials is dat de niet-gedepleerde patiënten niet uitgesloten werden van randomisatie. Gebeurde dit wel, dan waren de exclusiecriteria in het algemeen zeer mild. De controlegroepen ondergingen in veel gevallen niet de standaardbehandeling. maar werden preoperatief even lang in het ziekenhuis gehouden als de interventiepatiënten, zonder een adequate registratie van hun inname. Verder was de patiëntenpopulatie in het algemeen zeer divers met uiteenlopende opnameindicaties, variërend van electieve herniachirurgie tot uitgebreide thoraco-abdominale procedures. Het nagestreefde doel van een reductie van postoperatieve complicaties tot wel $50 \%$ in sommige studies demonstreert nog eens de veel te hoge verwachtingen van voedingstherapie.

In een studie van 172 maag- en darmkanker patiënten maakten wij een analyse van de depletie-parameters, tesamen met het effect van andere geaccepteerde chirurgische risico-factoren, zoals coëxistente ziekten, de lecftijd van de patiënt, de vaardigheid van de chirurg en het peroperatieve bloedverlies. Alle geanalyseerde depletieparameters hadden in monofactoriële analyses een goede 
correlatie met postoperatieve complicaties. Echter in een stapsgewijze regressieanalyse met postoperatieve complicaties als afhankelijke variabele bleek bloedverlies een zeer significante onafhankelijke associatie te hebben met de postoperatieve complicaties. Daamaast was ook de leeftijd van de patiënt een factor die significant geassocieerd was met de postoperatieve complicaties. Als er een complicatie opgetreden was, waren de duur van de operatie en het percentage ideaal gewicht geassocieerd met de ernst van de complicatie.

De resultaten van deze studie suggereren dat de uitgebreidheid van een procedure, weergegeven door het peroperatieve bloedverlies en de duur van de operatie, en de leeftijd van de patiënt, geassocieerd zijn met het optreden van een postoperatieve complicatie. Hiernaast zijn de depletieparameters, zoals weergegeven door het percentage gewichtsverlies en het percentage ideaalgewicht, geassocieerd met de ernst van een complicatie.

In de interventie-trial werden 151 patiënten met een bewezen maag of colorectale maligniteit gerandomiseerd. die on basis van een index ondervoed genoemd konden worden. Een-en-vijftig patiënten werden gerandomiseerd voor parenterale voeding, vijftig patiënten werden gerandomiseerd voor enterale voeding, welke beiden gedurende 10 dagen preoperatief gegeven werd. Vijftig patiënten werden gerandomiseerd als controlegroep en werden zonder uitstel geopereerd. Negen-en-veertig patiënten waren volgens de criteria niet ondervoed. $\mathrm{Zij}$ werden niet gerandomiseerd en fungeerden als goedgevoede referentiegroep. De postoperatieve complicaties werden aan de hand van de ernst van de complicatie gescoord als geen complicatie, een geringe complicatie of een ernstige complicatie. Septische abdominale complicaties zoals intraabdominale abcessen en sepsis traden in de ondervoede patiënten duidelijk frequenter op dan in de goedgevoede referentiegroep. De beide voedingsondersteunde trialgroepen lieten een afname van deze complicaties zien. In de ondervoede controlegroep kwamen significant meer multipele complicaties voor. In de ernstig gedepleerde patiëntengroepen met een percentage ideaal gewicht van $95 \%$ of lager was het effect van voeding nog nadrukkelijker met een significant verhoogd aantal septische complicaties in de gedepleerde controle groep. In de groep patiënten met een peroperatief bloedverlies van meer dan $500 \mathrm{ml}$ werden minder abcessen en sepsis gezien in de beide voedingsondersteunde groepen ten opzichte van de gedepleerde controlegroep. We concluderen uit deze studie dat het routinematig geven van perioperatieve voeding in ondervoede maag- en darmkankerpatiënten met tekenen van ernstige depletie. een voordelig effect heeft. Septische en abdominale, infectieuze complicaties hebben een verlaagde incidentie in de voedingsondersteunde groepen. Deze resultaten rechtvaardigen routinematige preoperatieve voeding 
bij ernstig gedepleerde patiënten, met name in die groep die bij opname een gewichtsverlies heeft van meer dan $10 \%$ van hun gebruikelijke gewicht.

Tevens werd het effect van depletieparameters op de overleving nagegaan om te analyseren welke invloed depletie op survival heeft, onafhankelijk van tumorstadium. Het stadium van de ziekte, het preoperatieve percentage gewichtsverlies, het percentage ideaal gewicht, totaal plasma-eiwit, plasmaalbumine, plasma-prealbumine en peroperatief bloedverlies waren significant gecorreleerd met de overleving in Kaplan-Meier analyses (log rank $p<0,05)$ van zowel maagkanker als van colorectale tumoren. Er werden geen nadelige effecten van voeding gezien op de overleving. Een Cox regressieanalyse liet naast de invloed van het stadium van de ziekte, een onafhankelijk effect op de overleving zien van het percentage ideaalgewicht, het plasma-albumine gehalte en het peroperatieve bloedverlies. Hoewel lang gedacht is dat het gewichtsverlies en een laag plasma-albumine epifenomenen van een gevorderd tumorstadium waren, toonden we aan dat deze parameters een effect op overleving hebben, onafhankelijk van tumor stadium. Het gewichtsverlies, de cachexie en het albumine zijn mogelijk een uiting van de metabole relatie tussen gastheer en tumor.

We concluderen uit deze studie dat depletie een nadelig effect heeft op de overleving van gastro-intestinale kankerpatiënten, welke onafhankelijk is van het stadium van de ziekte.

De effecten van perioperatieve voeding op tumorgroei en overleving zijn niet beschreven. Een versnelde tumorgroei en gereduceerde overleving bij mensen is niet beschreven. Het routinematig geven van (parenterale) voeding als adjuvans bij chemotherapie of bestralingstherapie hebben niet geresulteerd in een verbeterde tolerantie van therapie, morbiditeit, mortaliteit en overleving. Bij 149 opeenvolgende patiënten (62 vrouwen, 87 mannen) opgenomen voor de chirurgische behandeling van een colorectale tumor, werd het lange termijn effect van perioperatieve voeding onderzocht. Gedepleerde, stadium IV colorectale kankerpatiënten hadden een significant kortere overleving als niet gedepleerde patiënten. Gedepleerde, stadium IV colorectale kankerpatiënten, die perioperatieve voeding ontvingen, leefden significant langer dan gedepleerde patiënten zonder perioperatieve voeding ( $\log$ rank $p<0,05$ ). Er werden geen verschillen gevonden ten aanzien van de tumorlocalisatie, de grootte van de tumor, de leeftijd van de patiënt, het geslacht, en de pre-operatieve depletieparameters. In stadium I, II en III werden deze verschillen niet gevonden. Een Cox-regressie analyse toonde aan dat dit voordelige effect in stadium IV onafhankelijk was van andere factoren. 
We concluderen hieruit dat perioperatieve voeding een voordelig effect heeft op de overleving van gedepleerde, stadium IV colorectale kankerpatiënten.

De resultaten van dit proefschrift hebben geleid tot veranderingen in het preoperatieve klinische beleid in het AZM. Gedepleerde patiënten, die een grote geplande ingreep moeten ondergaan, en die een gewichtsverlies van meer dan $10 \%$ van hun normale lichaamsgewicht vertonen, worden 10 dagen preoperatief gevoed, vooropgezet dat uitstel van de operatie verantwoord is. De bevinding clat perioperatieve voedingsondersteuning in gedepleerde, stadium IV colorectale kankerpatiënten tot een verbeterde overleving leidt, zal in een grotere trial bevestigd moeten worden. 


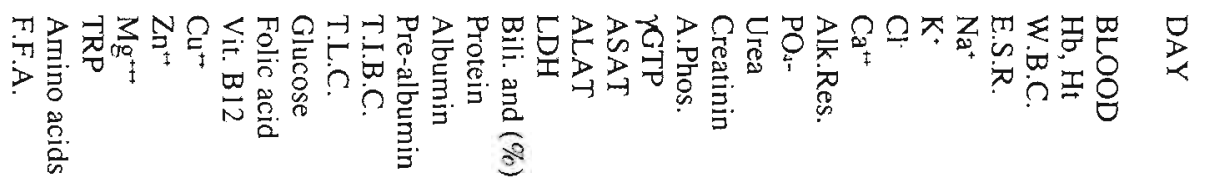

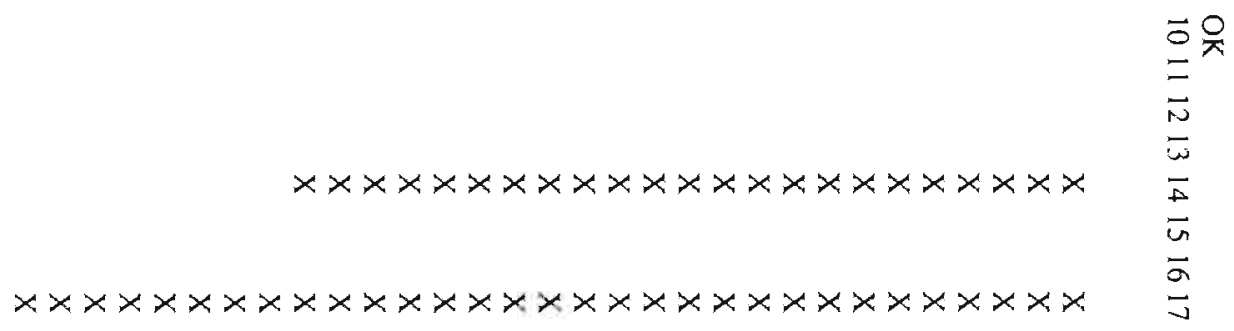


DAY

GENERAL

Tension

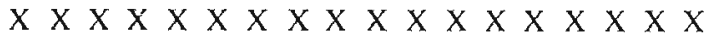

Temperature

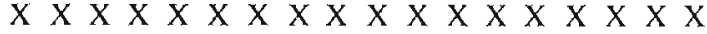

Weight

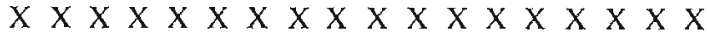

Fluid balance

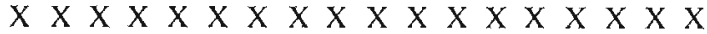

diet anamnesis

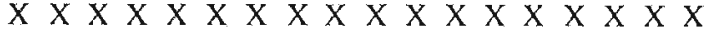

DAY

0123456678991011121314151617

URINE

Amount

total $\mathrm{K}$

Glucose

Total N

3-MH

Creat.

Density

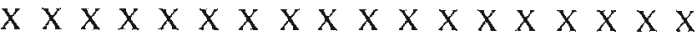

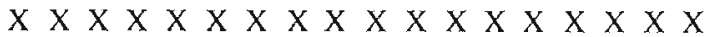

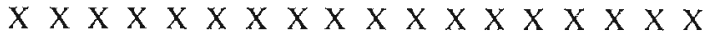

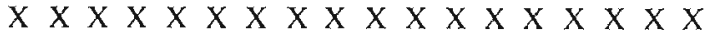

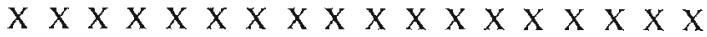

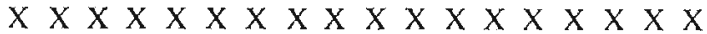

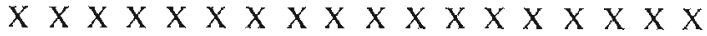

A: admittance

OK: day of operation

TRP: tryptophan

FFA: free fatty acids

3-MH: 3 methyl-histidin 


\section{APPENDIX 2}

\section{TNM Classification Gastric Cancer}

\section{Primary Tumor $(\mathrm{T})$}

$T_{x} \quad$ Minimum requirements to assess the primary tumor cannot be met.

$\mathrm{T}_{0} \quad$ No evidence of primary tumor.

$\mathrm{T}_{\text {is }} \quad$ Tumor limited to the mucosa without penetration into the lamina propria.

$T_{1} \quad$ Tumor limited to mucosa or mucosa and submucosa regardless of its extent.

$T_{2} \quad$ Tumor involves mucosa and the submucosa (including the muscularis propria), and extents to or into the serosa but does not penetrate through the serosa.

$\mathrm{T}_{3} \quad$ Tumor penetrates through the serosa without invading contiguous structures.

$\mathrm{T}_{\text {tu }} \quad$ Tumor penetrates through the serosa and involves immediately adjacent tissues, such as lesser omentum, perigastric fat, regional ligaments, greater omentum, transverse colon, spleen, esophagus, or duodenum by way of intraluminal extension.

$\mathrm{T}_{\mathrm{ab}} \quad$ Tumor penetrates through the serosa and involves the liver, diaphragm, pancreas, abdominal wall, adrenal glands, kidney, retroperitoneum, small intestine or esophagus, or duodenum by way of of serosa.

\section{Nodal Involvement $(\mathrm{N})$}

$N_{x} \quad$ Minimum requirements to assess the regional lymph nodes cannot be met.

$\mathrm{N}_{0} \quad$ No metastases to regional lymph nodes.

$N_{1} \quad$ Involvement of perigastric lymph nodes within $3 \mathrm{~cm}$ of the primary tumor along the lesser or greater curvature.

$\mathrm{N}_{2} \quad$ Involvement of the regional lymph nodes more then $3 \mathrm{~cm}$ from the primary tumor. which are removed or removable at operation, including those located along the left gastric, splenic, celiac, and common hepatic arteries.

$\mathrm{N}_{3}$ Involvement of other intra-abdominal lymph nodes, such as the para-aortic, hepatoduodenal, retropancreatic, and mesenteric nodes.

Distant Metastasis (M)

$M_{x} \quad$ Minimum requirements to assess the presence of distant metastasis cannot be met.

$M_{f} \quad$ No (known) distant metastasis.

M, Distant metastasis present.

Stage grouping

Stage $0 \quad T_{i s}, N_{0}, M_{0}$

Stage I $\quad T_{1}, N_{0}, M_{0}$

Stage II $\quad T_{2}, T_{3}, N_{4}, M_{0}$

Stage III $\quad T_{1}-T_{3}, N_{1}, N_{2}, M_{0}$

$\mathrm{T}_{4 a}, \mathrm{~N}_{0}-\mathrm{N}_{2}, \mathrm{M}_{0}$

Stage IV $\mathrm{T}_{1}-\mathrm{T}_{3}, \mathrm{~N}_{3}, \mathrm{M}_{0}$

$T_{A b}$, any $N, M_{0}$

any $\mathrm{T}$, any $\mathrm{N}, \mathrm{M}_{\text {, }}$ 
TNM Classilication Colon and Rectal Cancer

Primary Tumor (T)

$\mathrm{T}_{\mathrm{x}} \quad$ Minimum requirements to assess the primary tumor cannot be met.

$\mathrm{T}_{0} \quad$ No evidence of primary tumor.

$\mathrm{T}_{\mathrm{is}} \quad$ Tumor limited to the mucosa without penetration into the lamina propria.

$T_{1} \quad$ Tumor limited to mucosa or mucosa and submucosa regardless of its extent.

$\mathrm{T}_{2}$ Tumor involves mucosa and the submucosa (including the muscularis propria), and extents to or into the serosa.

$\mathrm{T}_{3 \mathrm{a}} \quad$ Tumor with extension beyond colon to immediately contigeous structures, without fistula formation.

$\mathrm{T}_{3 \mathrm{~b}} \quad$ Tumor with extension beyond colon to immediately contigeous structures, with fistula formation.

$\mathrm{T}_{4} \quad$ Tumor extending beyond the immediately adjacent organs or tissues.

Nodal Involvement $(\mathrm{N})$

$\mathrm{N}_{\mathrm{x}} \quad$ Minimum requirements to assess the regional and/or juxta regional lymph nodes cannot be met.

$\mathrm{N}_{0} \quad$ No metastases to regional lymph nodes.

$\mathrm{N}_{1} \quad$ Evidence of involvement of regional lymph nodes.

$\mathrm{N}_{4} \quad$ Evidence of involvement of juxta-regional lymph nodes

$\mathrm{N}_{2}$ and $\mathrm{N} 3$ are not applicable.

Distant Metastasis (M)

$\mathrm{M}_{x} \quad$ Minimum requirements to assess the presence of distant metastasis cannot be met.

$\mathbf{M}_{0} \quad$ No (known) distant metastasis.

$\mathrm{M}_{1} \quad$ Distant metastasis present.

Stage grouping

Stage 0 Tis, $\mathrm{N}_{0}, \mathrm{M}_{0}$

Stage I $\Upsilon_{1}, N_{0}, M_{0}$

Stage II $\quad T_{2}, T_{3 n}, N_{0}, M_{0}$

Stage IIl $\quad T_{1}-T_{3 k}, N_{1}, N_{4}, M_{n}$

$\mathrm{T}_{4}, \mathrm{~N}_{0}, \mathrm{~N}_{1}, \mathrm{~N}_{4}, \mathrm{M}_{0}$

Stage IV $T_{1}-T_{3 \mid,}, N_{4}, M_{0}$

$\mathrm{T}_{4}$, any $\mathrm{N}, \mathrm{M}_{0}$

any $T$, any $N, M_{\text {, }}$ 


\section{Slechts verwondering?}

Veel waardevolle zaken als relaties, hobbies, studie, boeken, etcetera hebben de laatste jaren moeten wijken voor dit onderzoek. Gelukkig is er tijd gebleven voor verwondering.

Verwondering?

Hoezo?

Het belangrijkste wat je leert tijdens het proces van promoveren is dat je je gaat verwonderen over relaties. Je gaat vraagtekens zetten bij allerlei verbanden. Zijn relaties wel zo absoluut als ze lijken?

Het wordt je geleerd je hersenen te trainen in het leggen van relaties en verbanden. Verbanden die je doen verwonderen en verbazen. Je beseft dat er zo veel is dat je niet weet. Die grote hersenen, vol met informatie, die relaties zoeken tussen allerlei gegevens en zich verwonderen over verbanden die er lijken te bestaan of zouden kunnen bestaan. Relaties tussen punten van een grafiek en de individuele patiënt, tussen de resultaten van dit boekje en de klinische praktijk. Die verwondering gaat ook buiten het onderzoek door: relaties tussen een boom en een auto, tussen de samenhang van de verhoudingen in de opbouw van een kathedraal en religie, etcetera. Voor ieder individueel van ons zijn die relaties vaak zo absoluut en zo waar, een individuele wijsheid. eigen-wijsheid. Maar van iedere relatie of van iedere eigen-wijsheid is het tegendeel evenzeer waar.

Je gaat je eigenlijk steeds meer verbazen over al die wonderbaarlijke relaties die er tussen de dingen lijken te bestaan. Door je op een wetenschappelijke manier te verwonderen, bepaal je niet alleen je eigen standpunt opnieuw, maar maak je jouw wijsheid ook voor anderen inzichtelijk.

Peter en Maarten, het bijbrengen van dit inzicht en het wegwijs maken hierin zonder dat je blijft steken in slechts verwondering, beschouw ik als jullie grootste bijdrage aan mijn wetenschappelijke vorming en dit boekje. Heel erg veel dank hiervoor.

Verder wil ik allen die op enigerlei wijze hebben bijgedragen aan het tot stand komen van dit proefschrift hartelijk danken. Met name wil ik hierbij noemen Resi Buil-Maassen en Margriet Rouflart die het vergaren van de data voor het overgrote deel voor hun rekening hebben genomen. 


\section{Curriculum vitae}

Wilhelmus Jan Hendrik Jeroen Meijerink was born on October 27, 1961 in Hoeven (Nbr.), The Netherlands. He attended secondary school at the 'Pius-Xcollege' in Almelo from 1974 to 1980. He studied medice at the Catholoic University Nijmegen, The Netherlands, and obtained his M.D. degree in March 1988. From March 1987 till October 1987 he worked as 'student doctor' in the Biharamulo District Hospital, Tanzania. From october 1987 to april 1988 he was research fellow at the University of Antwerpen at the laboratory of Prof.dr. R.H.G.G. van Hee. From april 1988 he was research fellow and member of the Nutritional Support team at the Academic Hospital Maastricht in the metabolic and nutrition research group of Prof.dr. P.B. Soeters. From januari 1990 he is in training as surgical resident in the Academic Hospital Maastricht (Chairman Prof.dr. G. Kootstra). 


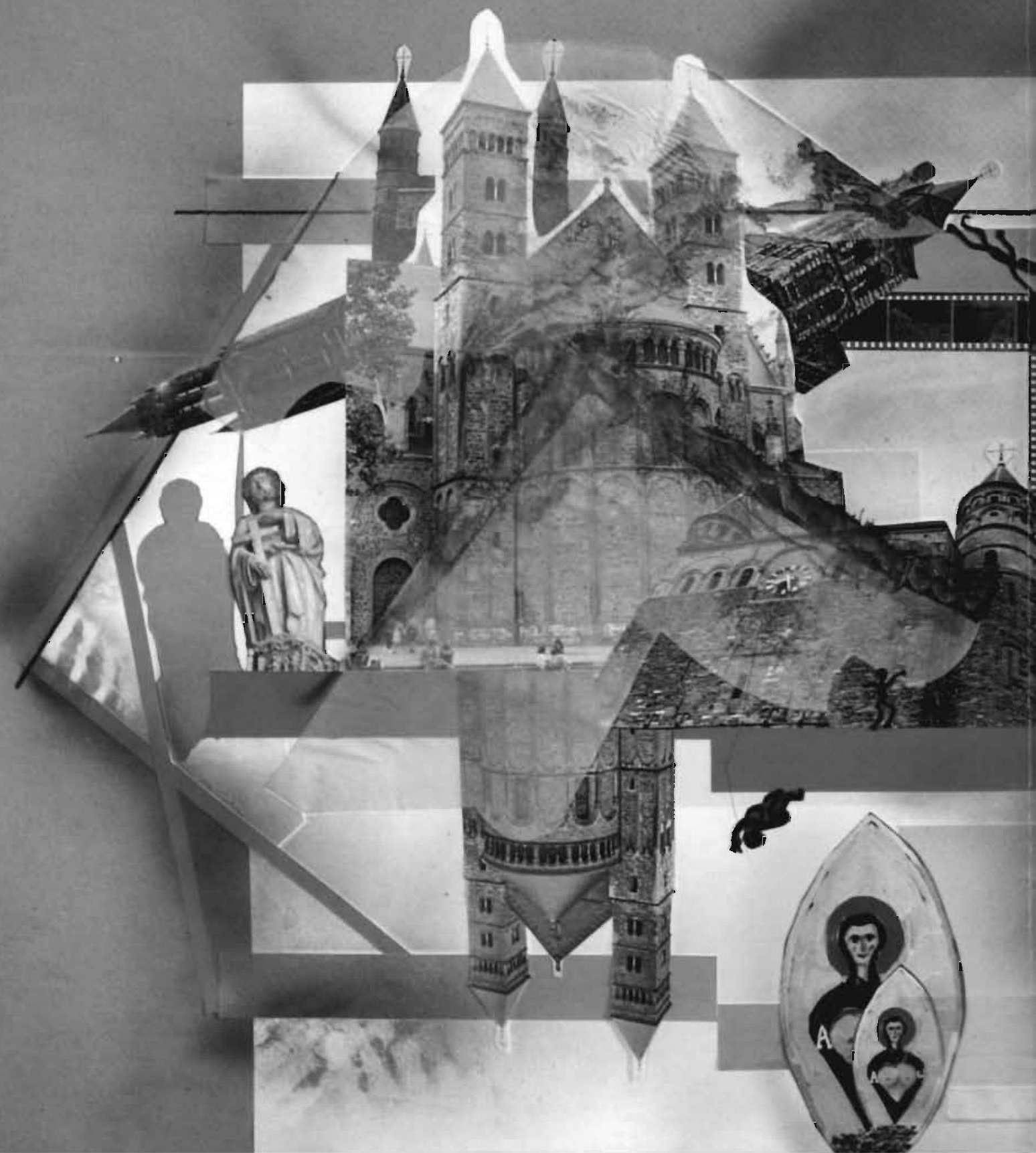

